\title{
High Temperature Size Selective Membranes
}

\author{
Final Report \\ September 1992 - March 1995
}

\section{DISCLAIMER}

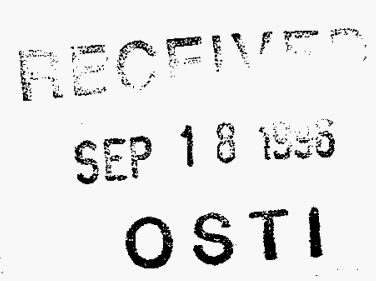

This report was prepared as an account of work sponsored by an agency of the United States Government. Neither the United States Government nor any agency thereof, nor any of their employees, makes any warranty, express or implied, or assumes any legal liability or responsibility for the accuracy, completeness, or usefulness of any information, apparatus, product, or process disclosed, or represents that its use would not infringe privately owned rights. Reference herein to any specific commercial product, process, or service by trade name, trademark, manufacturer, or otherwise does not necessarily constitute or imply its endorsement, recommendation, or favoring by the United States Government or any agency thereof. The views and opinions of authors expressed herein do not necessarily state or reflect those of the United States Government or any agency thereof.

February 1996

Work Performed Under Contract No.: DE-AC21-92MC29245

For

U.S. Department of Energy

Office of Fossil Energy

Morgantown Energy Technology Center

Morgantown, West Virginia

By

Allied-Signal Research and Technology

50 East Algonquin Road

Des Plaines, IL 60017 


\section{Disclaimer}

This report was prepared as an account of work sponsored by an agency of the United States Government. Neither the United States Government nor any agency thereof, nor any of their employees, makes any warranty, express or implied, or assumes any legal liability or responsibility for the accuracy, completeness, or usefulness of any information, apparatus, product, or process disclosed, or represents that its use would not infringe privately owned rights. Reference herein to any specific commercial product, process, or service by trade name, trademark, manufacturer, or otherwise does not necessarily constitute or imply its endorsement, recommendation, or favoring by the United States Government or any agency thereof. The views and opinions of authors expressed herein do not necessarily state or reflect those of the United States Government or any agency thereof. 


\title{
High Temperature Size Selective Membranes
}

\author{
Final Report \\ September 1992-March 1995
}

Work Performed Under Contract No.: DE-AC21-92MC29245

\author{
For \\ U.S. Department of Energy \\ Office of Fossil Energy \\ Morgantown Energy Technology Center \\ P.O. Box 880 \\ Morgantown, West Virginia 26507-0880 \\ By \\ Allied-Signal Research and Technology \\ 50 East Algonquin Road \\ Des Plaines, IL 60017
}




\section{DISCLAIMER}

Portions of this document may be illegible in electronic image products. Images are produced from the best available original document. 


\section{TABLE OF CONTENTS}

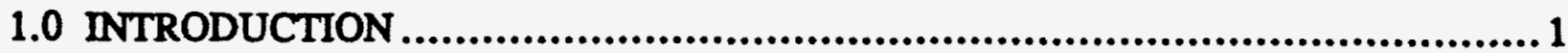

1.1 High Temperatures Membrane Separation ................................................1

1.1.1 Technical Requirements ..................................................................1

1.1.2 Current Membrane Technologies and Their Limitations ..............................2

1.1.3 Membrane Applications..............................................................3

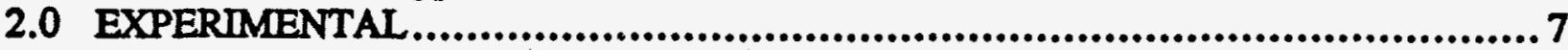

2.1 General Analytical Procedures ......................................................... 7

2.1.1 Pore Size and Pore Size Distribution ..............................................7

2.1.2 Gas Permeation Measurement ..............................................................7

2.1.3 Mechanical Strength Measurement......................................................8 8

2.2 Preparative Procedures ..................................................................13

2.2.1 Porous Blackglas ${ }^{\mathrm{TM}}$ Support.......................................................13

2.2.2 Composite Carbon Molecular Sieve (CMS) Membrane ...............................14

2.2.3 Chemical Vapor Deposition of $\mathrm{SiO}_{2}$ Film ..........................................19

2.2.4 Carbon Film Preparation (8046-162-3) ................................................19

2.3 Hydrogen Adsorption Porosimetry ..................................................20

3.0 RESULTS AND DISCUSSION......................................................34

3.1 Porous Blackglas ${ }^{\mathrm{TM}}$ Membrane Support ..................................................34

3.1.1 Mechanical Strength..................................................................34

3.1.2 Pore Size, Pore Size Distribution and Porosity ........................................36

3.1.3 Scanning Electron Micrograph (SEM) Studies......................................37

3.1.4 Nitrogen Permeation Rate ..............................................................38

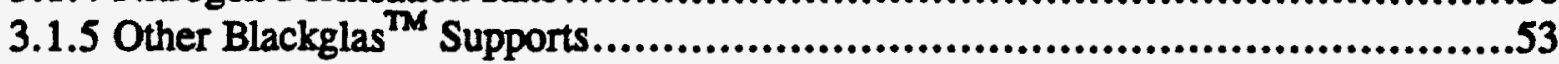

3.2 Thin Film Composite Membrane .......................................................53

3.2.1 SEM Micrographs of CMS Membrane...............................................54

3.2.2 Gas Permeation Through the CMS Membrane.......................................55

3.2.3 $\mathrm{SiO}_{2}$ Film ......................................................................57

3.3 Carbon Film Studies................................................................76

3.3.1 Rationale .....................................................................76

3.3.2 Scoping Carbonization Conditions for Carbon Film Preparation......................76

3.3.3 Optimizing Conditions for Preferential Adsorption of Hydrogen ....................79

3.3.4 Flux Measurements with Unsupported Carbon Films............................... 100

4.0 CONCLUSIONS ........................................................................ 103

5.0 ACKNOWLEDGEMENTS .......................................................... 105

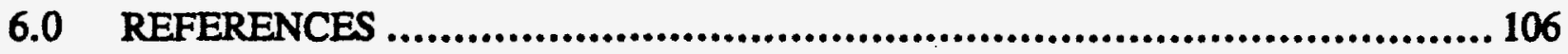




\section{LIST OF TABLES}

Table Title

Page

1.1.3-1 Molecular Weights and Sizes of Several Compounds

2.2-1 Pyrolysis and Carbonization Conditions for Blackglas ${ }^{\mathrm{TM}}$

Supports and Composite Membranes

2.3-1 Kinetic Diameters for All Gases Whose Diameter Was

Obtained From van der Waal's Equation

3.1-1 Short Fiber/Blackglas ${ }^{\mathrm{TM}}$ Composite Supports

3.1-2 Tensile Test Results of Blackglas ${ }^{\mathrm{TM}}$ Ceramic Membrane Support

3.1-3 Pore Size and Porosity Results from Mercury Intrusion Measurements

3.2-1 Permeation Fluxes for Nitrogen, Hydrogen, and Methane

3.3.3-1 Summary of Pyrolysis Conditions for Polymide Films

3.3.3-2 Summary of Surface Area Results $\left(\mathrm{m}^{2} / \mathrm{g}\right)$ for Pyrolyzed Polymide Films

3.3.3-3 Summary of Monolayer Volume Results (cc/g STP) for Pyrolyzed Polyimide Films

3.3.3-4 Summary of Horvath-Kowzace Pore Size Statistics 


\section{LIST OF FIGURES}

Figure Title

Page

2.1-1 Room Temperature Gas Permeability Measurement Apparatus

9

2.1-2 High Temperature Gas Permeability Measurement Apparatus

10

2.1-3 Schematic Of High Temperature Gas Permeability Cell Inside Retort Furnace

2.1-4 Instron Bend Test Of Blackglas'TM Support

2.2-1 Schematic Diagram Of TEOS CVD Apparatus

2.2-2 Detailed Drawing Of TEOS CVD Reactor

2.3-1 Vapor Pressure Of Nitrogen As A Function Of Pressure

2.3-2 Vapor Pressures Of Hydrogen And Helium As A Function Of Pressure

2.3-7 Porosimetry Printout for Nitrogen Isotherm of Sample 8046-170-1

2.3-8 Porosimetry Printout for Carbon Dioxide Isotherm of

2.3-9 Porosimetry Printout for Hydrogen Isotherm of Sample 8046-170-1

3.1-1 Pore Size Distribution Of Blackglas ${ }^{\mathrm{TM}}$ Support After One Infiltration 39

3.1-2 Pore Size Distribution Of Blackglas'm Support After Two Infiltrations 40

3.1-3 Pore Size Distribution Of Blackglas TM Support After Three Infiltrations 
3.1-6 SEM Micrograph Of Blackglas ${ }^{\text {TM }}$ Support Top Surface Structure After One Infiltration

3.1-7 SEM Micrograph Of Blackglas ${ }^{\text {TM }}$ Support Top Surface Structure After Two Infiltrations

3.1-8 SEM Micrograph Of Blackglas TM Support Top Surface Structure After Three Infiltrations

3.1-9 SEM Micrograph Of Blackglas ${ }^{\text {TM }}$ Support Top Surface Structure After Four Infiltrations

3.1-10 SEM Micrograph Of Blackglas ${ }^{\text {TM }}$ Support Cross Section Structure After One Infiltrations

3.1-11 SEM Micrograph Of Blackglas'm Support Cross Section Structure After Two Infiltrations

3.1-12 SEM Micrograph Of Blackglas ${ }^{\text {TM }}$ Support Cross Section Structure After Three Infiltrations

3.1-13 SEM Micrograph Of Blackglas ${ }^{\text {TM }}$ Support Cross Section Structure After Four Infiltrations

3.1-14 Nitrogen Flow Rate Through Porous Blackglas ${ }^{\text {TM }}$ Supports At Two Different Support Pore Sizes

SEM Micrograph Of PAN Coated Blackglas'm Support Top Surface

SEM Micrograph Of Blackglas'm Support Top Surface After Pyrolysis Of One Thick Polyimide Coating Layer

3.2-4 SEM Micrograph Of Blackglas'M Support Top Surface After Pyrolysis Of One Thick Polyimide Coating Layer At Higher Magnification

3.2-5 SEM Micrograph Of Blackglas ${ }^{\mathrm{mM}}$ Support Top Surface After Pyrolysis Of One Slightly Thin Polyimide Coating Layer

3.2-6 SEM Micrograph Of Blackglas TM Support Cross Sectional Structure After Pyrolysis Of One Thick Polyimide Coating Layer 
3.2-7 SEM Micrograph Of Blackglas TM Support Top Surface After Pyrolysis

Of One Slightly Thin Polyimide Coating Layer

3.2-8 Total Weight Of Two Composite Blackglas'M Supported CMS Membrane

As A Function Of Number Of Coatings/Carbonization Cycles

3.2-9 SEM Micrograph Of Blackglas TM Support Top Surface After Pyrolysis Of Ten Extremely Thin Polyimide Coating Layers

3.2-10 SEM Micrograph Of BlackglasTM Support Top Surface After Pyrolysis

Of Ten Extremely Thin Polyimide Coating Layers At Higher

Magnification, Showing The Crack Structure And Width

3.2-11 SEM Micrograph Of Blackglas ${ }^{\text {TM }}$ Support Top Surface After Pyrolysis

Of Ten Extremely Thin Polyimide Coating Layers At Higher

Magnifications, Showing The Repaired Crack Structure

3.2-12 SEM Micrograph Of BlackglasTM Support Cross Sectional Structure After Pyrolysis Of Ten Extremely Thin Polyimide Coating Layers, Showing The Total Thickness Of The Carbon Layer

3.2-13 Hydrogen And Nitrogen Flow Rate And Selectivity Through Composite CMS Membrane As A Function Of Applied Pressure At Room Temperature

3.2-14 Hydrogen And Nitrogen Flow Rate And Selectivity Through Composite CMS Membrane As A Function Of Applied Pressure At $520^{\circ} \mathrm{C}$

3.2-15 Hydrogen And Nitrogen Flow Rate And Selectivity Through Composite CMS Membrane As A Function Of Applied Pressure At $630^{\circ} \mathrm{C}$

3.2-16 Hydrogen And Nitrogen Flow Rate And Selectivity Through Composite CMS Membrane As A Function Of Applied Pressure At $717^{\circ} \mathrm{C}$

3.2-17 SEM Micrograph Of Blackglas TM Support Cross Sectional Structure After CVD Coating Of Silicon Dioxide Layer At Atmospheric Pressure And At Low Temperature

3.2-18 SEM Micrograph Of Blackglas TM Support Cross Sectional Structure After CVD Coating Of Silicon Dioxide Layer At Atmospheric Pressure And At Low Temperature Using Higher Magnifications 
3.3.2-1 Structure Of Polyimide Film Used In Unsupported Film Studies

3.3.2-2 SEM Photo of Pyrolyzed Unsupported Polyimide Film (500x) 81

3.3.2-3 SEM Photo of Pyrolyzed Unsupported Polyimide Film (20000x) 82

3.3.2-4 Change In Weight Of Unsupported Films As A Function Of Temperature 83

3.3.2-5 Change In Density Of Unsupported Films As A Function Of Temperature 84

3.3.3-1 Isotherm For Carbon Dioxide On Unactivated Carbon Film 85

3.3.3-2 Isotherm For Hydrogen On Unactivated Carbon Film 86

3.3.3-3 Pore Size Distribution For Unactivated Carbon Film Using Carbon Dioxide As Probe Gas

3.3.3-4 Isotherm For Carbon Dioxide On Activated Carbon Film 88

3.3.3-5 Isotherm For Hydrogen On Activated Carbon Film 89

3.3.3-6 Isotherms For Hydrogen And Carbon Dioxide On Unactivated Carbon Film Produced At High Temperature Ramp Rate

3.3.3-7 Pore Size Distribution For Unactivated Carbon Film Produced At High Temperature Ramp Rate Using Carbon Dioxide As Probe Gas

3.3.3-8 Isotherms For Hydrogen And Carbon Dioxide On Unactivated Carbon Film Produced Beneath Heavy Weight

3.3.3-9 Pore Size Distribution for Unactivated Carbon Film Produced Beneath Heavy Weight Using Carbon Dioxide as Probe Gas

3.3.4-1 Schematic Drawing of Postulated Carbonization Process from Outside In 102 


\begin{abstract}
Availability of a high temperature size selective membrane capable of separating hydrogen from carbon dioxide and other gases is seen as highly desirable from an economic perspective. Preparation of such a membrane is technically very difficult due to the limitations that the high temperature places on materials selection. We have prepared high temperature membranes as thin film composites of a porous Blackglas ${ }^{\mathbf{M}}$ support and a carbon molecular sieve selective film.'

Porous Blackglas ${ }^{\mathrm{TM}}$ supports have been prepared by pyrolysis of a formed mixture of Blackglas $^{\mathrm{TM}}$ B-staged precursor and short carbon fibers. Such supports have the necessary smoothness for use as a membrane support, good mechanical properties, and an appropriate pore size distribution. Transmembrane nitrogen permeation fluxes are in the range of $10^{-3}-10^{-4}$ $\mathrm{cm}^{3}$ (STP) $\mathrm{cm}^{-2} \mathrm{sec}^{-1} \mathrm{cmHg}^{-1}$. These supports can be made either in flat sheet form or in a tubular configuration.
\end{abstract}

A carbon molecular sieve layer can be added to the support by repeated coating/pyrolysis with a dilute solution of precursor polymer. The preferred precursors are polyimide or polyamic acid. Crack formation is observed after the first pyrolyses, but these cracks are repaired during later pyrolyses. The final membrane thickness is only $2.5 \mu \mathrm{m}$. The permeation flux of the membrane for hydrogen ranges from $8.1 \times 10^{-5}$ at room temperature to $3.0 \times 10^{-3} \mathrm{~cm}^{3}$ (STP) $\mathrm{cm}^{-2} \mathrm{sec}^{-1} \mathrm{cmHg}^{-1}$ at $717^{\circ} \mathrm{C}$, and the selectivity for hydrogen over nitrogen from 2.8 to 3.8 , and a selectivity for hydrogen over carbon dioxide of 2.4 . This selectivity is close to the Knudsen diffusion limit.

In a companion study, unsupported carbon molecular sieve films were also prepared under pyrolysis conditions similar to those used for the supported film. Hydrogen adsorption porosimetry at $19.7^{\circ} \mathrm{K}$ was used to show that, under appropriate activation or pyrolysis conditions, such films can be prepared which adsorb hydrogen to a much greater extent than carbon dioxide. 


\subsection{INTRODUCTION}

\subsection{High Temperatures Membrane Separation}

\subsubsection{Technical Requirements}

High temperature membranes have attracted so much interest within the membrane community primarily because they have the potential of accomplishing separations of reaction products without the energy-wasting steps of reducing the temperature to permit separation, then increasing it again. In order to accomplish their mission, they must be able to separate gaseous components from each other at high temperatures and in corrosive atmospheres without cracking or failing in other ways. They must also be sufficiently low in cost that it is cost-effective to use them in place of low temperature membranes or some other technology.

The production of power from coal is one example of an industrial process which would strongly benefit from the availability of high temperature membranes. For example, separation of hydrogen from the product mixture of a water-gas shift reactor at high temperature would allow this hydrogen to be used directly in further reactions. Purification steps are also of interest. For these, Cicero and Jarr recently noted that the membrane operating conditions of interest involve temperatures between 540 and $1230^{\circ} \mathrm{C}$, and pressures between 1 and $7 \mathrm{Mpa}$. More specifically, they note that for a direct coal-fired turbine system, the feed conditions are $980-1230^{\circ} \mathrm{C}$ and $0.8-3.5 \mathrm{Mpa}$. Under these conditions, the membrane must separate sulfur compounds, gaseous alkali metals, ammonia and $\mathrm{HCl}$ from methane. In contrast, for the integrated gasification combined cycle system, the feed conditions are $540-980^{\circ} \mathrm{C}$ and $0.8-7 \mathrm{Mpa}$, and the same impurities must be removed.

These requirements translate into requirements that the membrane be thermally stable at the indicated temperatures, that it not be reactive with such components as $\mathrm{HCl}$ or ammonia at these temperatures, and that it have sufficient mechanical strength to withstand the applied pressure. The membrane must also be able to separate components differing in molecular size by as little as $0.1 \mathrm{~A}$ at this temperature. 


\subsubsection{Current Membrane Technologies and Their Limitations}

Many research groups have recently focused on the development of high temperature membranes. Reviews of this field ${ }^{2,3}$ reveal that most of these membranes have been of two types, metallic and ceramic membranes. The metallic membrane is typically a thin film of a metal, usually palladium alloy, which is selective for hydrogen due to the unusual solubility of hydrogen in these metals. As such, their use is limited to applications in which hydrogen separations are required. Ceramic membranes have much broader utility. These may be prepared by sintering, leaching or a sol/gel process, and have pore sizes stretching from the microfiltration to the ultrafiltration pore regime. The primary exemplars of this technology are Vycor-type glass membranes and porous alumina membranes. The use of porous alumina membranes for gas separation has recently been described in a series of papers by Burggraaf, ${ }^{4,5}$. These $\alpha$-alumina membrane films have pores smaller than $30 \AA$, and porosities larger than 50\%. The structure of these membrane films has been shown to consist of stacked plates of boehmite particles, resulting in slit-shaped pores approximately as wide as the crystallites are thick. This pore size can be adjusted by changing the crystallite thickness, but the smallest pore cited is $25 \AA$. Similar membranes have been prepared from higher order aluminas, titania and ceria. Because of their large pore diameters, these membranes are believed to separate primarily by Knudsen diffusion. The Knudsen diffusion coefficient for a gas is given by equation 1. Since diffusion is inversely proportional to the square root of the molecular weight, lighter gases will diffuse more rapidly than heavy gases. Thus the separation factor will be related to the molecular weight ratio as in equation 2. Such a separation will be effective if the molecular weights of the gases to be separated are significantly different, but if they are similar, many stages of separation will be required.

(1)

$$
D_{i}=\sqrt{\frac{8 R T}{\pi M_{i}}}
$$




$$
\alpha_{i j}=\sqrt{\frac{M_{j}}{M_{i}}}
$$

Efforts to improve the separation from that provided by the Knudsen mechanism have focused primarily on the use of chemical vapor deposition to add a thin separating film ${ }^{2,6}$. For instance Gavalas et al $^{6}$ deposited a thin layer of silica, titania, alumina or boria onto a porous Vycor substrate, and obtained a membrane with $\mathrm{H}_{2}-\mathrm{N}_{2}$ permeation ratios of $1000-5000$. This is substantially better than equation 2 above would provide, and probably results from a solubility-type separation between these two gases. It is not yet known what other materials will be separable by this mechanism.

We do not believe that true molecular sieve-size pores will be obtained using the inorganic membrane technologies discussed here. Since the origin of the porosity ${ }^{4}$ in these membranes is spacing between plate-like crystallites, pores of molecular dimensions would require crystallites of molecular dimensions. Essentially, one would need one-molecule thick sheets, laid down with a very high degree of order to obtain a sharp molecular sieve-like pore size distribution. Such order is much more likely in a crystalline zeolite than in alumina, silica or other similar materials.

Our concept is based on the use of molecular sieves in a membrane. Following early work by Bird and Trim ${ }^{7}$, the most direct approach to this problem has been the work of Koresh and Soffer. These authors prepared carbon molecular sieve membranes by pyrolysis of polymeric hollow fibers between $500-800^{\circ} \mathrm{C}$ in an inert atmosphere, and have good thermal stability and high selectivities. They cite permselectivities for hydrogen over methane of 35-57. The membranes were found to be brittle. We believe that it will be difficult for these authors to achieve good selectivities and improved mechanical strength simultaneously with such materials.

\subsubsection{Membrane Applications}

Our proposed molecular sieve membrane will have a pattern of selectivity which is significantly different from that provided by existing high temperature membranes. As we noted above, existing membranes separate by molecular weight, while our proposed membranes will separate by molecular size. In addition, while membranes which separate by the Knudsen diffusion method have limits on their selectivity dictated by equation 2 , there is no inherent limitation on the selectivity of a molecular sieve 
membrane. Adsorptive separations using molecular sieves can have extremely high separations factors.

Based on known kinetic diameters, one application for which these membranes will be particularly well suited is the removal of hydrogen from other components. This can have a direct impact on the energy industry, since hydrogen separation is of critical importance to them. In the conversion of coal or other fuels to synthetic natural gas, coal is first converted to $\mathrm{CO}$ and hydrogen(3), then $\mathrm{CO}$ is further processed to make additional hydrogen by the water gas shift reaction (4). The reaction products are then combined to make methane (5). Since carbon dioxide is the undesired waste product of this sequence, separation of it from hydrogen is necessary.

$$
\mathrm{C}+\mathrm{H}_{2} \mathrm{O} \rightarrow \mathrm{CO}+\mathrm{H}_{2}
$$

$$
\mathrm{CO}+\mathrm{H}_{2} \mathrm{O} \rightarrow \mathrm{CO}_{2}+\mathrm{H}_{2}
$$

$$
\mathrm{CO}+3 \mathrm{H}_{2} \rightarrow \mathrm{CH}_{4}+\mathrm{H}_{2} \mathrm{O}
$$

Table 1.1.3-1 shows the molecular weights and sizes of several components of interest in such feeds. Since we note that there is a clear difference in size between $\mathrm{CO}_{2}$ and hydrogen, it is reasonable to propose that high temperature membranes of the type described above could be useful in this application. Interestingly, workers at Oak Ridge ${ }^{9}$ have also predicted, based on a separations model, that a membrane with pore sizes in our range is the most desirable for this application.

Another highly attractive application for the molecular sieve membrane is in the removal of sulfur and nitrogen contaminants in gas streams from advanced coal-based power generation systems. A recent paper by Cicero and Jarr ${ }^{1}$ noted that such separations will be essential if untreated coal is to be used in such systems. In the two applications cited in their work, one would require the separation of $\mathrm{H}_{2} \mathrm{~S}$ and $\mathrm{NH}_{3}$ from a gas stream, while the second would require the removal of $\mathrm{NO}_{\mathbf{x}}$ and $\mathrm{SO}_{\mathbf{x}}$. Note that ammonia and hydrogen sulfide, for instance, are smaller than carbon monoxide, 
leading us to predict a good separation for these two impurities. Numerous other separations can be predicted from the above information.

Table 1.1.3-1: Molecular Weights and Sizes of Several Compounds

\begin{tabular}{|c|c|c|}
\hline Component & $\begin{array}{l}\text { Molecular Weight } \\
(\mathrm{g} / \mathrm{mol})\end{array}$ & Rinetic Diameter \\
\hline $\mathrm{H}_{2}$ & 2.0 & 2.89 \\
\hline $\mathrm{O}_{2}$ & 32.0 & 3.46 \\
\hline $\mathbf{N}_{2}$ & 28.0 & 3.64 \\
\hline No & 30.0 & 3.17 \\
\hline $\mathrm{N}_{2} \mathrm{O}$ & 44.0 & 3.3 \\
\hline $\mathrm{CO}$ & 28.0 & 3.76 \\
\hline $\mathrm{CO}_{2}$ & 44.0 & 3.3 \\
\hline $\mathrm{NH}_{3}$ & 17.0 & 2.6 \\
\hline $\mathrm{SO}_{2}$ & 64.1 & 3.6 \\
\hline $\mathrm{CH}_{4}$ & 16.0 & 3.8 \\
\hline $\mathrm{H}_{2} \mathrm{~S}$ & 34.1 & 3.6 \\
\hline Benzene & 78.1 & 5.85 \\
\hline
\end{tabular}


Apart from the coal-related applications, there are several other applications for which a molecular sieve membrane's high selectivity would be highly desirable. Chief among these are high temperature catalyzed processes for which the thermodynamic equilibrium is unfavorable. A membrane separations process which removed a product component from such a process could be used to shift the equilibrium, improving the economics of such a process. Examples of such processes are:

$$
\begin{aligned}
& \mathrm{N}_{2}+\mathrm{H}_{2} \rightarrow \mathrm{NH}_{3} \\
& \mathrm{C}_{2} \mathrm{H}_{6} \rightarrow \mathrm{C}_{2} \mathrm{H}_{4}+\mathrm{H}_{2} \\
& \mathrm{CH}_{4} \rightarrow \mathrm{C}_{2}^{\prime} \mathrm{s}+\mathrm{H}_{2}
\end{aligned}
$$

Substantial energy savings are implicit in this approach to each of these reactions. For instance, the ethane to ethylene conversion is extremely endothermic ${ }^{10}$, and is therefore run at extremely high temperatures in order to shift the equilibrium in the desired direction. Use of a reactor/separator combination would permit the reaction temperature to be lowered substantially. In addition, use of a high temperature membrane unit in place of a conventional membrane unit means that there is no necessity to lower the temperature for the separation step, then raise it back to the reactor temperature again. 


\subsection{EXPERIMENTAL}

\subsection{General Analytical Procedures}

\subsubsection{Pore Size and Pore Size Distribution}

Pore size analysis was completed using mercury intrusion porosimetry. The mercury intrusion technique is performed on a Micrometrics Autopore Model 9220. This technique determines the pore size distribution and porosity for macropores in the sample with pore diameters lager than $500 \AA$.

\subsubsection{Gas Permeation Measurement}

The pure gas permeabilities through the Blackglas ${ }^{\mathrm{TM}}$ support and through the carbon molecular sieve (CMS) membrane was measured using a device similar to the ASTM method D1434 ${ }^{11}$. Figure 2.1-1 shows a schematic drawing of the apparatus. It consisted of a membrane holder having high and low pressure sides separated by the membrane whose gas permeation properties need to be measured. The holder is either immersed in a constant temperature water bath or left in ambient conditions for low temperature measurement. The Blackglas ${ }^{\text {MM }}$ support or composite CMS membrane is mounted in the holder using rubber gaskets, which provided the gas-tight seal between the high and low pressure sides. Both sides have an inlet and an outlet for introducing gases into the membrane holder.

At the start of the test, a gas pressure is applied to the high pressure side of the membrane and the pressure monitored by the pressure gauge on the high pressure side. The support or the CMS composite membrane is allowed to equilibrate with the applied gas pressure for 30 to 60 minutes before commencing measurement. The gas permeability is measured by the gas flow rate at the low-pressure side. The relationship between the gas flow rate and permeability is given by the following equation:

$$
J=\operatorname{PA}\left(\rho_{h}-\rho_{1}\right) / \delta
$$


where $J$ is the gas flow rate, $A$ is the membrane area exposed to the gas, $p_{h}$ and $p_{1}$ are the pressures at the high and low pressure sides, respectively, $\sigma$ is the membrane thickness, and $P$ is the permeability.

The ideal separation factor between two different gases is defined as the ratio of permeabilities at the given conditions. Thus, for gases A and B, the ideal separation factor is expressed as:

$$
\alpha(\mathrm{A} / \mathrm{B})=\mathrm{P}_{\mathrm{A}} / \mathrm{P}_{\mathrm{B}}
$$

It should be noted that the permeability measured by the present apparatus represents an overall permeability of the pure gas through the support or the CMS composite membrane under the given conditions. No attempt is made to determine the individual contributions from surface diffusion, Knudsen diffusion, and from other diffusion mechanisms to the overall gas permeability because of the uncertainty in such procedures.

The apparatus for measuring gas permeabilities at temperatures higher than $400^{\circ} \mathrm{C}$ is the same as the one described for the low temperature measurement with minor modifications to the sealing mechanism in the membrane holder. The rubber gaskets used at low temperatures are replaced by either metallic gaskets or graphite gaskets. The sealing surface has small grooves to ensure proper gas-tight sealing as depicted in Figure 2.1-2. The membrane holder is placed inside a retort furnace which controls the measurement temperature. The inlet gas is heated to the desired temperature by a spiral tube heat exchanger inside the furnace. Figure 2.1-3 is a schematic of the membrane cell inside the fumace retort.

\subsubsection{Mechanical Strength Measurement}

Tensile strength of the Blackglas ${ }^{\mathrm{TM}}$ supports is measured by an Instron bend test. The samples used are in the form of bars 6 to $7^{\prime \prime}$ long and 1/4" wide. The thickness of the samples is fixed during the support preparation. The test is performed at room temperature. Figure 2.1-4 depicts the test in progress. 


\section{Apparatus for Gas Permeability Measurement at Room Temperature}

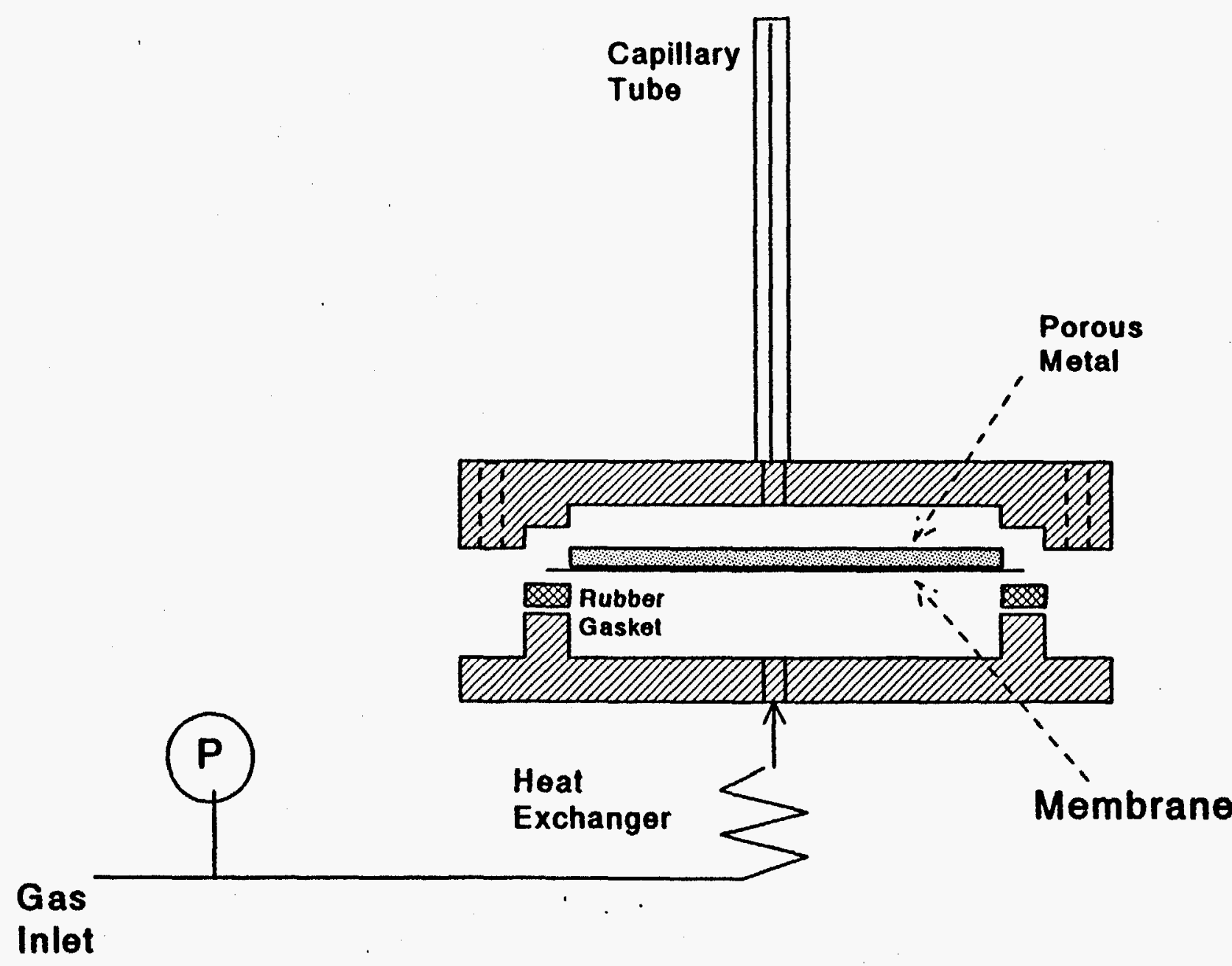

FIGURE 2.1-1 ROOM TEMPERATURE GAS PERMEABILITY MEASUREMENT APPARATUS 

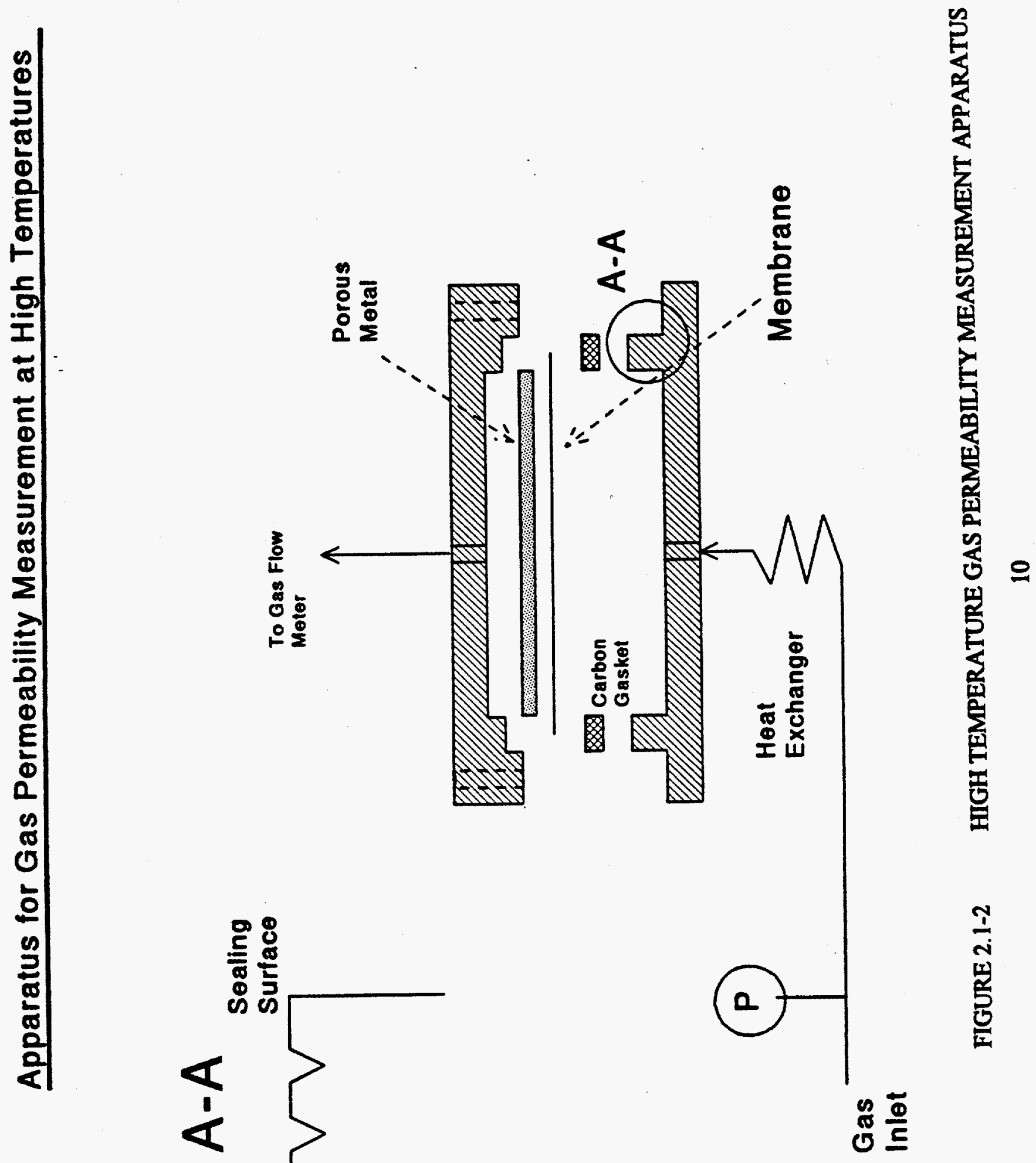


\section{Schematic of Membrane Cell}

1. Feed Inlet

2. Feed Outlet

3. Permeate Sweep Gas Inlet

4. Permeate Sweep Gas Outlet

5. Purge Gas Inlet

6. Purge Gas Outlet

7. Thermocouple to Measure Cell Temperature

8. Membrane Cell

9. Membrane
14. Lindberg Furnace

15. Membrane Support

16. Stainless Steel Insert

17. Lid

2.1-3 Schematic Of High Temperature Gas Permeability Cell Inside Retort Furnace 


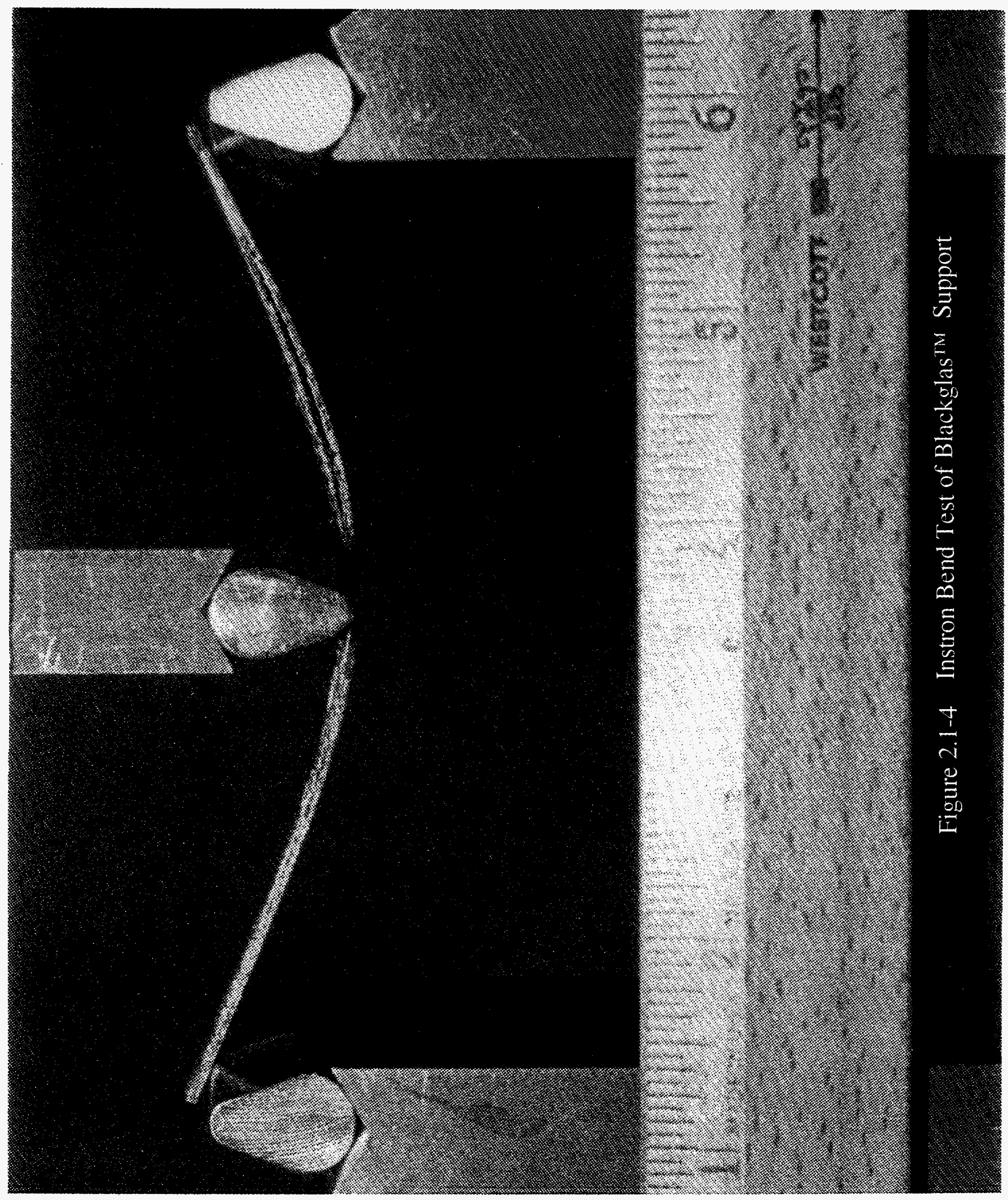




\subsection{Preparative Procedures}

\subsubsection{Porous Blackglas ${ }^{\mathrm{TM}}$ Support}

The porous Blackglas ${ }^{\mathrm{TM}}$ support is made by three different methods depending on the nature of the fibrous materials used. The first method uses short chopped fibers such as carbon fibers, glass fibers, or metallic fibers. These types of fibers are mixed with the Blackglas ${ }^{\mathrm{TM}}$ precursor and shaped into flat sheets or tubes using a press, or mold cast at $150^{\circ} \mathrm{C}$ to cure the resin. The second method uses a woven or nonwoven fabric layer made from the above listed fibers. These woven or nonwoven fabrics can be placed on one side of the sheet or tube during the forming process for increased mechanical strength of the support. The third method uses all woven or nonwoven fabric stacked in layers and bonded together by the Blackglas ${ }^{\mathrm{TM}}$ resin.

The prepared sheet or tube is pyrolyzed under certain conditions to produce the support. These conditions are given in Table 2.2-1.

The pore size and porosity of the pyrolyzed support are modified by repeated reinfiltration with Blackglas ${ }^{\mathrm{TM}}$ monomer.

A typical example of the porous support preparation procedure is as follows. Amoco VMX-11 pitch-based carbon fibers were mixed thoroughly with the B-staged Blackglas $^{\mathrm{MM}}$ precursor to a composition of $30 \mathrm{wt} \%$ fiber and shaped into round or rectangular sheets. The mixture was gelled at 60 to $85^{\circ} \mathrm{C}$ for 4 to 12 hours depending on the temperature and then hot pressed at $150^{\circ} \mathrm{C}$ at 100 to 200 psig pressure for one hour. The sheet after hot pressing was pyrolyzed under $\mathrm{N}_{2}$ flow and temperature ramp rate of 1 to 5 degrees per minute up to $950^{\circ} \mathrm{C}$ and held at that temperature for one hour. The pyrolyzed sheet was re-infiltrated with the Blackglas ${ }^{\mathrm{TM}}$ monomer and the catalyst for curing the monomer. The re-infiltrated sheet was cured at 40 to $50^{\circ} \mathrm{C}$ under $\mathrm{N}_{2}$ for 4 to 5 hours and pyrolyzed the same way as before. The resulting support can be used to make the composite membrane described in the following section. 


\subsubsection{Composite Carbon Molecular Sleve (CMS) Membrane}

The microporous Blackglas ${ }^{\mathrm{TM}}$ support such as the ones prepared by the above described procedure and other commercially available porous supports can be used to make the composite CMS membrane. The general procedures are as follows:

1) The support is cleaned with water, dried, and fired at the desired maximum temperature to further clean the surface to be coated.

2) A carbon molecular sieve precursor polymer or monomer is dissolved in a suitable solvent and diluted to a concentration less than $5 \%$ by weight. The polymers that can be used for this purpose are polyimide or its precursor polyamic acid, polyacrylnitrile, cellulose, and many other types of polymeric materials capable of producing a carbon molecular sieve upon carbonization at high temperatures under inert atmosphere.

3) The solution is either spin coated or brush coated onto the porous support surface in extremely small quantities. Even slightly larger quantity causes cracks on the resulting carbon film.

4) The solvent in the solution is removed by evaporation at certain temperatures depending on the nature of the solvent. If a monomer is used, the monomer on the surface is polymerized.

5) The solvent free polymer film may go through a curing process where the polymer is crosslinked or changed to a different chemical state such that during carbonization the polymer does not change shape.

6) The cured polymer is carbonized under nitrogen or helium at a given temperature program.

7) The carbonized composite membrane is tested at room temperature for permeability of nitrogen and hydrogen.

8) Steps 3 to 6 are usually repeated at least 5 times before a good composite membrane can be obtained. 


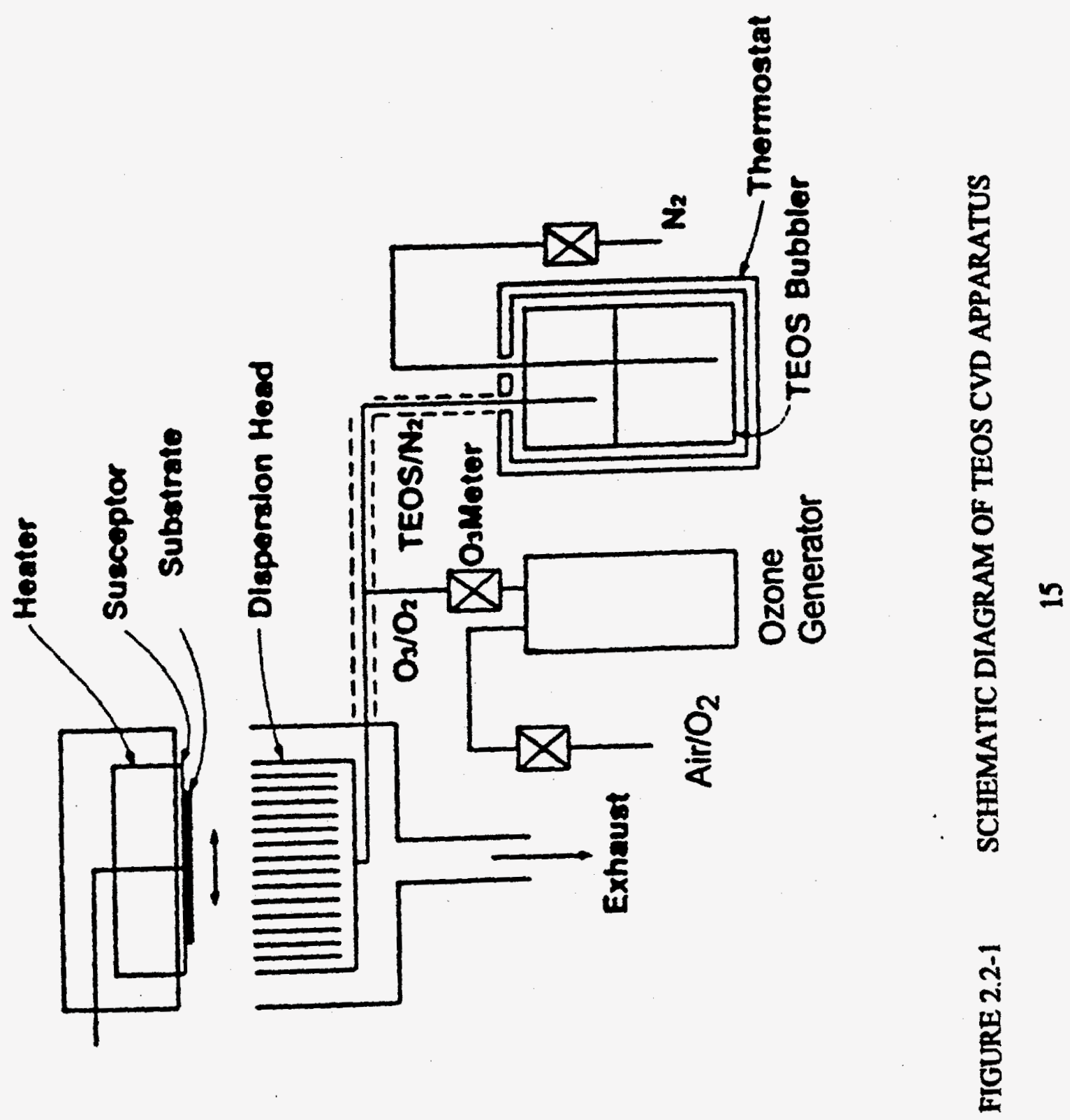




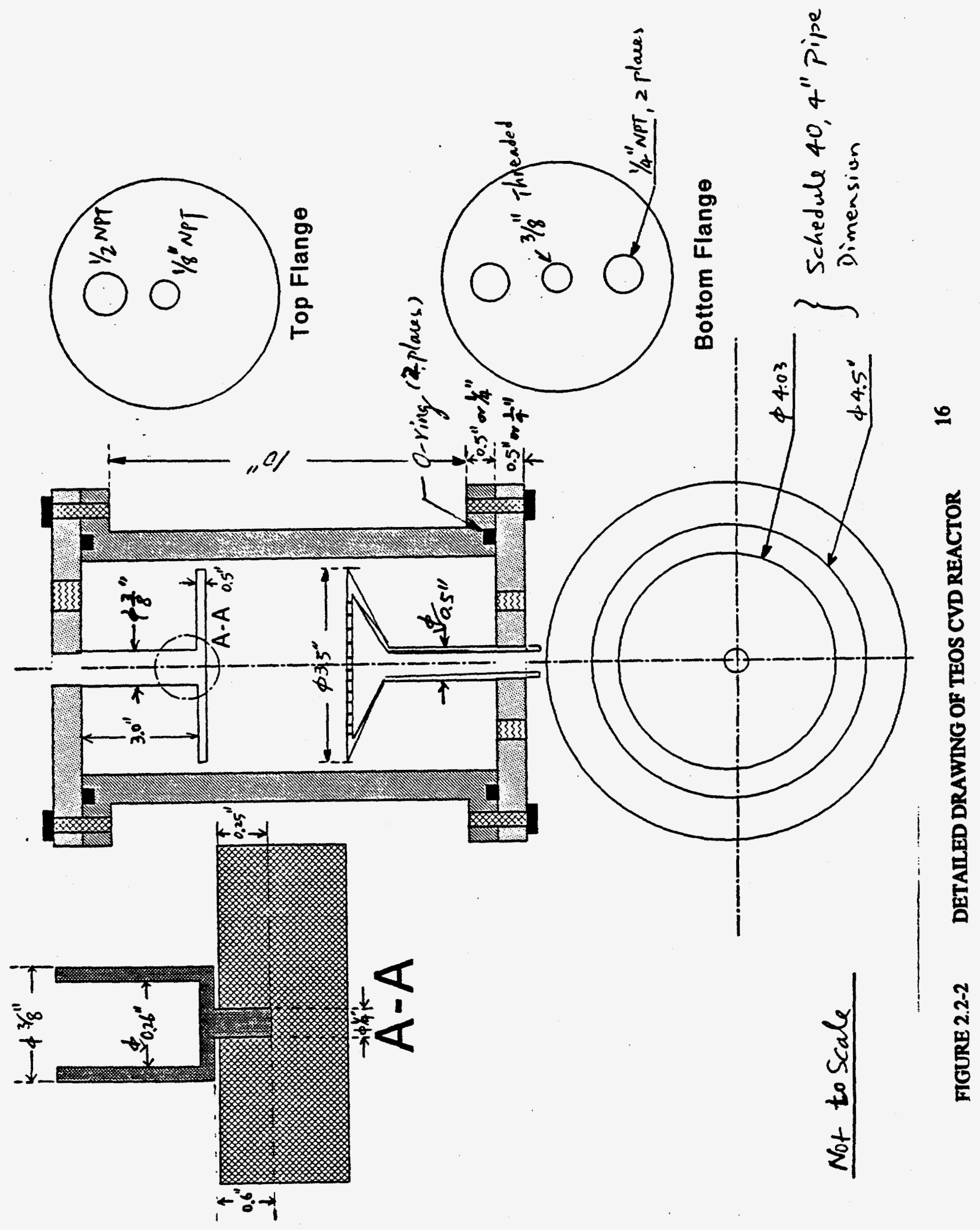


TABLE 2.2-1 PYROLYSIS AND CARBONIZATION CONDITIONS FOR BLACKGLAS ${ }^{\text {TM }}$ SUPPORTS AND COMPOSITE MEMBRANES

\begin{tabular}{|c|c|c|c|c|}
\hline SAMP WE \% & COMPOSIMON & $\begin{array}{l}7 \\
\text { BLACKGLAS }\end{array}$ & $\begin{array}{l}\text { PYROLYSIS } \\
\text { TEMPERATURES }\end{array}$ & COMMENTS: \\
\hline $8046-11-1$ & Carbon coated Nicalon & $7985-101 / 102$ & $\begin{array}{l}3^{\circ} \mathrm{C} / \mathrm{min} \text { to } 350^{\circ} \mathrm{C} \\
2^{\circ} \mathrm{C} / \min \text { to } 750^{\circ} \mathrm{C} \\
1^{\circ} \mathrm{C} / \text { min to } 950^{\circ} \mathrm{C} \\
1 \mathrm{hr} \text { hold at } 950^{\circ} \mathrm{C}\end{array}$ & First support made \\
\hline $8046-53-1$ & 7 & “ & $\begin{array}{l}3^{\circ} \mathrm{C} / \mathrm{min} \text { to } 350^{\circ} \mathrm{C} \\
2^{\circ} \mathrm{C} / \mathrm{min} \text { to } 750^{\circ} \mathrm{C} \\
1^{\circ} \mathrm{C} / \mathrm{min} \text { to } 950^{\circ} \mathrm{C} \\
1 \mathrm{hr} \text { hold at } 950^{\circ} \mathrm{C}\end{array}$ & $\begin{array}{l}\text { First CMS film coated on } \\
\text { to support using PAN }\end{array}$ \\
\hline 8046-95-1 & $\begin{array}{l}\text { Sandwich of } \\
\text { Fabric/10\%chopped carbon } \\
\text { fiber/fabric }\end{array}$ & 489D & $\begin{array}{l}1^{\circ} \mathrm{C} / \mathrm{min} \text { to } 800^{\circ} \mathrm{C} \\
1 \mathrm{hr} \text { hold at } 800^{\circ} \mathrm{C}\end{array}$ & $\begin{array}{l}\text { Combination of fabric and } \\
\text { chopped carbon fiber }\end{array}$ \\
\hline 8046-99-1 & $\begin{array}{l}\text { Sandwich of } \\
\text { Pabric/25\%chopped carbon } \\
\text { fiber/fabric }\end{array}$ & 489D & $\begin{array}{l}1^{\circ} \mathrm{C} / \mathrm{min} \text { to } 800^{\circ} \mathrm{C} \\
1 \mathrm{hr} \text { hold at } 800^{\circ} \mathrm{C}\end{array}$ & $\begin{array}{l}\text { Combination of fabric and } \\
\text { chopped carbon fiber }\end{array}$ \\
\hline $8046-105-1$ & $\begin{array}{l}\text { Steel fabric } \\
\text { ST10AL3 }\end{array}$ & $5 \%$ polyimide $(\mathrm{PI})$ in NMP & $\begin{array}{l}1^{\circ} \mathrm{C} / \mathrm{min} \text { to } 800^{\circ} \mathrm{C} \\
1 \mathrm{hr} \text { hold at } 800^{\circ} \mathrm{C}\end{array}$ & $\begin{array}{l}\text { Spin coating of PI solution } \\
\text { on fabric }\end{array}$ \\
\hline $8046-129-1$ & Alumina support & Polyimide (PI2611) & $\begin{array}{l}1^{\circ} \mathrm{C} / \mathrm{min} \text { to } 800^{\circ} \mathrm{C} \\
1 \mathrm{hr} \text { hold at } 800^{\circ} \mathrm{C}\end{array}$ & Spin coating \\
\hline
\end{tabular}


TABLE 2.2-1 PYROLYSIS AND CARBONIZATION CONDITIONS FOR BLACKGLAS ${ }^{\text {TM }}$ SUPPORTS AND COMPOSITE MEMBRANES (CONTINUED)

\begin{tabular}{|c|c|c|c|c|}
\hline SAMPLE F & COMPOSTIIIT & $\begin{array}{l}\text { BLACKGLAS } \\
\text { GII } \\
\text { GRADE }\end{array}$ & $\begin{array}{l}\text { PYROLYSIS } \\
\text { TEMPERATURES }\end{array}$ & COMMENIS \\
\hline $8046-139-1$ & Alumina support & Polyimide (PI2571) & $\begin{array}{l}1^{\circ} \mathrm{C} / \mathrm{min} \text { to } 800^{\circ} \mathrm{C} \\
1 \mathrm{hr} \text { hold at } 800^{\circ} \mathrm{C}\end{array}$ & Pendulum dip coating \\
\hline $8046-155-1$ & Alumina support & CVD of Cyclohexane & $\begin{array}{l}1^{\circ} \mathrm{C} / \min \text { to } 1050^{\circ} \mathrm{C} \\
6 \mathrm{hr} \text { hold at } 1050^{\circ} \mathrm{C}\end{array}$ & \\
\hline $8046-166-1$ & $\begin{array}{l}25 \% \text { carbon fiber } \\
\text { and one layer } \\
\text { Nicalon Fabric }\end{array}$ & 489D & $\begin{array}{l}1^{\circ} \mathrm{C} / \min \text { to } 850^{\circ} \mathrm{C} \\
6 \mathrm{hr} \text { hold at } 850^{\circ} \mathrm{C}\end{array}$ & $\begin{array}{l}\text { Infiltrated with Blackglas } \\
\text { monomer 489A\&B three times }\end{array}$ \\
\hline $8227-6-1$ & $25 \%$ carbon fiber & 489D & hold at $350^{\circ} \mathrm{C}$ & TEOS CVD \\
\hline $8227-68-A$ & $30 \%$ carton & $\begin{array}{l}\text { 489D/Polyimide } \\
\text { (Pyralin LXTM) Brush } \\
\text { coating }\end{array}$ & $\begin{array}{l}8^{\circ} \mathrm{C} / \text { min to } 950^{\circ} \mathrm{C} \\
1 \mathrm{hr} \text { hold at } 950^{\circ} \mathrm{C}\end{array}$ & Multiple coating with PI \\
\hline $8227-112-1$ & Nextel 312 fabric & 489D dip coated & $\begin{array}{l}3^{\circ} \mathrm{C} / \min 10950^{\circ} \mathrm{C} \\
1 \mathrm{hr} \text { hold at } 950^{\circ} \mathrm{C}\end{array}$ & Fabric nitrided \\
\hline $8227-149-1$ & Glass fiber & 489D & $\begin{array}{l}3^{\circ} \mathrm{C} / \min \text { to } 950^{\circ} \mathrm{C} \\
1 \mathrm{hr} \text { hold at } 950^{\circ} \mathrm{C}\end{array}$ & Glass fiber nitrided \\
\hline $8227-177-1$ & Nextel 312 & $489 \mathrm{C}$ & $\begin{array}{l}3^{\circ} \mathrm{C} / \mathrm{min} \text { to } 950^{\circ} \mathrm{C} \\
1 \mathrm{hr} \text { hold at } 950^{\circ} \mathrm{C}\end{array}$ & $\begin{array}{l}\text { Wound on wood mandrel and made } \\
\text { tubular support }\end{array}$ \\
\hline
\end{tabular}




\subsubsection{Chemical Vapor Deposition of $\mathrm{SiO}_{2}$ Film}

The experimental apparatus for $\mathrm{SiO}_{2}$ deposition at atmospherical pressures is shown in Figures 2.2-1 and 2.2-2. Figure 2.2-1 is a schematic diagram of the apparatus with the control and flow indicators. Figure $2.2-2$ is a detail drawing of the deposition chamber. The top flat sample holder is also a temperature-controlled heater. The bottom gas mixture inlet has shower-like distribution holes throughout the top surface. Tetraethylorthosilicate (TEOS) is introduced into the system through a bubbler temperature controlled at $65^{\circ} \mathrm{C}$. TEOS vapor is carried by nitrogen gas and mixed with oxygen (or air) from the ozone generator and introduced into the chemical vapor deposition (CVD) reactor through the distribution head. All tubings in the system are heated up to $80^{\circ} \mathrm{C}$ to prevent condensation of TEOS in the tubings. The reaction gas reacts on the substrate surface and in the gas phase and also on the reactor wall. The substrate is held upside down to avoid $\mathrm{SiO}_{2}$ particles formed in the gas phase from depositing on it.

\subsubsection{Carbon Film Preparation (8046-162-3)}

Kapton films 2-5 mil thickness were obtained from DuPont. Several 3.3 inch diameter circles of this material were cut, and carefully weighed. Each piece of film was placed between two $5 \times 5$ inch stainless steel plates with smooth surfaces, and the resulting sandwiches were stacked on each other. A 0.25 inch thick stainless steel plate was placed on top for added weight. In other runs, an additional weight was placed on this plate. The plate/film stack was placed in a sample holder and inserted into the furnace. Nitrogen was allowed to flow through the furnace at $1 \mathrm{~L} / \mathrm{min}$. The exiting nitrogen was passed through a cold trap, then bubbled through a stirred solution of $20 \%$ potassium hydroxide before venting. The furnace was heated at $1{ }^{\circ} \mathrm{C} / \mathrm{min}$ to $850^{\circ} \mathrm{C}$ setting $\left(800^{\circ} \mathrm{C}\right.$ according to internal thermocouple), and held at this temperature for one hour. It was then allowed to cool. Sample 162-3, which weighed $1.0476 \mathrm{~g}$ before pyrolysis, weighed $0.6116 \mathrm{~g}$ after (41.6\% weight loss). 


\subsection{Hydrogen Adsorption Porasimetry}

The analysis of any adsorptive material involves three fundamental measurements: (1) pore size analyses via either gravimetric or volumetric gas/vapor/liquid techniques (e.g. $\mathrm{N}_{2}$ BET or Hg porosimetry); (2) gas or liquid permeability to determine the cross sectional flux; and, finally, (3) diffusion which relates to the permeability but generally is applied only to particulate media. The first two analyses, that of pore size and permeability are done under equilibrium approaches whereas the diffusional analysis is done to simulate kinetic limits. In earlier sections, we dealt with the methods used in our classical analyses of the CMS membranes. Here, we will describe the method development and initial results obtained for $\mathrm{H}_{2}$ isotherms obtained at $19.7^{\circ} \mathrm{K}$.

Why should we want to measure such an isotherm? The isotherms certainly do not tell us if the membrane is permeable to $\mathrm{H}_{2}$, or selective for hydrogen, but they can tell us whether we have the pore size distribution about right before going through all the work of mounting up a membrane for high temperature permeability tests. To be sure, the measured pore distribution might still be of the outer surface rather than of the entire material. Only a permeability test would settle the ultimate question of whether we have been able to prepare a hydrogen-selective membrane.

As far as we have been able to determine through repeated searches of the literature, this is probably the first time that isotherms for $\mathrm{H}_{2}$ have been successfully measured at its boiling temperature on any material. The primary reason that it is desirable to measure adsorption isotherms at the adsorbate boiling temperature is that it is the lowest temperature at which we can condense them at atmospheric pressure, a. 760 torr. Accordingly, we obtain the total pore volume permeable to that adsorbate and if its physical size is equal or smaller than the smallest pores, the maximum pore volume is determined. Also, as is not often realized in application of analytical results obtained via the commonly used $\mathrm{N}_{2} \mathrm{BET}$, adsorption measurements at low temperatures reflect the electronic character and the physical size of the adsorbate used, and the pore size distribution calculated is therefore highly dependent on the effectiveness of the particular mathematical model in accounting for these effects. As the temperature is raised, electronic effects as expressed in chemisorption tend to dominate. Thus, $\mathrm{H}_{2}$ isotherms cited in the literature and, more generally, temperature programmed desorption curves are typically used to characterize interaction effects for catalytically active metals or metal oxides supported on $\mathrm{Al}_{2} \mathrm{O}_{3}$, for example. This work is done in the range of -150 to $700^{\circ} \mathrm{C}$. 
Although we can be sure that others have thought of measuring $\mathrm{H}_{2}$ isotherms at its condensation temperature, the practical difficulties of doing this are several. First, the pressure measuring device must be impermeable to $\mathrm{H}_{2}$ which means that the capacitance manometer must be constructed of stainless steel. Second, the capacitance manometer employed for the initial doses at low system pressures must be very stable electronically, be in a temperature stabilized enclosure, and give high resolution. This would require, a 0-10 or preferably a $0-1$ torr device to give sufficient accuracy and procision for micropore calculations down to $\mathrm{ca}$. $3 \mathrm{~A}$. Third, as shown in Figures 2.3-1 and 2.3-2, where the vapor pressure data of $\mathrm{N}_{2}, \mathrm{He}$, and $\mathrm{H}_{2}$ are plotted, the temperature stability required for $\mathrm{H}_{2}$ isotherms is extreme, on the order of $+1-0.1^{\circ} \mathrm{C}$.

The pressure measurement capability has only recently come available in commercial equipment with the introduction of the ASAP (Accelerated Surface Area and Porosimetry System) 2000 made by Micromeritics Inst. Corp., Norcross, GA. The compact design and simplicity of use is apparent in part by inspection of Figure 2.3-3 where a sketch of the instrument is given. A 386 model computer was used to control and record, via initial software setup, the measurement of each isotherm. The temperature stability required for this work was provided by SuperVariTemp liquid He Model SVT cryostat manufactured by Janis Research Co., Inc., Wilmington, MA which has a very sophisticated PID controller capable of holding $19.7^{\circ} \mathrm{K}$ for more than 30-hrs. The schematic of this cryostat is shown in Figure 2.3-4. By using a liquid $\mathrm{N}_{2}$ reservoir to surround the liquid He reservoir, the run time cited above of 30-hrs requires only about 15 liters of liquid He provided that the cryostat is precooled over night by filling the liquid $\mathrm{N}_{2}$ jacket. Examples of gases successfully measured or used either in the ASAP 2000 as delivered or by the present variable temperature modification as done are listed in Table 2.3-1. The molecular diameter data in Table 2.3-1 dramatically shows how much smaller $\mathrm{H}_{2}$ is than for example $\mathrm{CO}_{2}$.

Examples of results from this technique are shown in Figures 2.3-7 - 2.3-9, which show the $\mathrm{N}_{2}, \mathrm{CO}_{2}$, and $\mathrm{H}_{2}$ isotherms of a $\mathrm{CO}_{2}, 1^{\circ} \mathrm{C} / \mathrm{min}$ activated film as measured at 77,195 and a. $20{ }^{\circ} \mathrm{K}$. The amount of material analyzed in each case was between $0.1-0.3 \mathrm{~g}$. Each isotherm was obtained by using $1.0 \propto$ doses. The instrument is capable of measuring isotherms using $0.1 \propto$ doses and has a 200 data point storage limit. By inspection, we note at least two things, namely, there is very low porosity to nitrogen, and secondly, there is much more very fine porosity as seen in the $\mathrm{H}_{2}$ isotherm and which is not seen in the $\mathrm{CO}_{2}$ isotherm. Next, the wiggles in the $\mathrm{H}_{2}$ isotherm are probably due to small sample temperature fluctuations and manometer limitations. 
TABLE 2.3-1 Kinetic Diameters for All Gases Whose Diameter Was Obtained From van der Waal's Equation

\begin{tabular}{|c|c|c|}
\hline PROBEMOLFCULE & Boming Font, 'c & $\begin{array}{l}\text { MOLECUIIA } \\
\text { DLAMTER ? }\end{array}$ \\
\hline$\overline{\mathrm{CO}_{2}}$ & -57.5 & 4.00 \\
\hline $\mathrm{CO}$ & -205.0 & 3.76 \\
\hline $\mathrm{H}_{2}$ & -259.1 & 2.89 \\
\hline $\mathrm{CH}_{4}$ & -182.5 & 3.80 \\
\hline
\end{tabular}

Surface areas were calculated from each isotherm by the BET and Langmuir methods. For the BET method, points $B_{1}$ were calculated as transformed by equation 2.3-1, and a least squares fit was performed for $\mathrm{P}_{i} / \mathrm{P}_{0}, \mathrm{~B}_{1}$ data pairs. The BET surface area was then calculated via equation 2.3-2, and the BET monolayer volume via equation 2.3-3. The Langmuir calculations were calculated from the least squares fit for $P_{i} / P_{0}, L_{i}$ data pairs, where $L_{1}$ was defined by equation 2.3-3. Langmuir surface areas were calculated using equation 2.3-4, and Langmuir monolayer volumes via equation 2.3-5. Note that both surface area calculations require the use of an analytical gas molecular cross sectional area $\left(A_{c s}\right)$. The values used for this for nitrogen and carbon dioxide were 0.162 and 0.170 $\mathrm{nm}^{2}$, as recommended by Micromeritics. Hydrogen surface areas were corrected to a cross sectional area of $0.123 \mathrm{~nm}^{2}$, which was roughly estimated from the data of McClellan and Harnsberger ${ }^{12}$. Note that since calculations of monolayer volume do not require this assumption, they will not reflect any errors in this value. 
2.3.-1 $\quad B_{i}=\frac{P_{i} / P_{o}}{\left(1-P_{i} / P_{0}\right) N_{i}}$

2.3-2 $\quad A_{\text {BET }}=\frac{A_{C S}\left(6.023 \times 10^{23}\right)}{\left(22414 \mathrm{~cm}^{3} S T P\right)\left(10^{12} \mathrm{~nm}^{2} / \mathrm{m}^{2}\right)(\text { slope })}$

2.3-3 $\quad \mathrm{V}_{\mathrm{BET}}=(\text { slope }+ \text { intercept })^{-1}$

2.3-5 $\quad A_{\text {LNG }}=\frac{A_{G s}\left(6.023 \times 10^{23}\right)}{\left(22414 \mathrm{~cm}^{3} S T P\right)\left(10^{18} \mathrm{~nm}^{2} / \mathrm{m}^{2}\right)(\text { slope })}$

2.3-6 $\quad \mathrm{V}_{\text {LNG }}=(\text { slope })^{-1}$

3 
Pore size distributions were estimated using the Horvath-Kawazoe ${ }^{13}$ method. Due to the complexity of this tochnique, we did not attempt to estimate all of the parameters necescary to modify these calculations for use with hydrogen isotherm data.

What we have been able to show in this work is that $\mathrm{H}_{2}$ porosimetry is doable and will provide additional insight on microporous materials. The pore size resolution it should provide of $2.5 \mathrm{~A}$ as compared to $3.5 \mathrm{~A}$ of $\mathrm{CO}_{2}$ will clearly reach the same lateral resolution as conventional Scanning Transmission Electron Microscopy (STEM), a technique which requires an initial investment of $\$ 1.5$ million (US,1994) compared to less than $\$ 100 \mathrm{~K}$. Neither tochnique will reveal whether a material is bulk permeable but gas adsorption data is simpler to interpret, particularly for amorphous materials where electron or $\mathrm{x}$-ray techniques are very difficult to apply. 


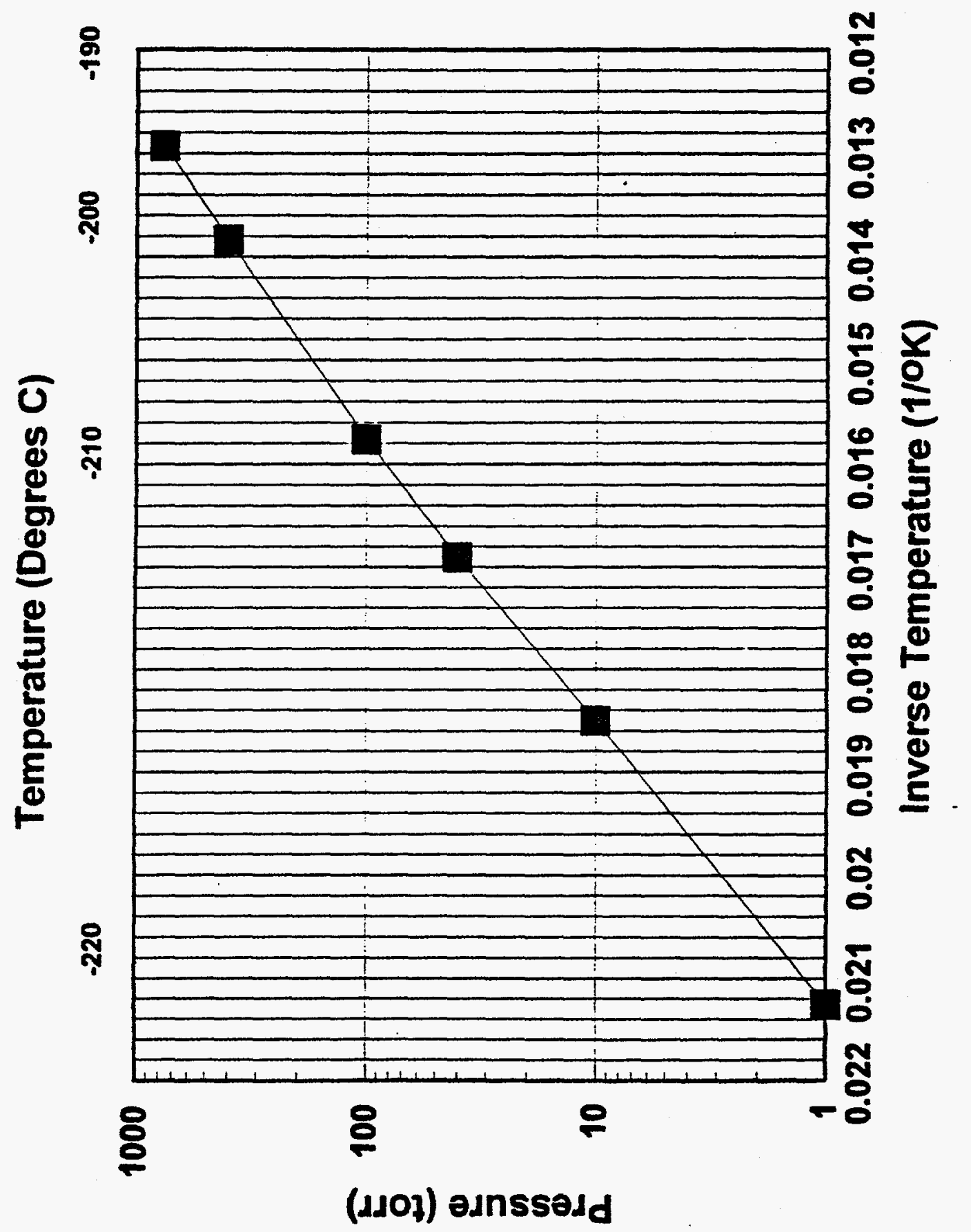

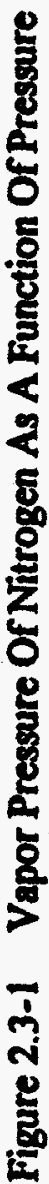




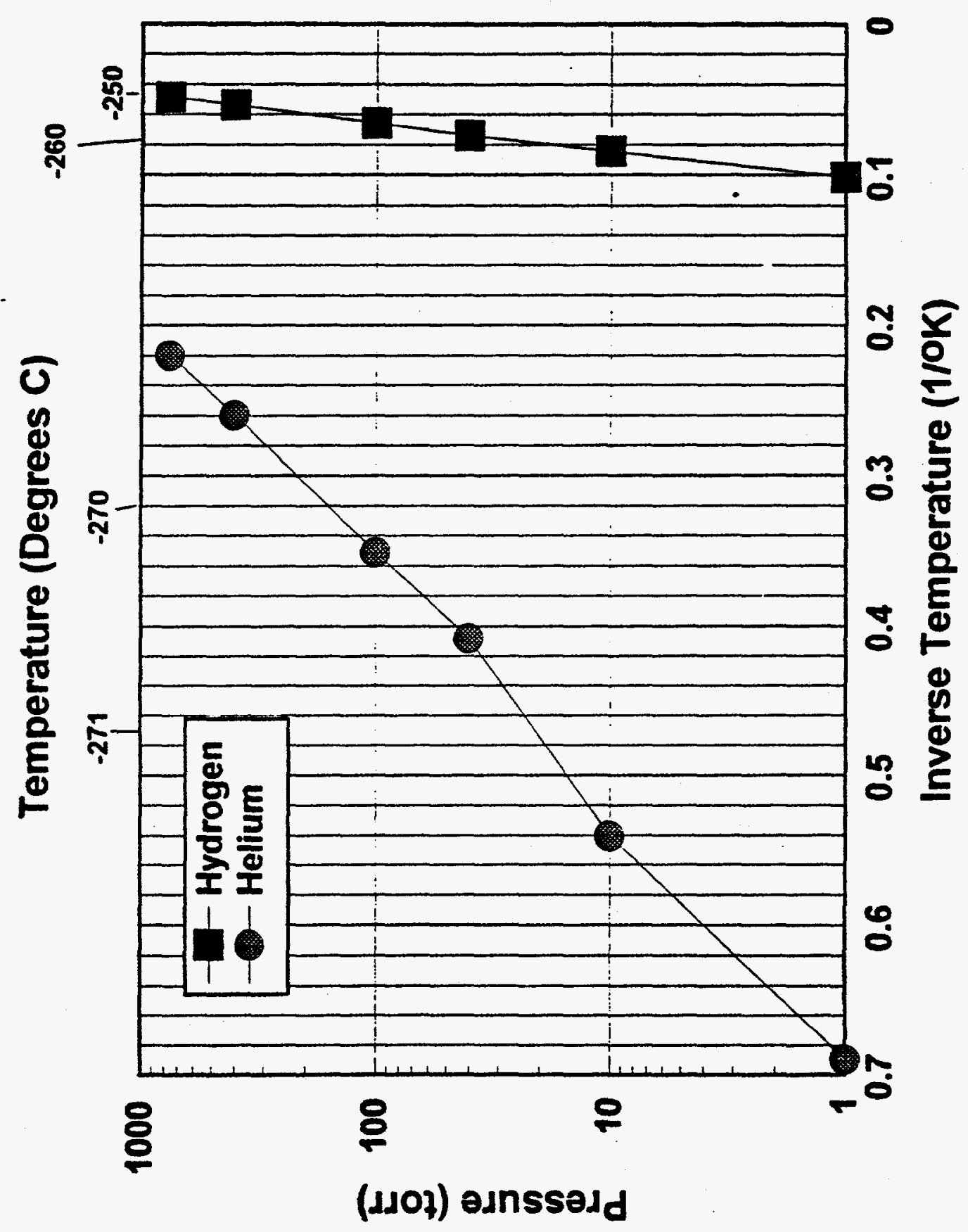

울 


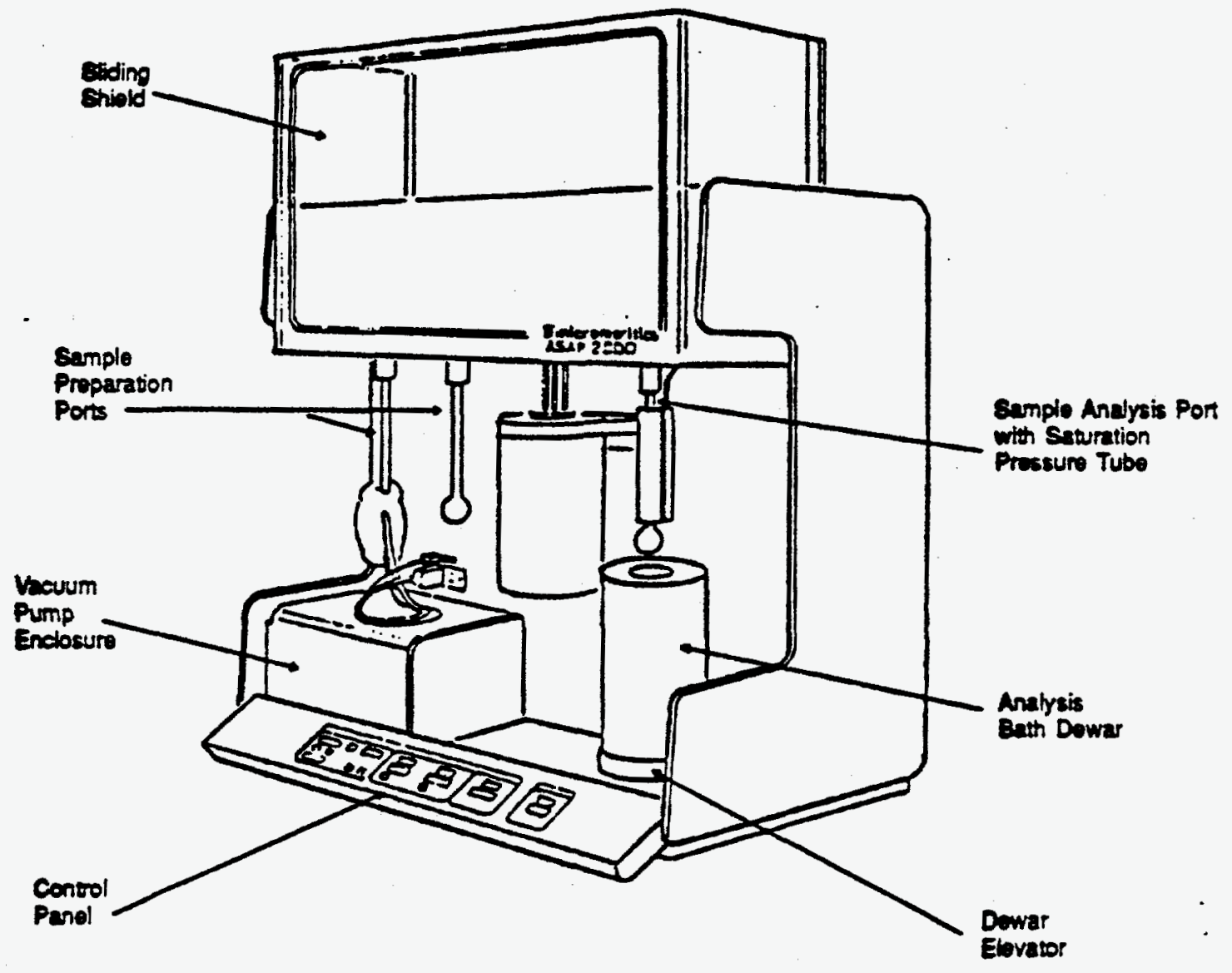

Figure 2.3-3 Drawing of ASAP 2000 System 


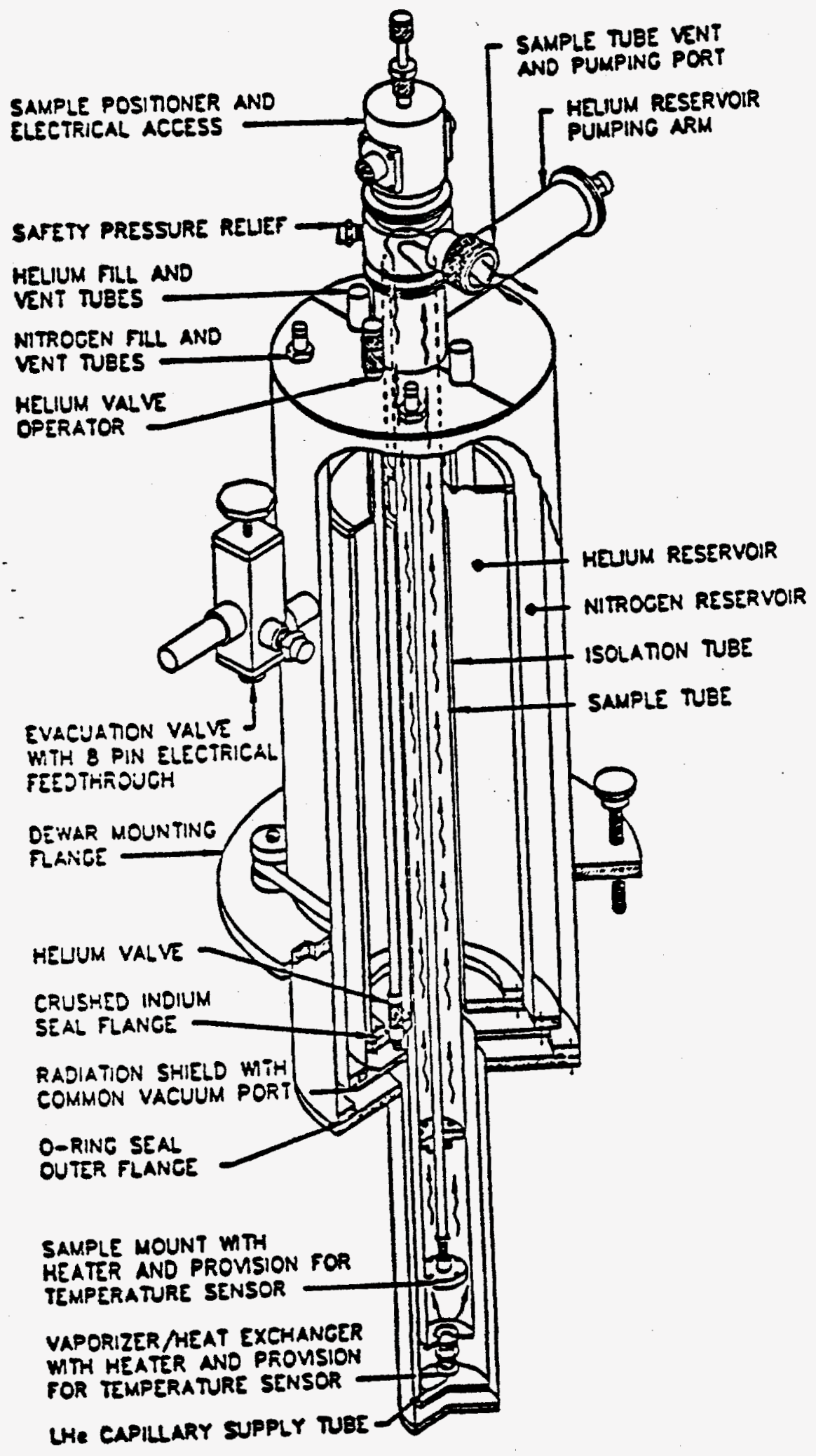

Figure 2.3-4 Drawing of Cryostat used for Hydrogen Porosimetry 


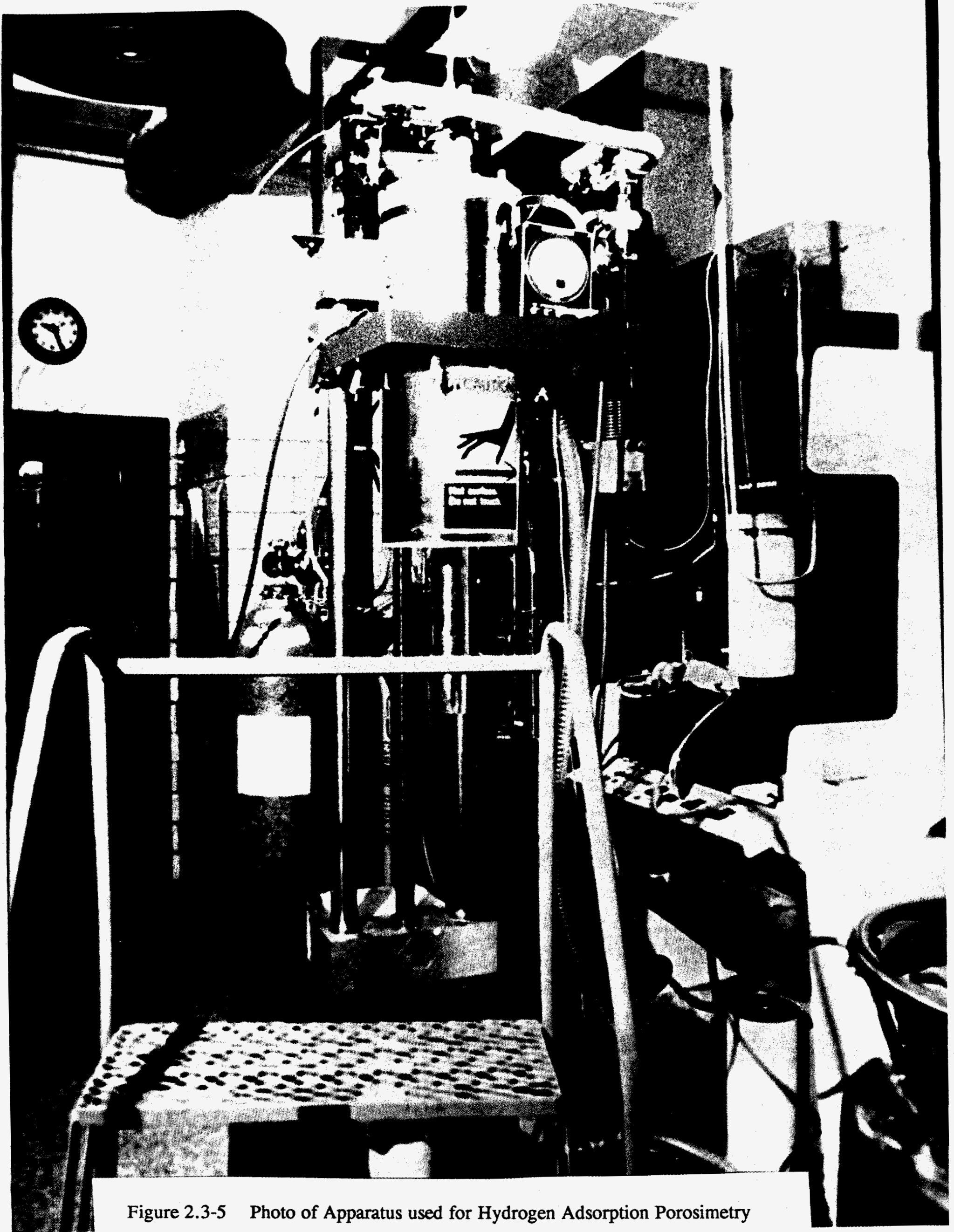




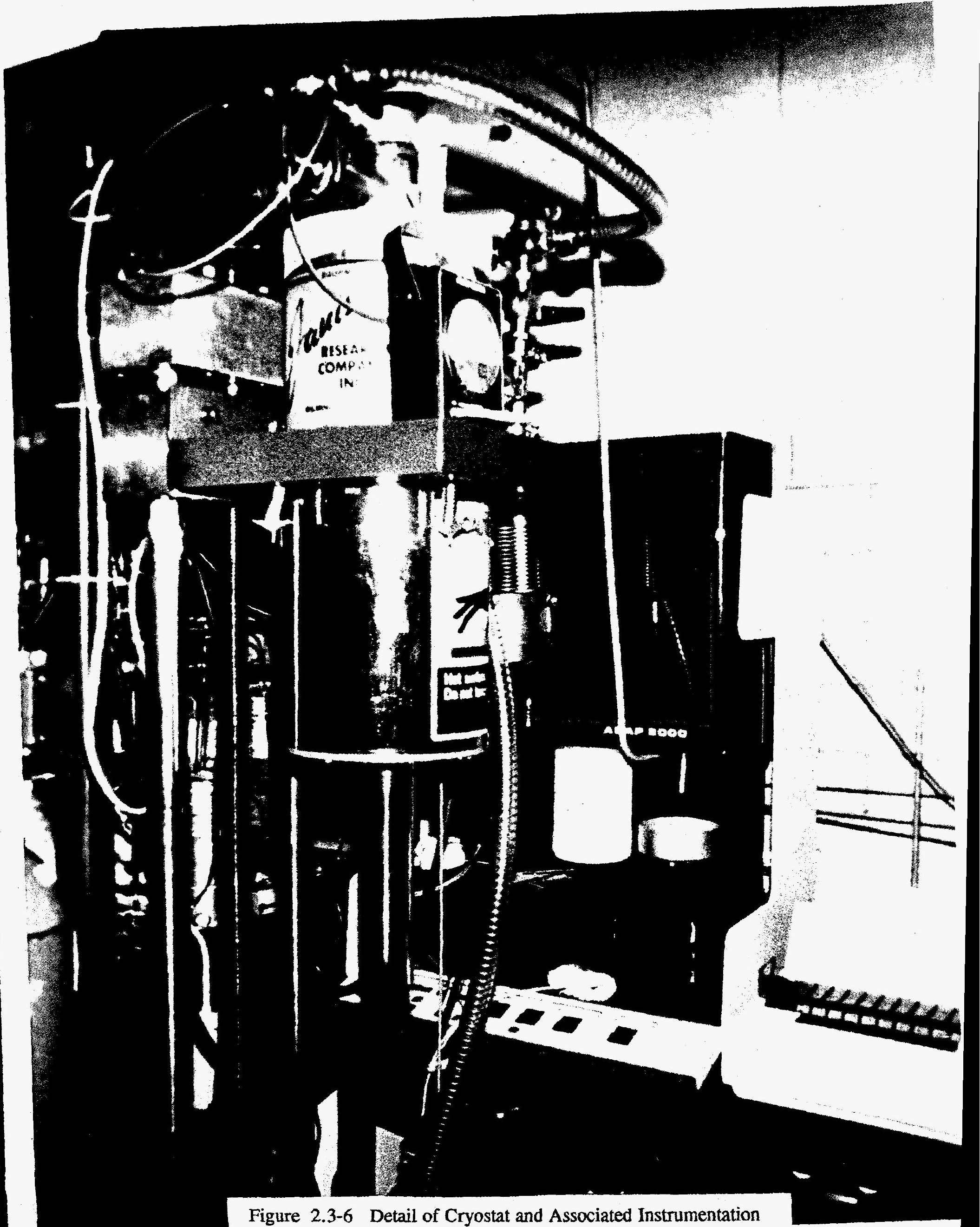

Figure 2.3-6 Detail of Cryostat and Associated Instrumentation 


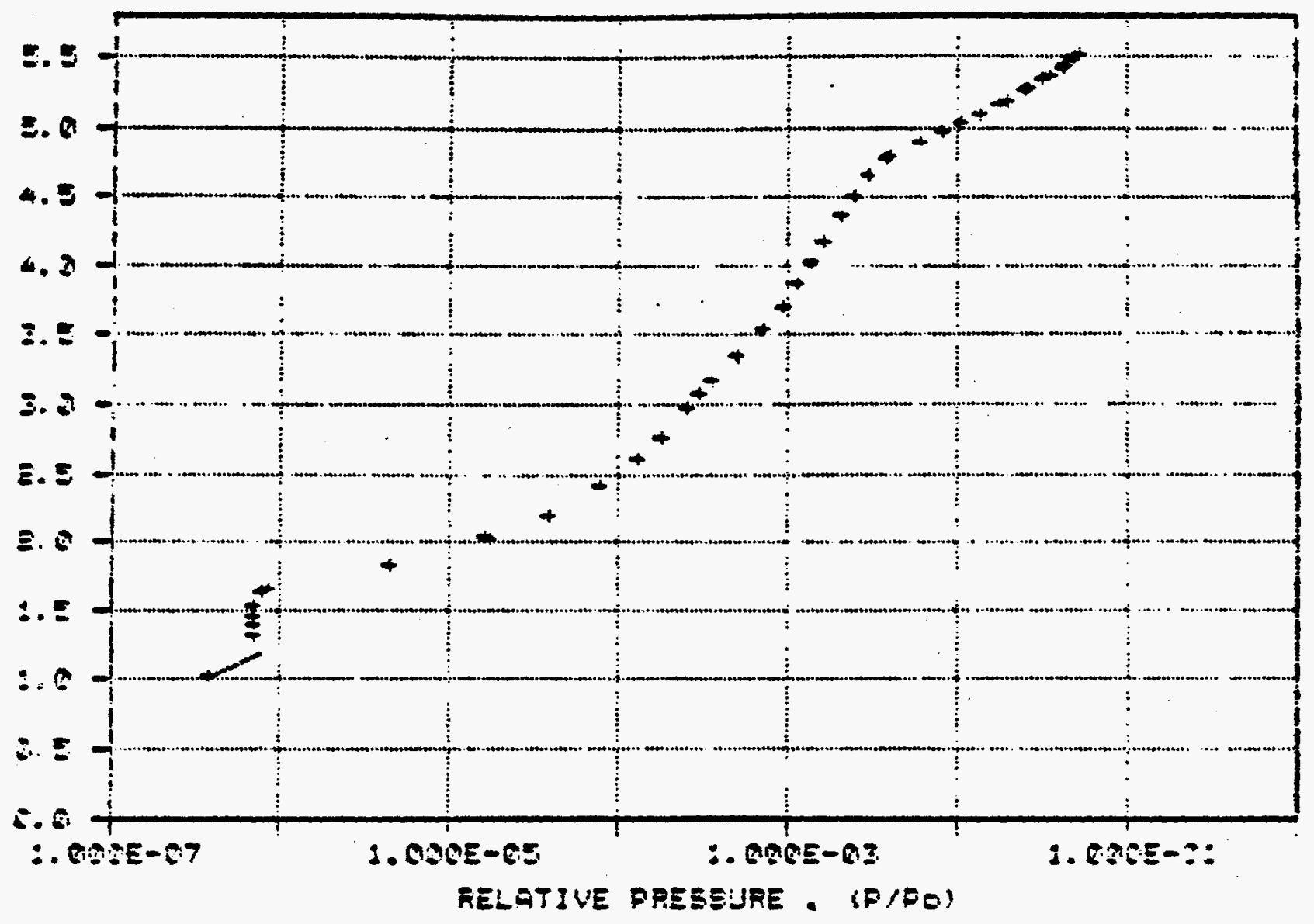

Figure 2.3-7 Porosimetry Printout for Nitrogen Isotherm of Sample 8046-170-1 


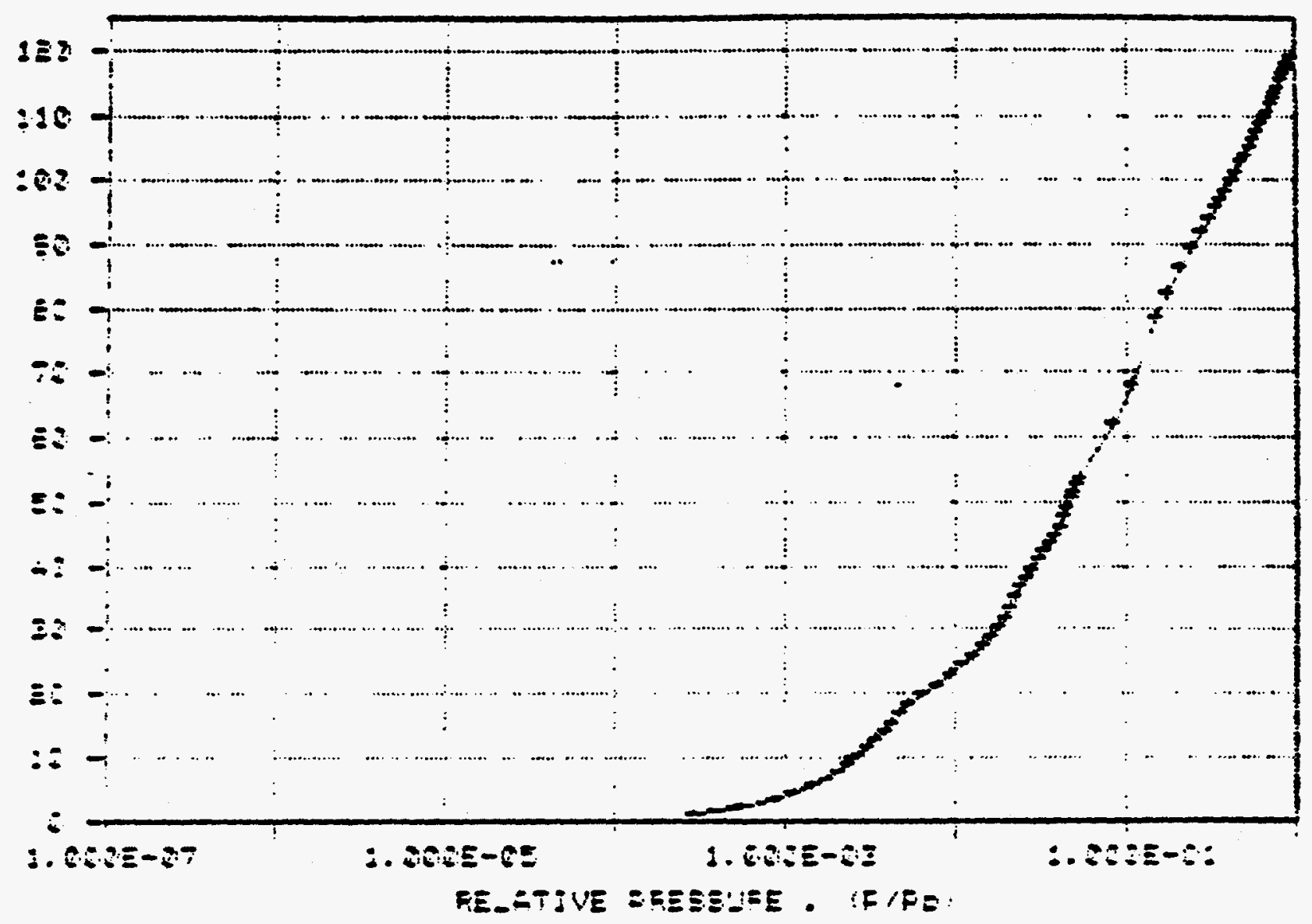

Figure 2.3-8 Porosimetry Printout for Carbon Dioxide Isotherm of Sample 8046-170-1 


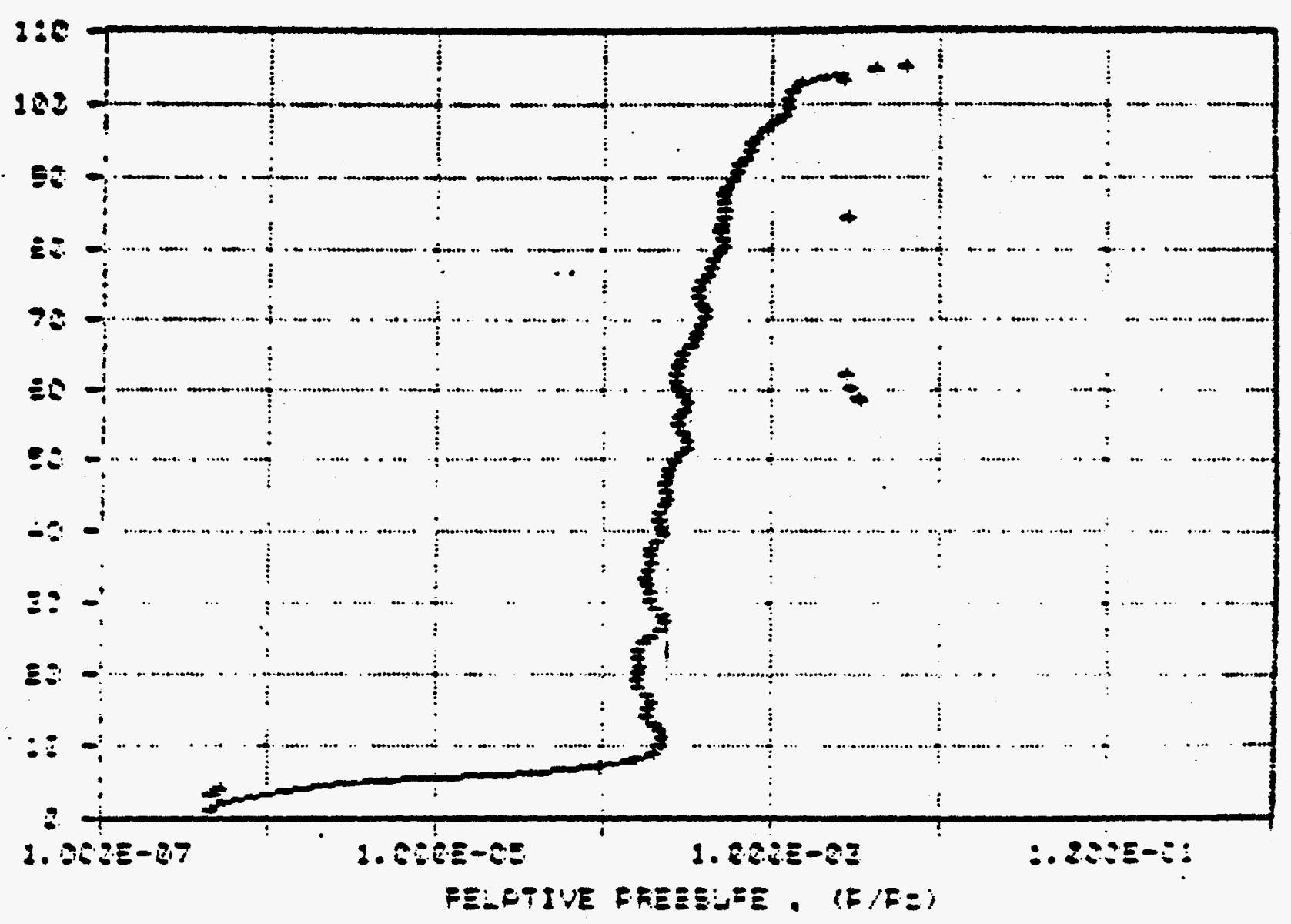

Figure 2.3-9 Porosimetry Printout for Hydrogen Isotherm of Semple 8046-170-1 


\subsection{RESULTS AND DISCUSSION}

\subsection{Porous Blackglas ${ }^{\mathrm{TM}}$ Membrane Support}

The permeability of a gaseous species through a membrane is inversely proportional to the thickness of the membrane as defined by the Fick's first law of diffusion. Thus, the selective membrane layer needs to be as thin as possible for maximum permeability. With this presumption, comes the problem of making the permselective membrane layer as thin as possible with adequate mechanical strength to withstand the operating pressure conditions. The idea of the thin film composite (TFC) membrane was proposed to solve just this type of problem in 1963 during the search for a better reverse osmosis membrane. The high temperature CMS membrane is no exception. The need for reduced permselective layer thickness and mechanical strength calls for a strong, porous support with appropriate properties. This section describes in detail the porous support made using the Blackglas ${ }^{\mathrm{MM}} 14,15,16$ material.

\subsubsection{Mechanical Strength}

We have made fiber reinforced Blackglas ${ }^{\text {TM }}$ ceramic microporous supports using chopped short fibers and woven ceramic and carbon fiber fabrics. It was found that the support mechanical strength and support flatness depend on the type of fiber used and on the interface coating between the fiber and the matrix material. Table 3.1-1 lists the chopped fibers tested for making the flat disk supports.

The results presented in Table 3.1-1 show that the only fiber/Blackglas ${ }^{\mathrm{TM}}$ matrix suitable for use as membrane supports is the pitch-based carbon fiber because the carbon fiber/Blackglas $^{\text {TM }}$ support is flat and flexible after first pyrolysis whereas the rest of the fibers tested either resulted in brittle structure or significantly curved surfaces. After repeated Blackglas ${ }^{\mathrm{TM}}$ monomer infiltration and pyrolysis, the carbon fiber/Blackglas ${ }^{\text {TM }}$ type of support becomes both strong and flexible. It is well known that high strain and damage tolerance in fiber reinforced ceramic composites depends strongly on the fiber/matrix material interface strength. To have high flexure strength and strain requires a low strength fiber/matrix interface bonding that can deflect the crack and produce fiber pull-out under stress and strain. The other important factor is 
the thermal expansion coefficient match between the fiber and matrix material. A close match means there will be minimum stress during pyrolysis and cooling. A large mismatch means that large stress will be created during pyrolysis and cooling and it has to be dissipated. Otherwise, the sample will be distorted because of such a large stress.

\section{Table 3.1-1 Short Fiber/Blackglas ${ }^{\mathrm{M}}$ Composite Supports}

\begin{tabular}{|c|c|c|c|c|}
\hline $\begin{array}{l}\text { Tiber: } \\
\text { Type in } \\
\text { Composite }\end{array}$ & $\begin{array}{l}\text { Easy To Mix } \\
\text { : With } \\
\text { Resin }\end{array}$ & $\begin{array}{l}\text { Coeff. Of Thermal } \\
\text { Expansion } \\
\text { (PPM/C) }\end{array}$ & $\begin{array}{l}\text { Quality } \\
\text { Ifter Itor } \\
\text { Pressing }\end{array}$ & $\begin{array}{l}\text { Condition } \\
\text { After } \\
\text { Prolysis. }\end{array}$ \\
\hline Glass & yes & 5.0 & $\operatorname{good}$ & flat, brittle \\
\hline Pitch-based carbon & yes & -1.1 & good & flat, flexible \\
\hline Carbon + glass & yes & variable & poor & flat, brittle \\
\hline 316 SS steel & no & 13.3 & poor & $\begin{array}{l}\text { curves significantly } \\
\text { strong }\end{array}$ \\
\hline $\begin{array}{c}316 \text { SS steel + } \\
\text { carbon }\end{array}$ & no & variable & poor & $\begin{array}{c}\text { flat } \\
\text { wrinkled surfaces } \\
\end{array}$ \\
\hline Fiberfax ${ }^{\circ}$ Ceramic & yes & 7.7 & poor & $\begin{array}{l}\text { curves significantly } \\
\text { strong but brittle }\end{array}$ \\
\hline
\end{tabular}

NOTE: coeff. of thermal expansion of Blackglas is $3.4 \mathrm{ppm} / \mathrm{C}$

The yield strength and strain of carbon fiber/Blackglas ${ }^{\mathrm{TM}}$ type of support as a function of the number of infiltrations were studied by the Instron bend test as discussed in section 2.1.3. The results are summarized in Table 3.1-2.

Table 3.1-2 Tensile Test Results of Blackglas ${ }^{\mathrm{M}}$ Ceramic Membrane Support

\begin{tabular}{|c|c|c|c|}
\hline Sample I & MIEID STRRESS (pSi) & MIEID STRAITN (\%) & Modulus(psi) \\
\hline 1 & $\begin{array}{ll}3 & 1457\end{array}$ & 0.36 & 500500 \\
\hline 2 & 3163 & 0.39 & 1031000 \\
\hline 3 & 3709 & 0.29 & 1482000 \\
\hline 4 & 5640 & 0.33 & 1984000 \\
\hline
\end{tabular}

It should be noted that the sample \# in the above table also corresponds to the number of infiltrations of the microporous support with Blackglas ${ }^{\mathrm{TM}}$ monomer. Thus, the 
results show that the supports are not only strong, but also flexible as indicated by the yield strain of 0.3 to $0.4 \%$. For a ceramic material, such a yield strain shows extreme flexibility. The yield stress and modules both increase with increasing number of infiltrations, as expected, because the apparent density of the support increases with infiltration whereas porosity and pore size decrease with infiltration. The denser material is expected to be stronger. What is not expected is the near constant value of yield strain. After four infiltrations, the support structure still has $\mathbf{0 . 3 3 \%}$ yield strain as compared with $0.36 \%$ after one infiltration.

\subsubsection{Pore Size, Pore Size Distribution and Porosity}

The microporous Blackglas ${ }^{\mathrm{TM}}$ ceramic supports made using the chopped carbon fibers were also tested for pore size, pore size distribution and porosity by mercury intrusion. The results of these tests are summarized in Table 3.1-3

Table 3.1-3 Pore Size and Porosity Results from Mercury Intrusion Measurements

\begin{tabular}{|c|c|c|c|c|}
\hline $\begin{array}{l}\text { NUMBER of } \\
\text { INFHTRATIONS }\end{array}$ & $\begin{array}{l}\text { MEDIAN PORE } \\
\text { DIAMEIER }\end{array}$ & $\begin{array}{l}\text { APPARENT } \\
\text { DENSHYY } \\
(\mathrm{g} / \mathrm{mL})\end{array}$ & $\begin{array}{l}\text { BUILY } \\
\text { oENSIIT' } \\
(\mathrm{g} / \mathrm{mI})\end{array}$ & 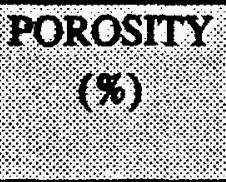 \\
\hline 1 & 2.4077 & 1.8645 & 1.4207 & 23.8 \\
\hline 2 & 1.1787 & 1.8679 & 1.6103 & 13.79 \\
\hline 3 & 0.6216 & 1.9553 & 1.818 & 7.02 \\
\hline 4 & 0.2596 & 1.9661 & 1.895 & 3.62 \\
\hline
\end{tabular}

This table shows that the pore size and porosity decrease with increasing number of infiltrations. The apparent density of the matrix increases with increasing number of infiltrations as expected. Thus, one can use the number of infiltrations in order to obtain a specific pore size and porosity. It should be pointed out that the pore size and porosity cannot be independently controlled because an increase in the number of infiltrations means a decrease in pore sice and porosity. If one desires to control these two properties independently, then a different method has to be used which changes independently the pore size and porosity. 
The pore size distribution of the Blackglas ${ }^{\mathbf{M}}$ supports is also obtained by mercury intrusion. The results are presented in Figures 3.1-1 to 3.1-4. These results show that the pore size distribution is generally narrow and Gaussian centered around the median pore size, especially when the support pore size is large and porosity high. After four infiltration and pyrolysis cycles, the porosity becomes small, and the pore size changes correspondingly, the pore size distribution also becomes relatively wider as shown in Figure 3.1-4.

\subsubsection{Scanning Electron Micrograph (SEM) Studies}

We have also studied the micro structures of the Blackglas ${ }^{\mathrm{MM}}$ supports by SEM. The main objective is to determine the pore shape and the formation of the pores. The SEM micrographs of the porous Blackglas ${ }^{\text {MM }}$ ceramic support structure show that the pores are formed by microcracks in the composite matrix. These microcracks come from the shrinkage associated with the pyrolysis of Blackglas ${ }^{\mathrm{TM}}$ resin. Thus, the pores generally have an elongated slit structure.

Figures 3.1-5 to 3.1-9 are SEM micrographs of the top surface structure of the Blackglas ${ }^{\mathrm{TM}}$ supports in order of increasing number of infiltrations. It can be clearly seen that the surface structure becomes increasingly dense as the number of infiltrations increases. This is in accordance with the findings that the pore size and porosity decrease with increasing number of infiltrations. For example, Figure 3.1-5 is the top surface structure of the support made for the first time without any infiltration. The surface has many long, slit shaped cracks forming the porous structure of the support. On the other hand, Figure 3.1-9 is the top surface structure of the support after four infiltrations. This figure shows that the top surface is almost completely dense with very small cracks which form the porous structure of this support with very small pores and low porosity.

The cross sectional structure of the support is also examined by SEM. The micrographs are presented in Figures 3.1-10 to 3.1-13. Essentially the same conclusion can be drawn from these pictures as those drawn from the top surface structure SEM.

Since the pore size and porosity are dependent on each other, it is very hard to control the pore size and porosity. Thus, other pore size controlling techniques, such as using 
a pore former, can be used to modify the pore size, porosity and pore structure of the support.

\subsubsection{Nitrogen Permeation Rate}

The nitrogen permeation rate is used to determine the flow characteristics of the support. If a support shows a large nitrogen flux, then the structure has more pores open from one surface of the support to the other surface of the support. We have measured nitrogen flow rates through the Blackglas ${ }^{\mathrm{TM}}$ support at room temperature as a function of applied pressure for supports infiltrated with Blackglas ${ }^{\mathbf{M}}$ monomer three and four times. The results are presented in Figure 3.1-14. For the two supports measured, the nitrogen permeation fluxes at room temperature are in the range of $10^{-3}$ to $10^{-4}\left[\mathrm{~cm}^{3}(\mathrm{STP}) /\left(\mathrm{cm}^{2} . \mathrm{s}\right.\right.$. torr) $)$. Such fluxes indicate that the resistance to flow through the support is small even when the pore size and porosity of the support are small. The flow rates are also linear functions of applied pressure indicating straightforward flow through porous media. 


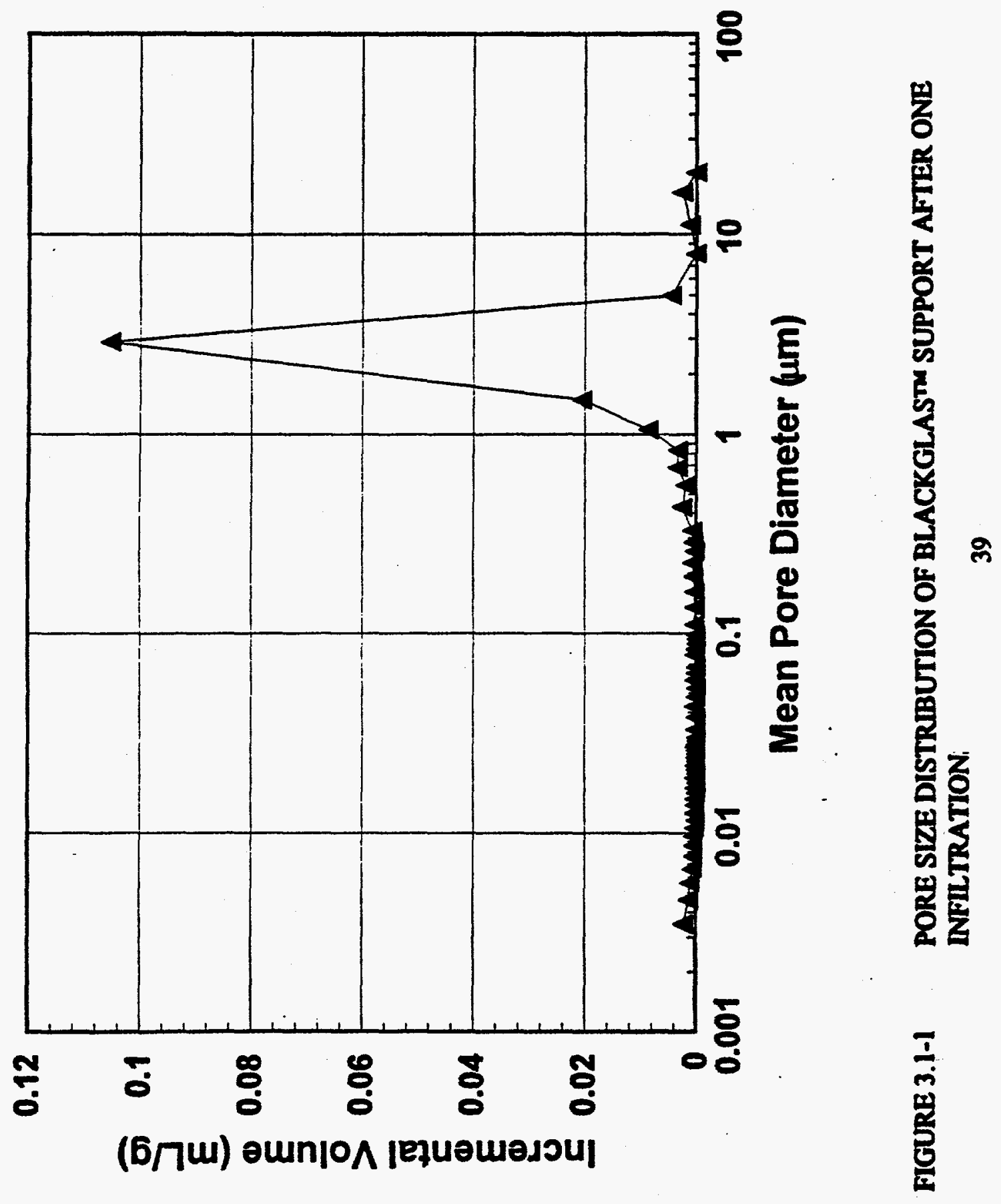



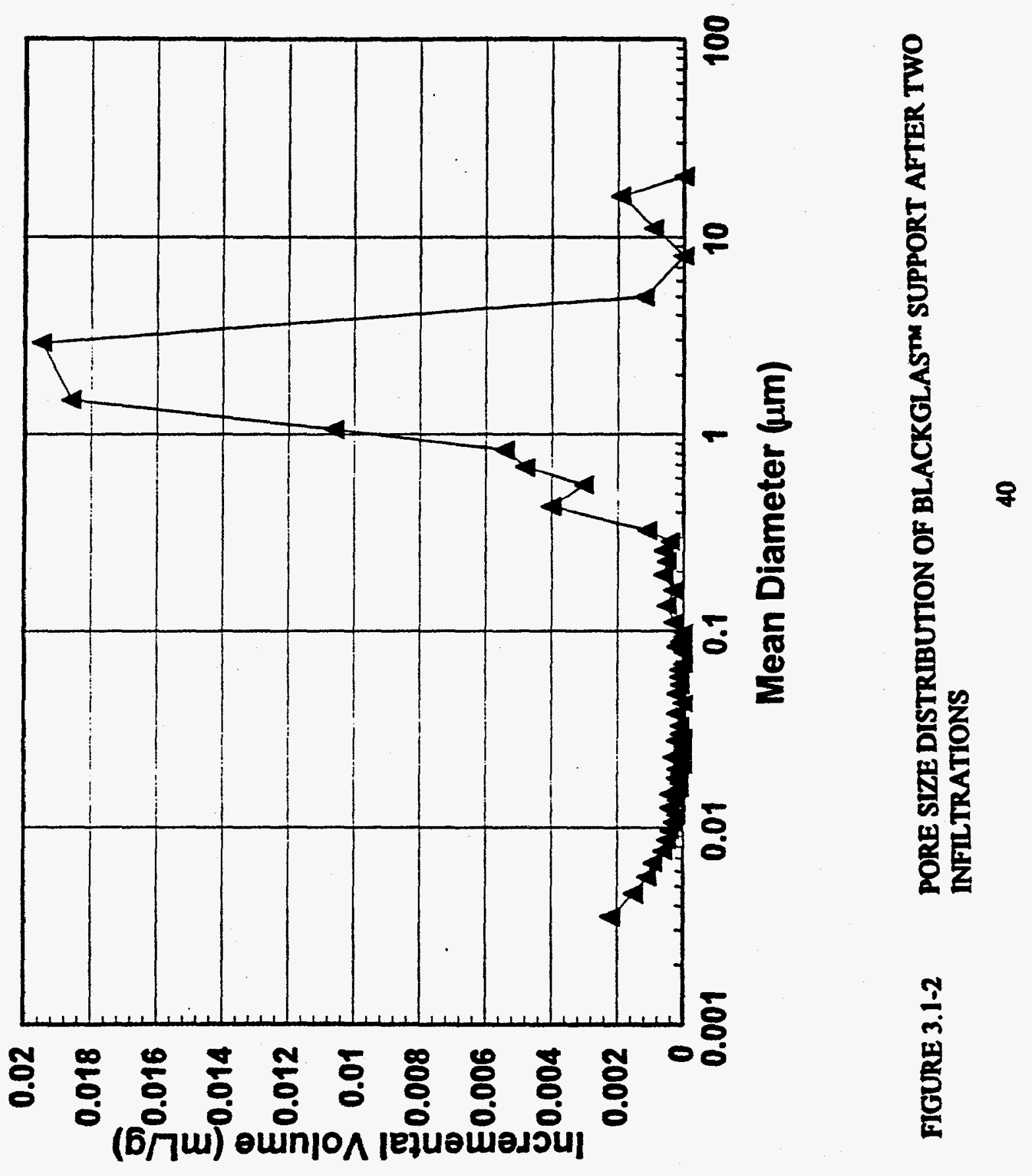


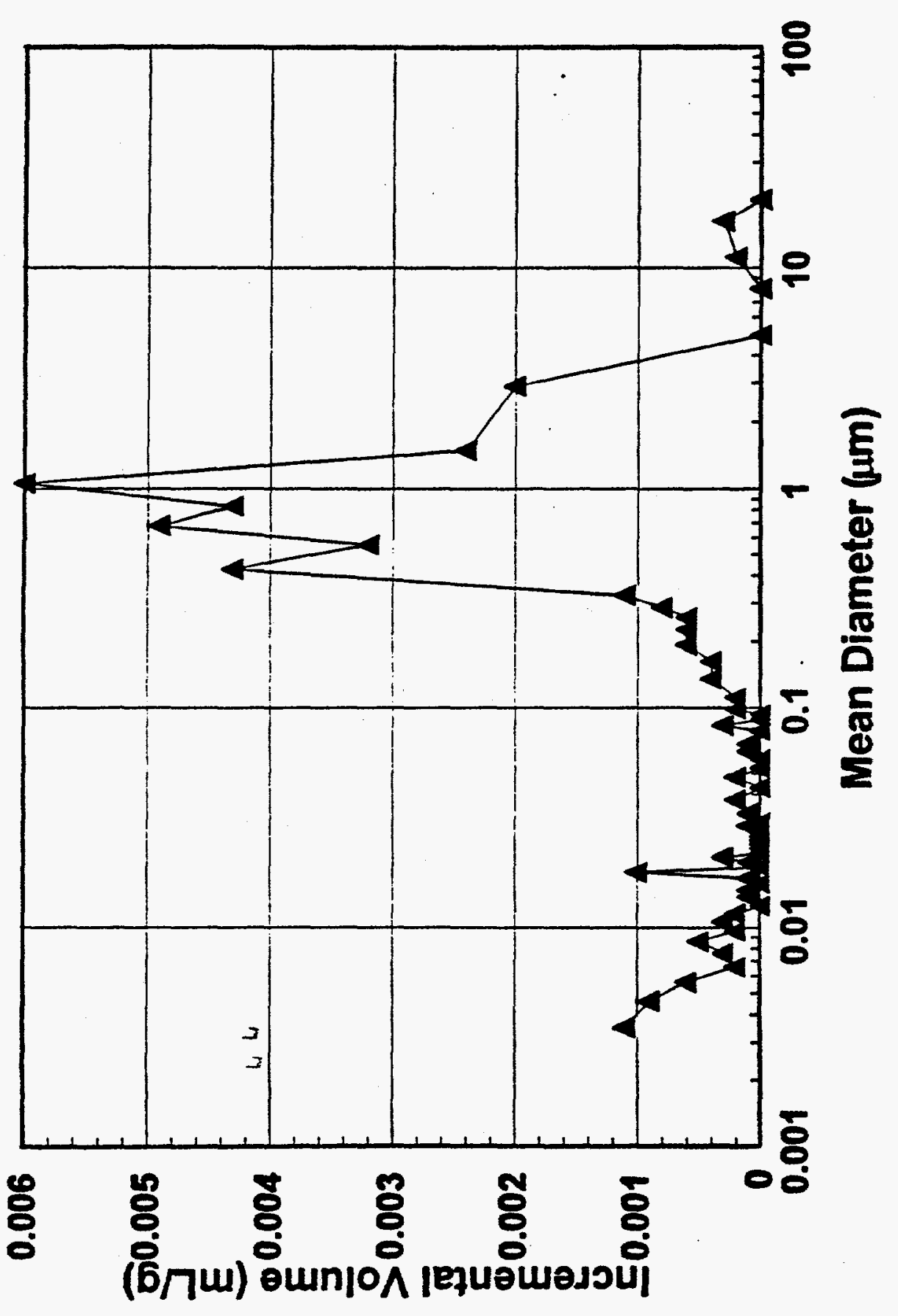

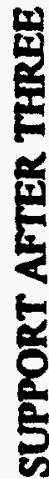

5

$\frac{7}{2}$ 


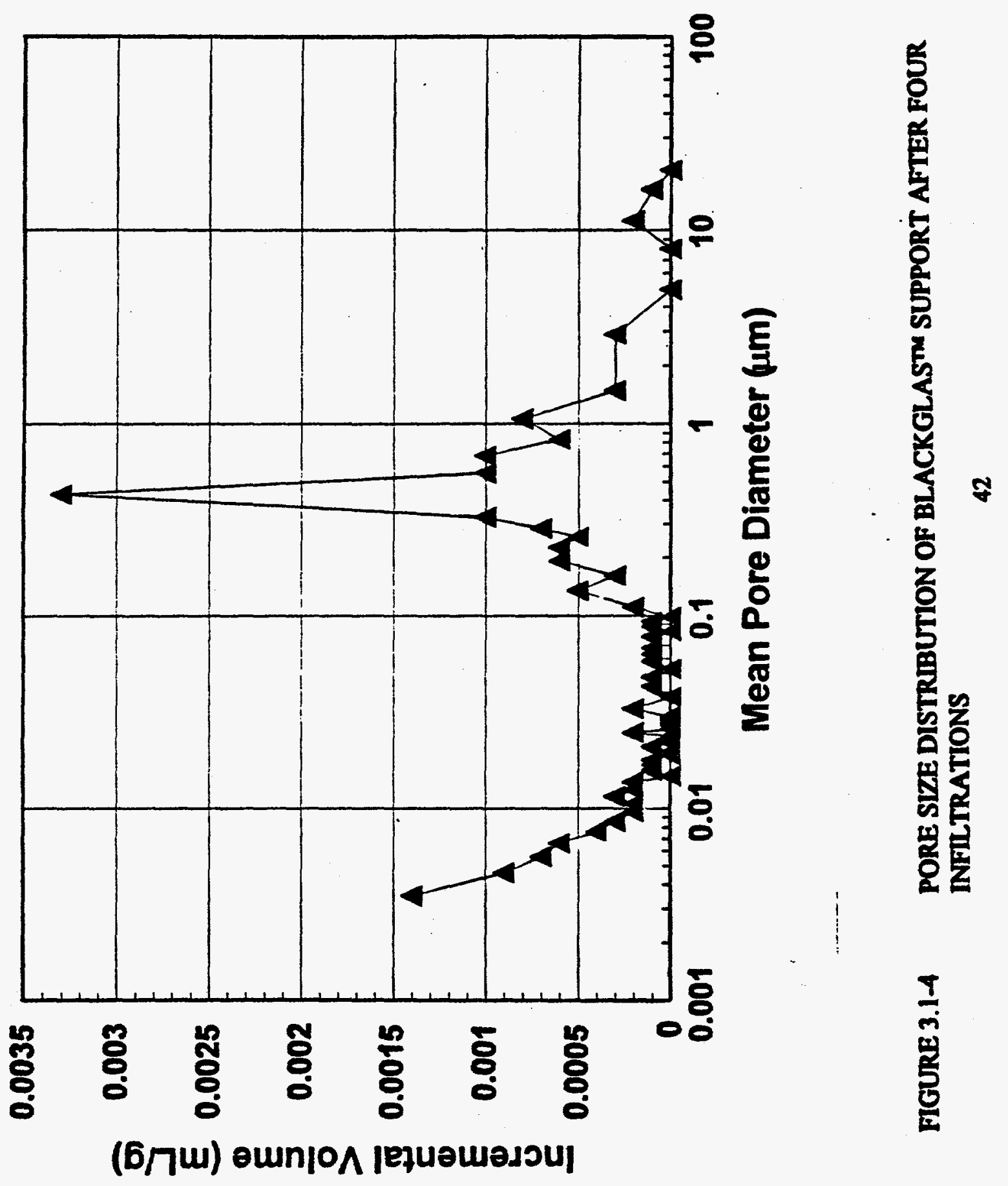




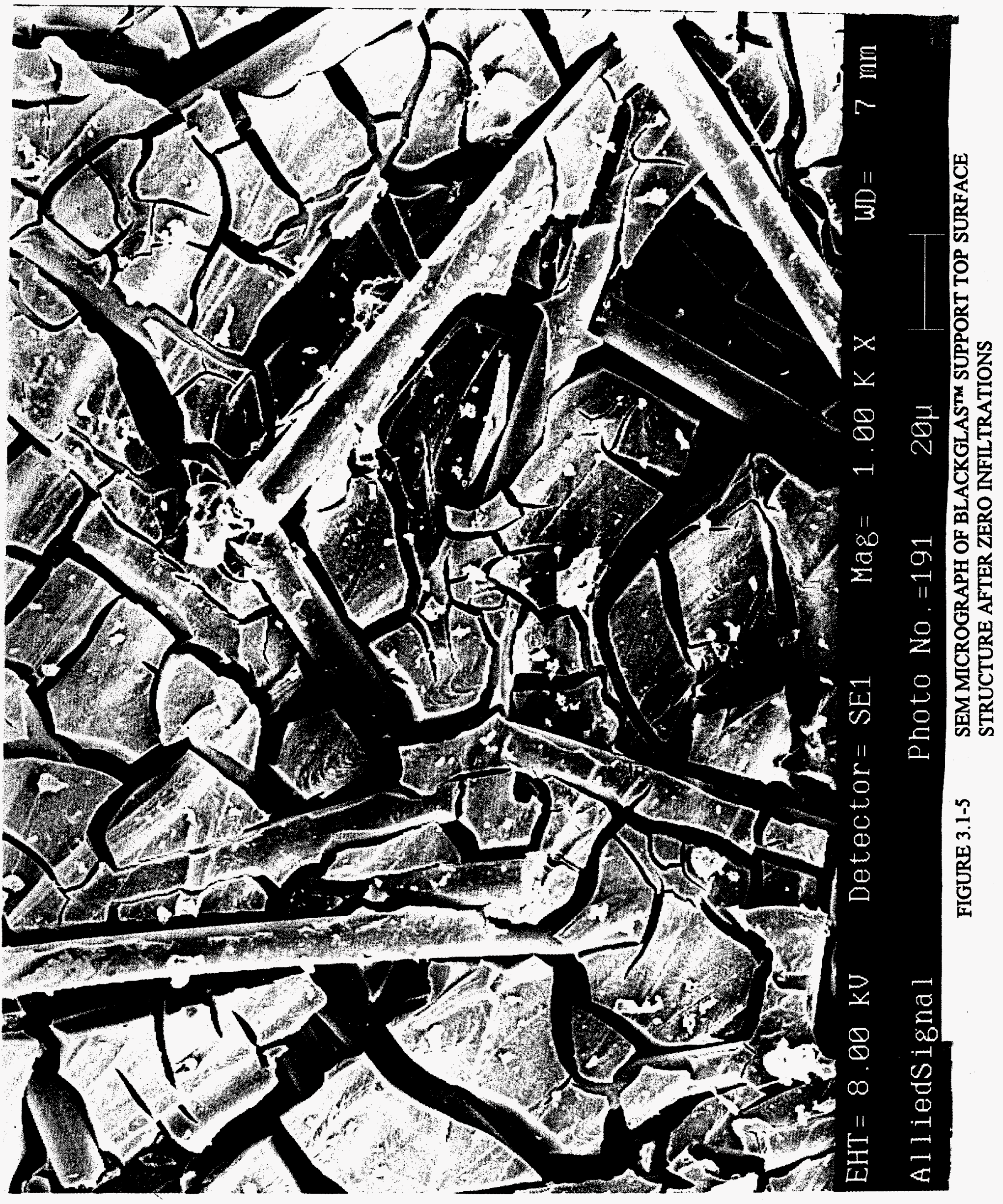




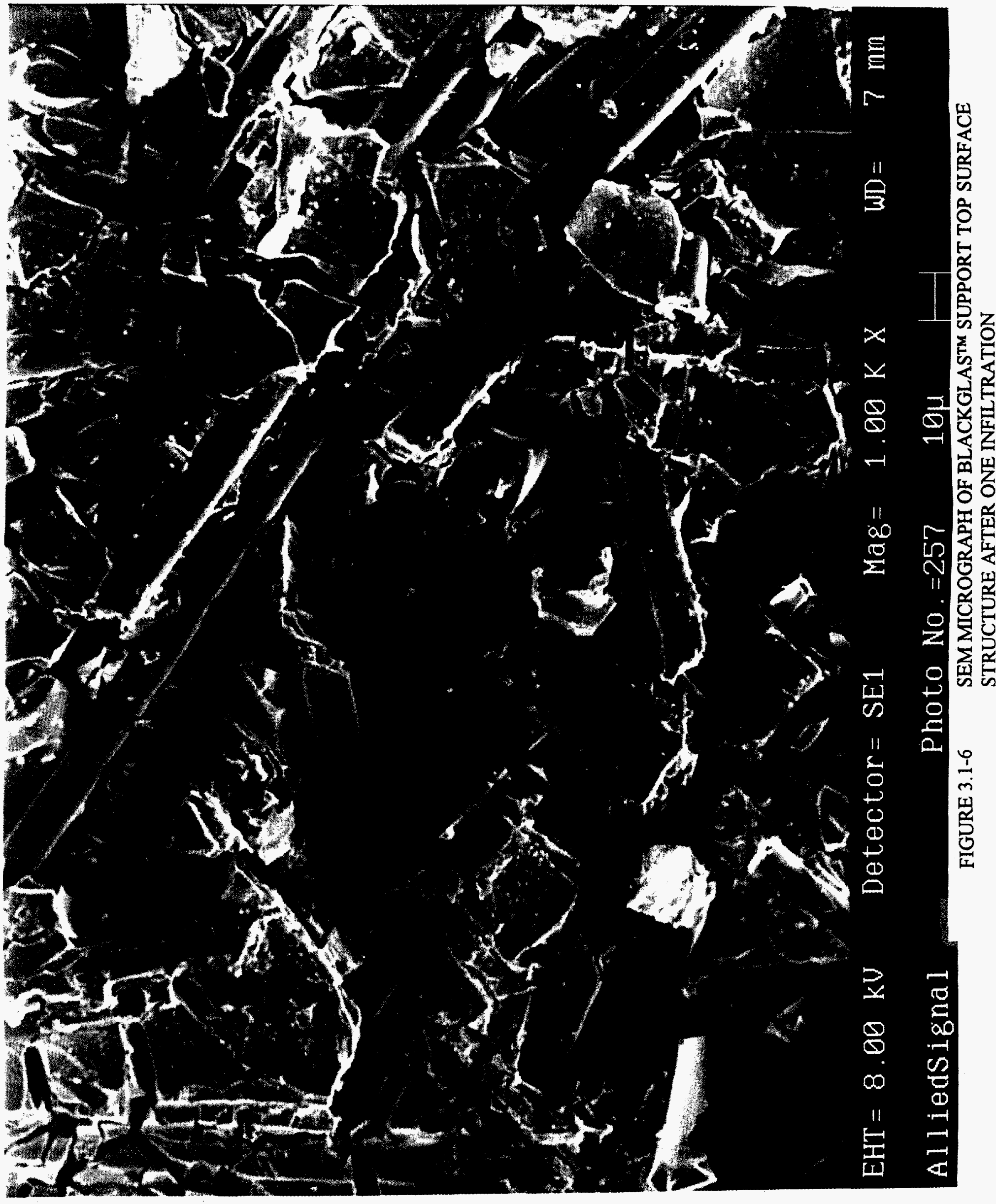


(9)

a

forer

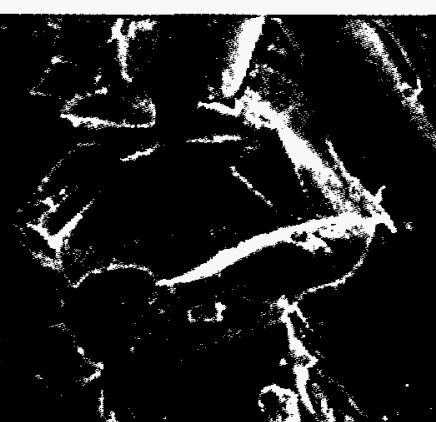

Kor.

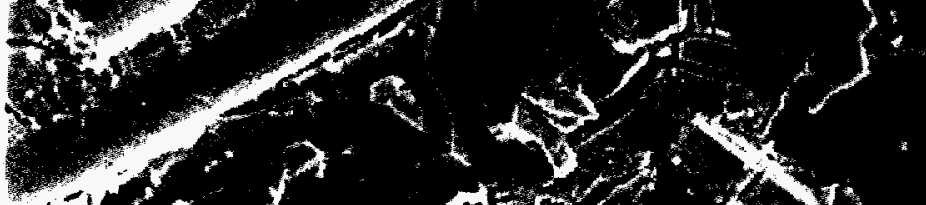

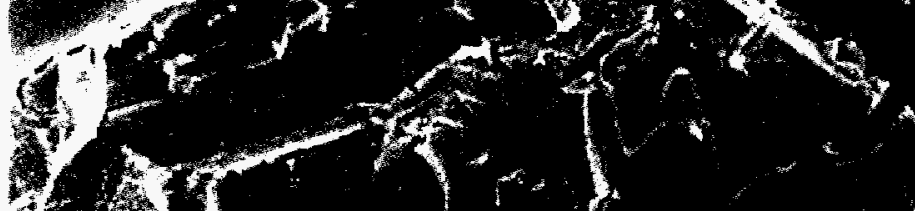

7)

$\% 1$

\%

1.<smiles>C1[13CH][13CH][13CH][13CH]1</smiles>

t

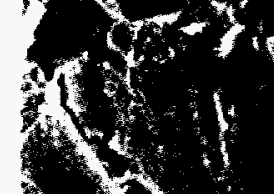

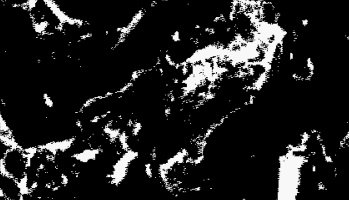

\%

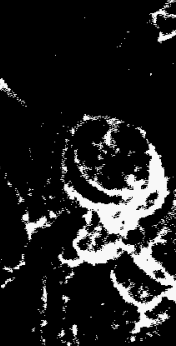

8

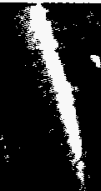

$\operatorname{lom}_{2}=$

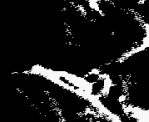

$\int_{1}$

i.

$+1$

$0^{*} \cdot 1+4$

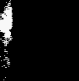

$\Omega_{3}^{11}$

(3)

$\operatorname{lol}_{x \rightarrow \infty}$

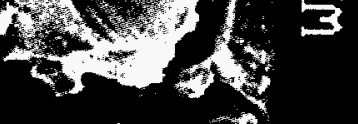

b.

$87 \rightarrow$

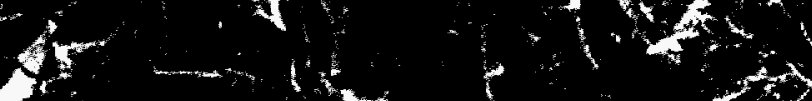

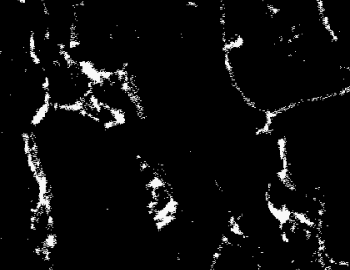

atg h

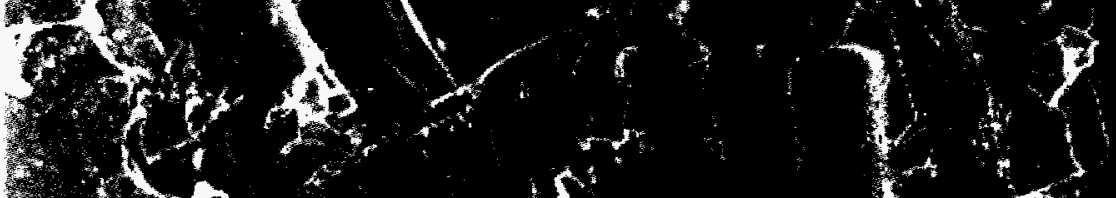

(1) $x$

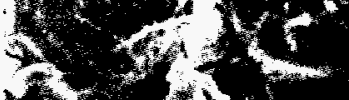

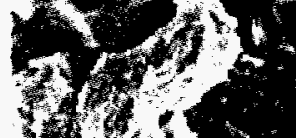

Wh

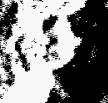

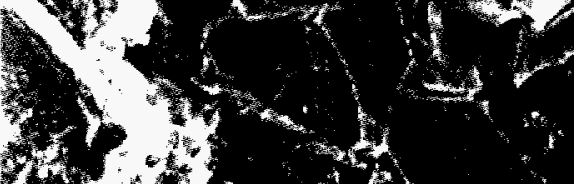

$\log ^{4}$

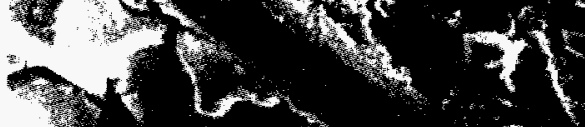

tow

1

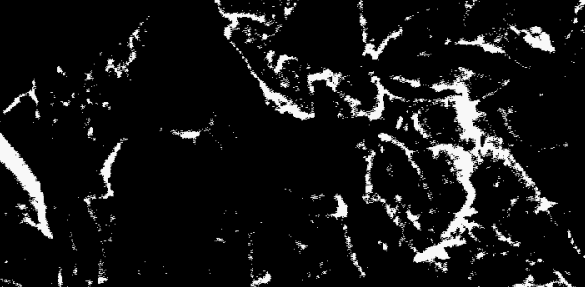

1. 1 


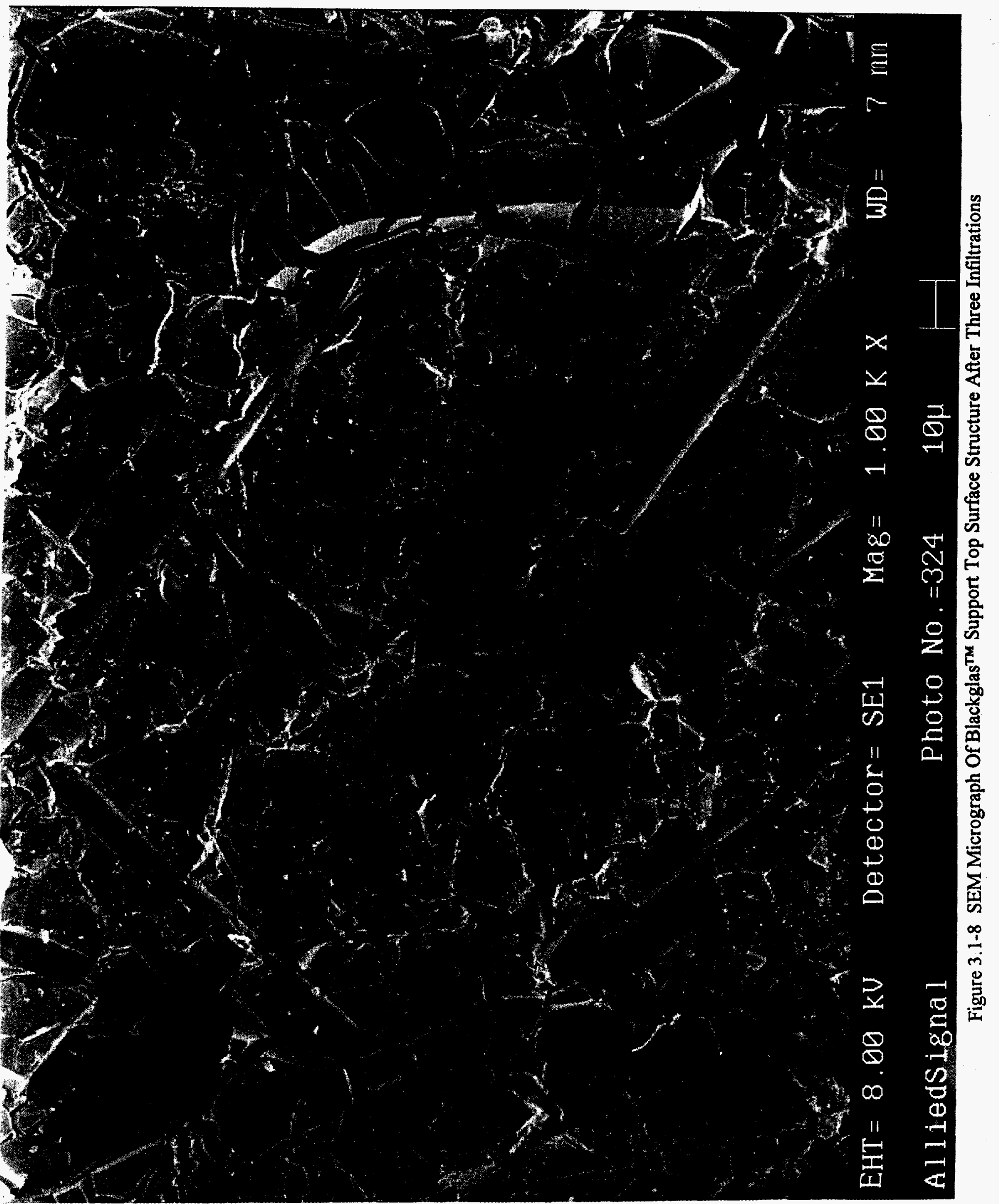


ate

YW

13.

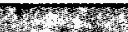

Wh

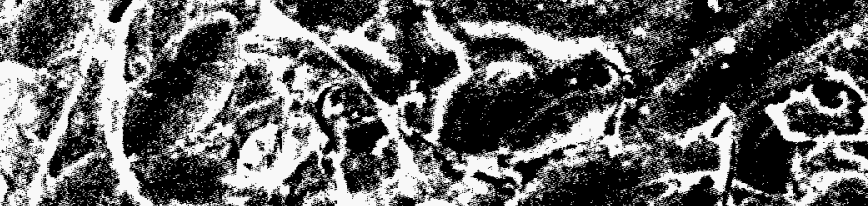

3
3

3
3

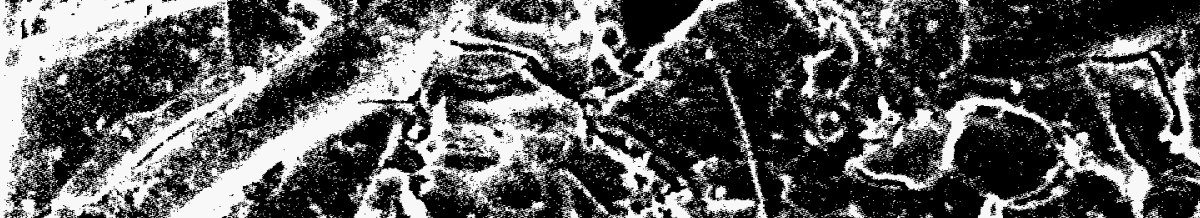

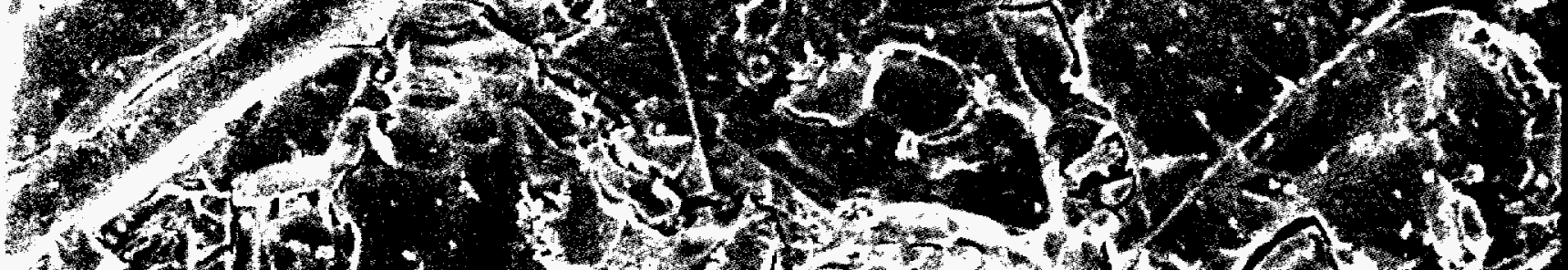

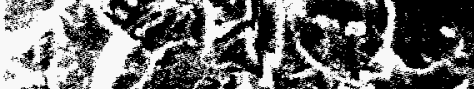

15

s.

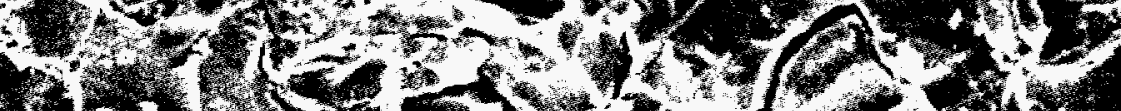

a.

$\left.x^{2}+x^{2}+1\right)$ (1)

212

3.

H.

,

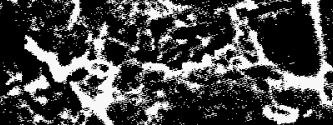
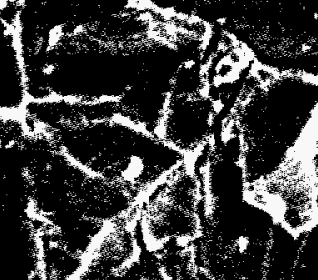
$8 \times 2$ is

6. II

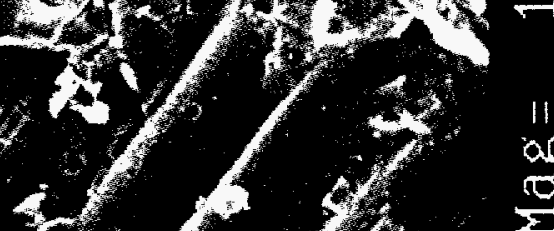

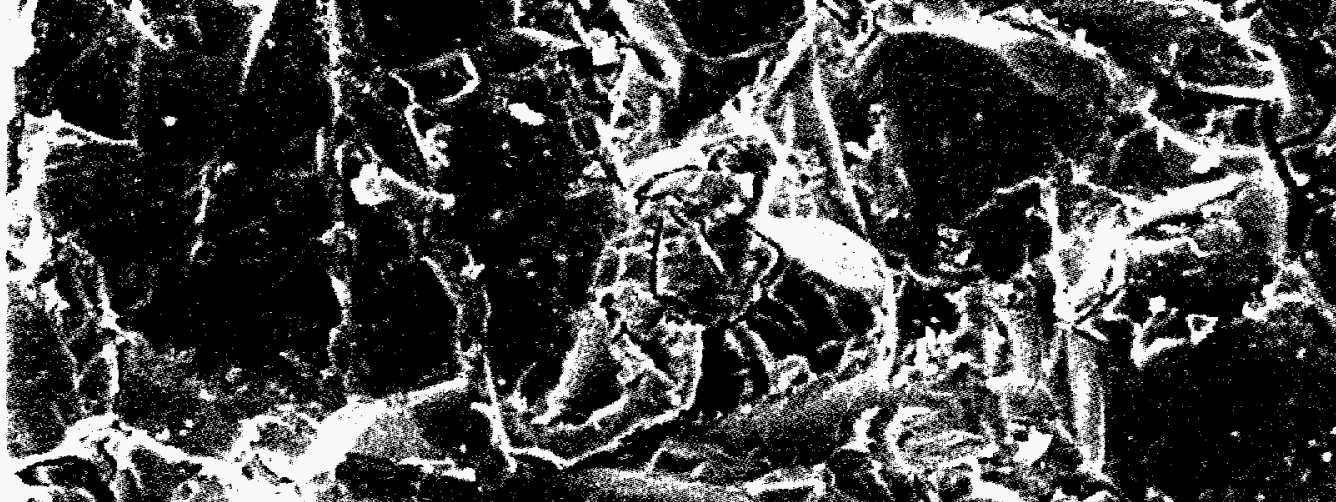

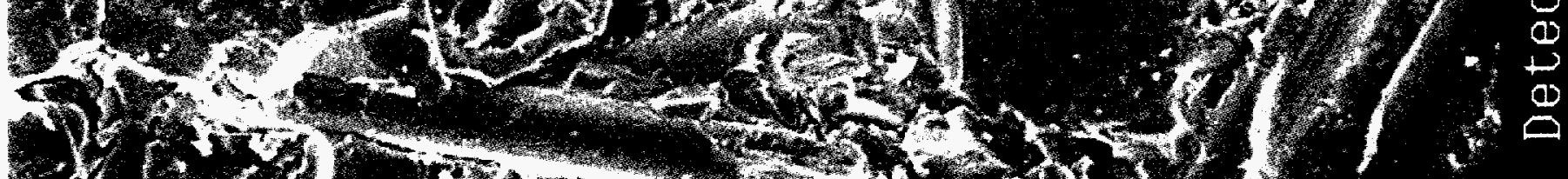

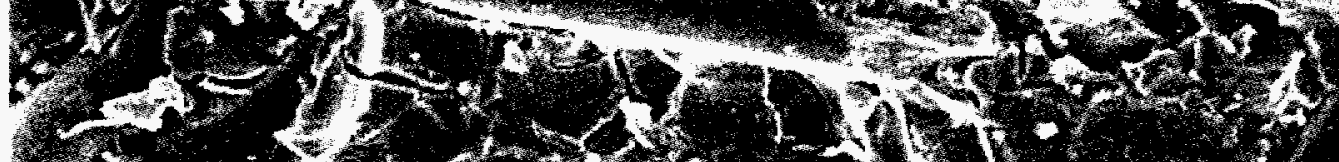

(2)

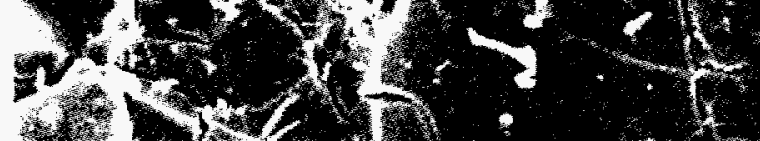

ato 1

- $>2,140$

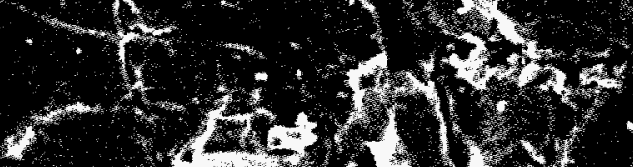

rota

8

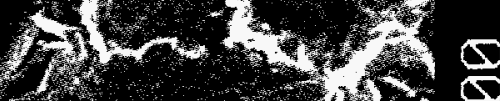

$\overbrace{-\infty}^{\infty}$ 


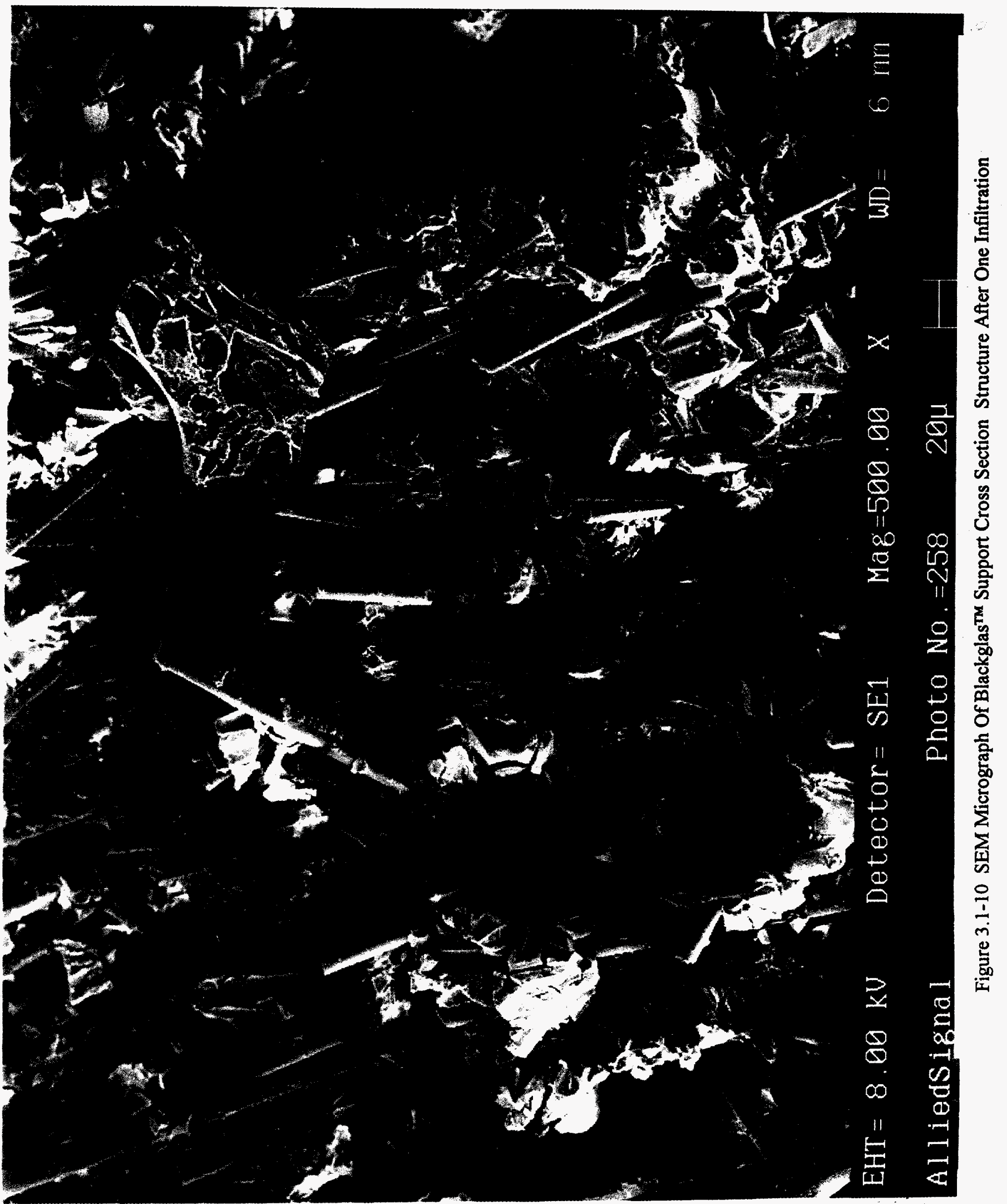


4.

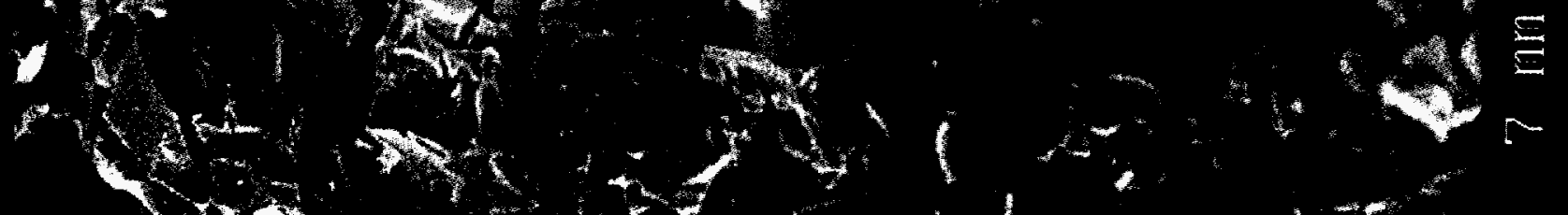

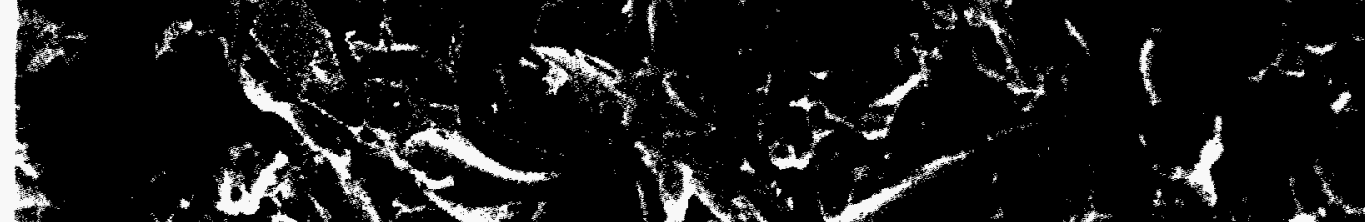

\%

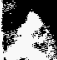

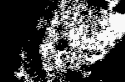

$+i$

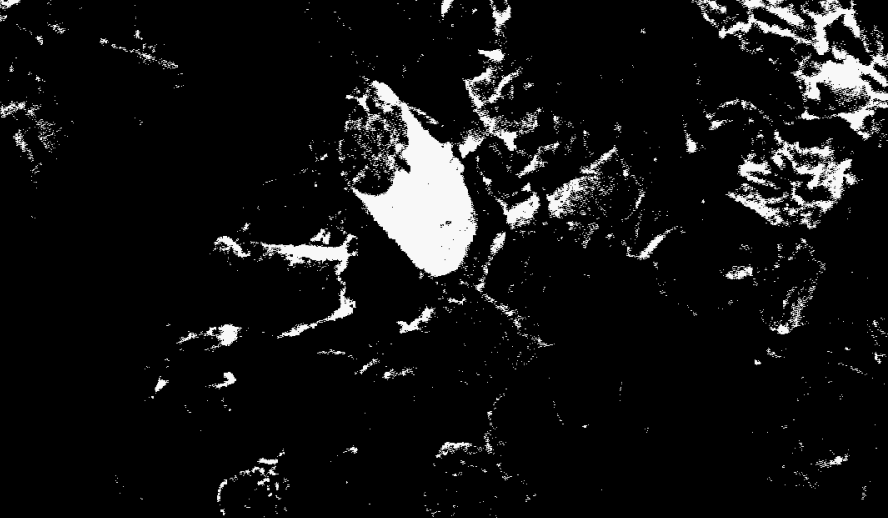

x $x$

Fin

1,

thy

19.

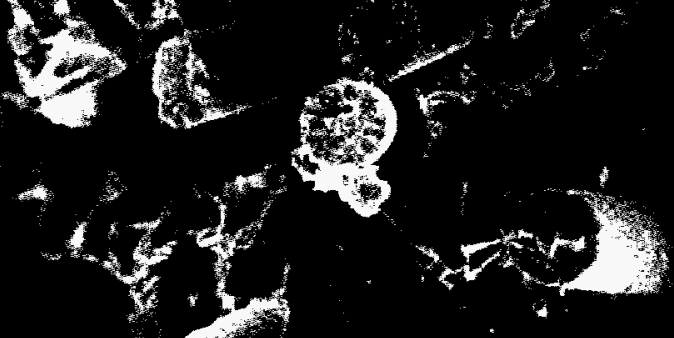

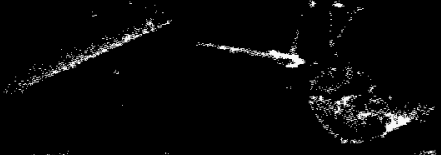

$+$
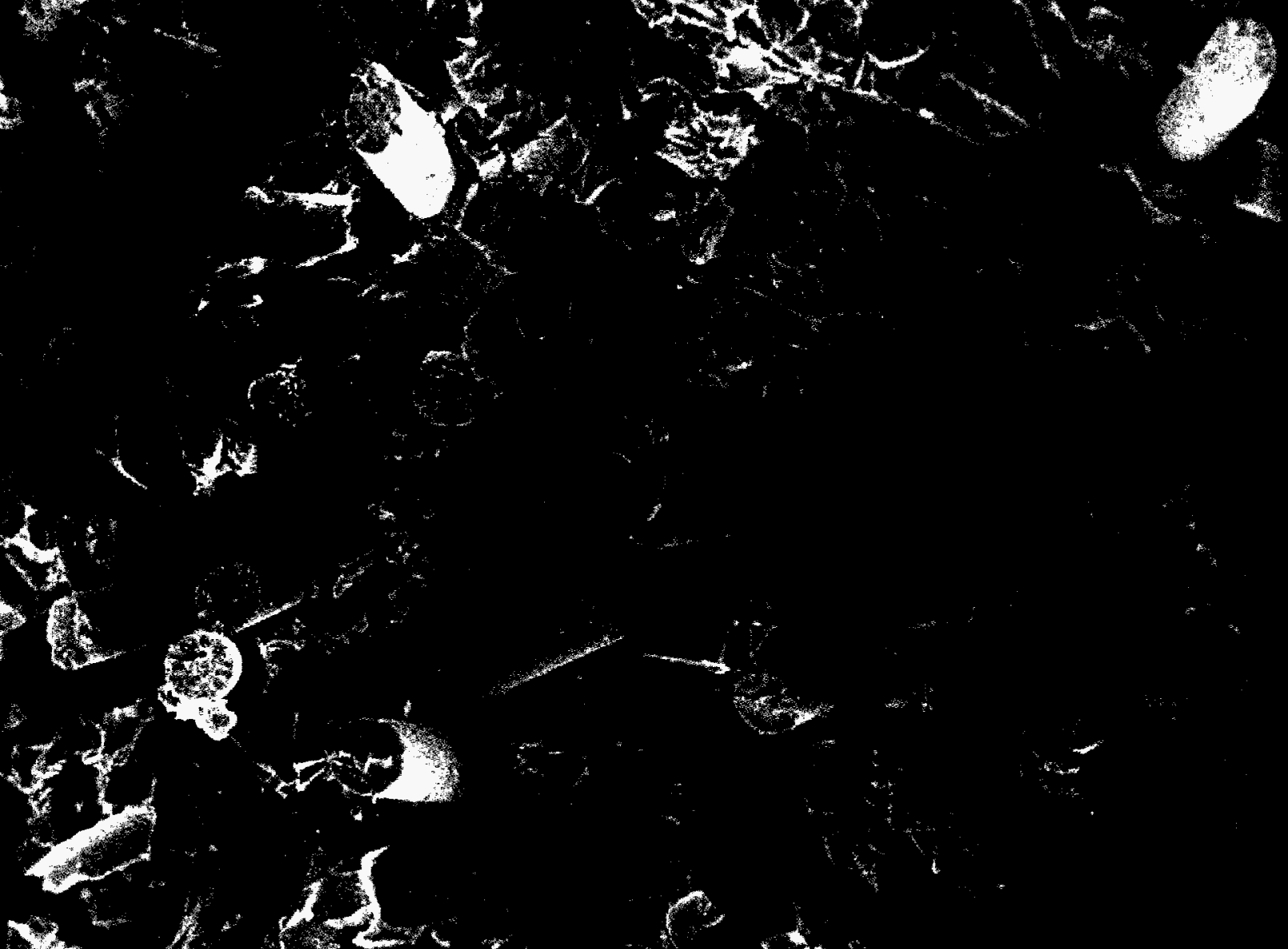

- 4 ,

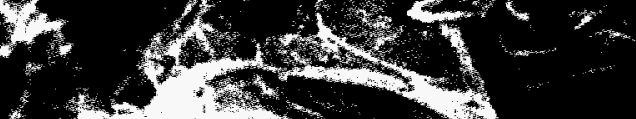

4. 30,12

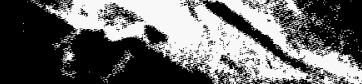

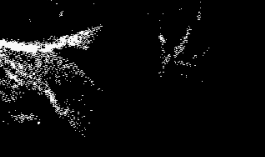

Y

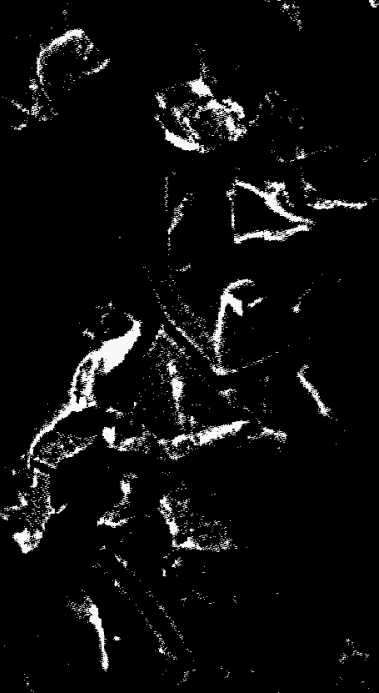

${ }_{4}+2$

$0-3$

$\Delta$

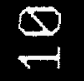

$-1$

11

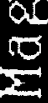

O

ii

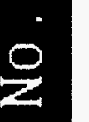

당

in

$\omega$

0

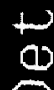

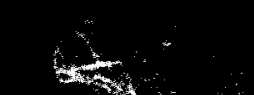

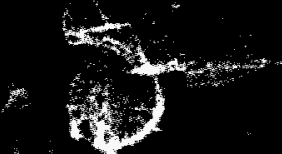

1.

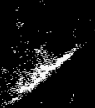

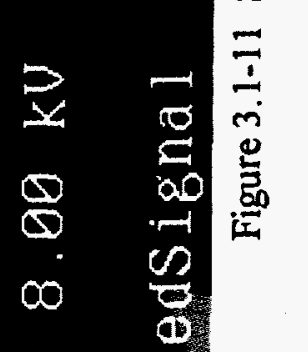

11

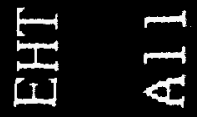




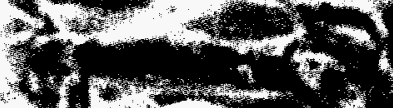

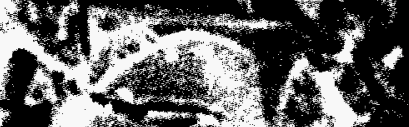

W

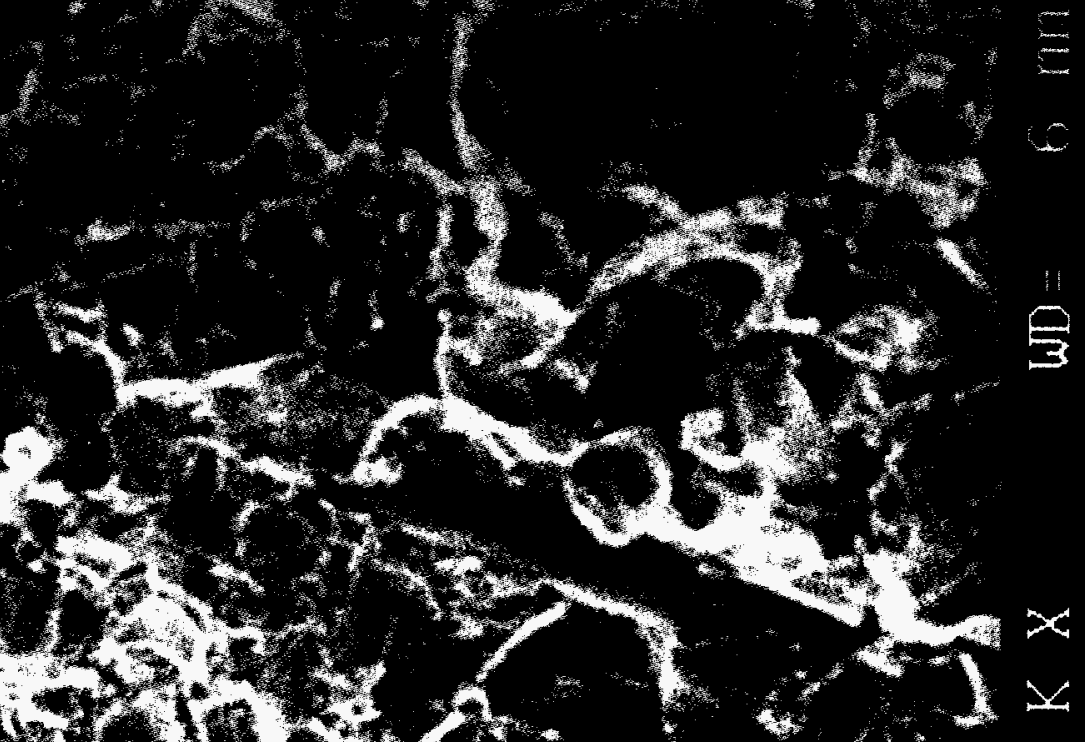

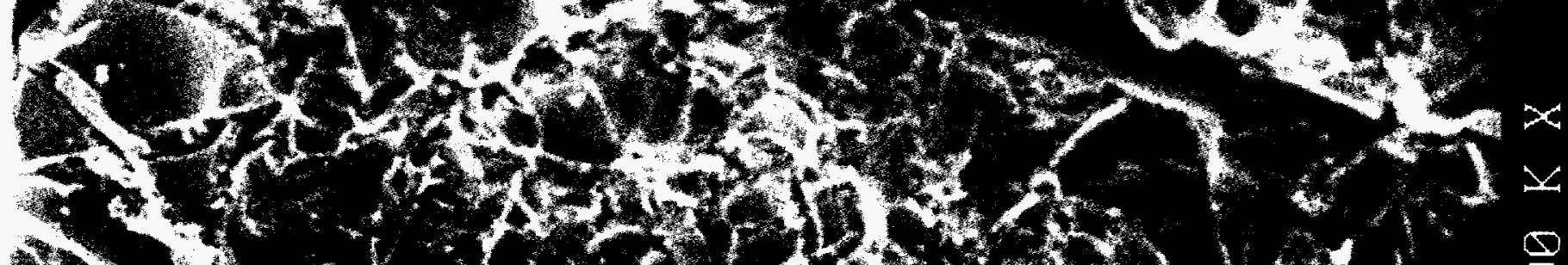

(5)

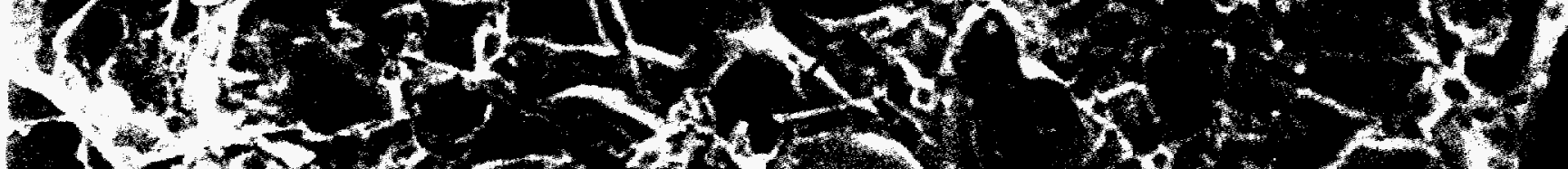

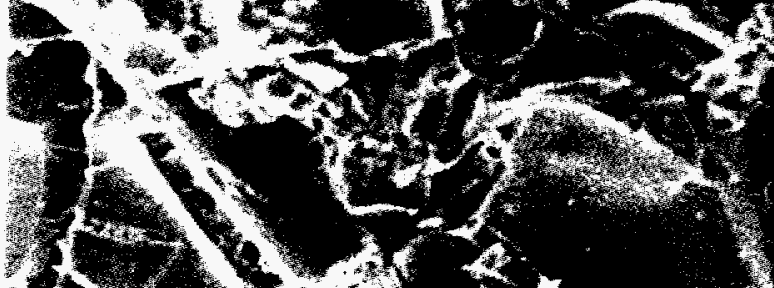

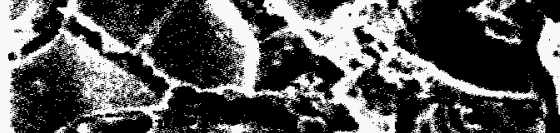

$\left.+x^{2}+y^{2}\right)^{2}$

$$
\text { (1) }
$$

$x^{2}+2$

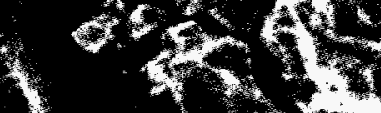

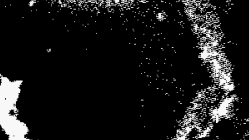

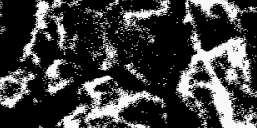

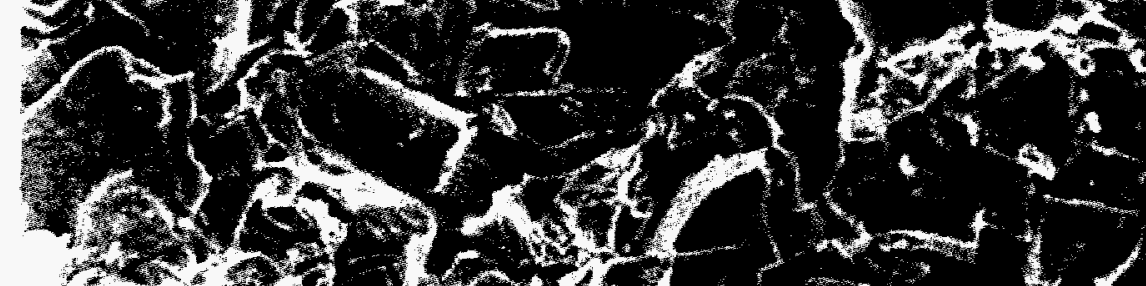

. 825

(3)

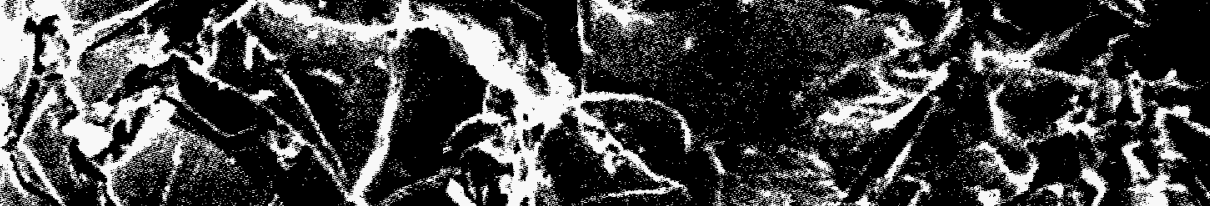

Wh (1)

into

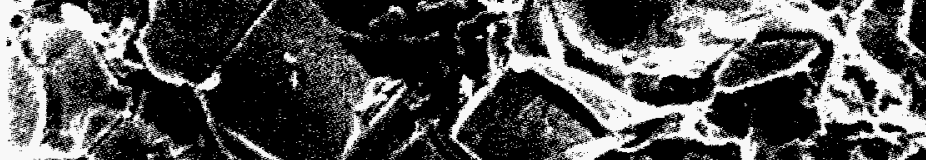

If

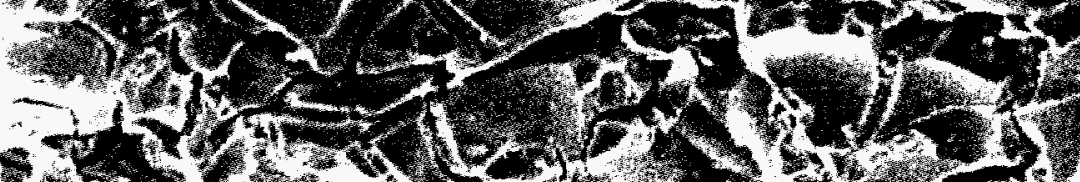

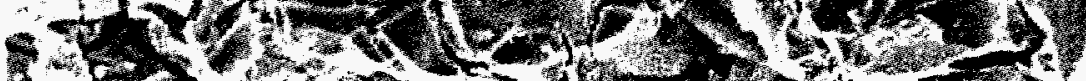

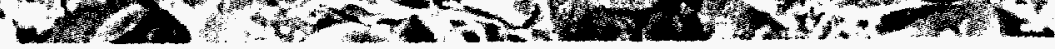

$+1 b^{2}, 4$

18

F.

$x^{2}+2$

,

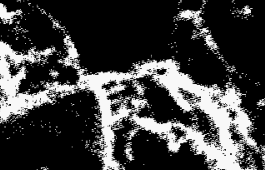

$\sqrt{11}$

$\underset{\infty}{\infty}$

兽

$\infty$

0

a

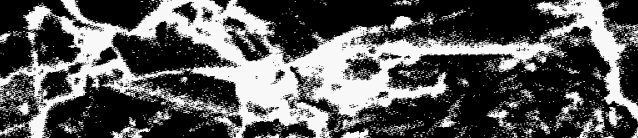

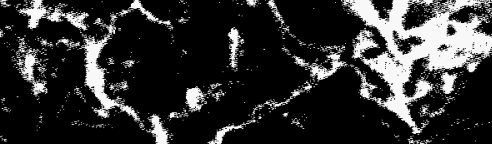

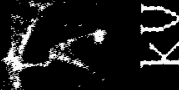

$\infty$ $\infty$ 


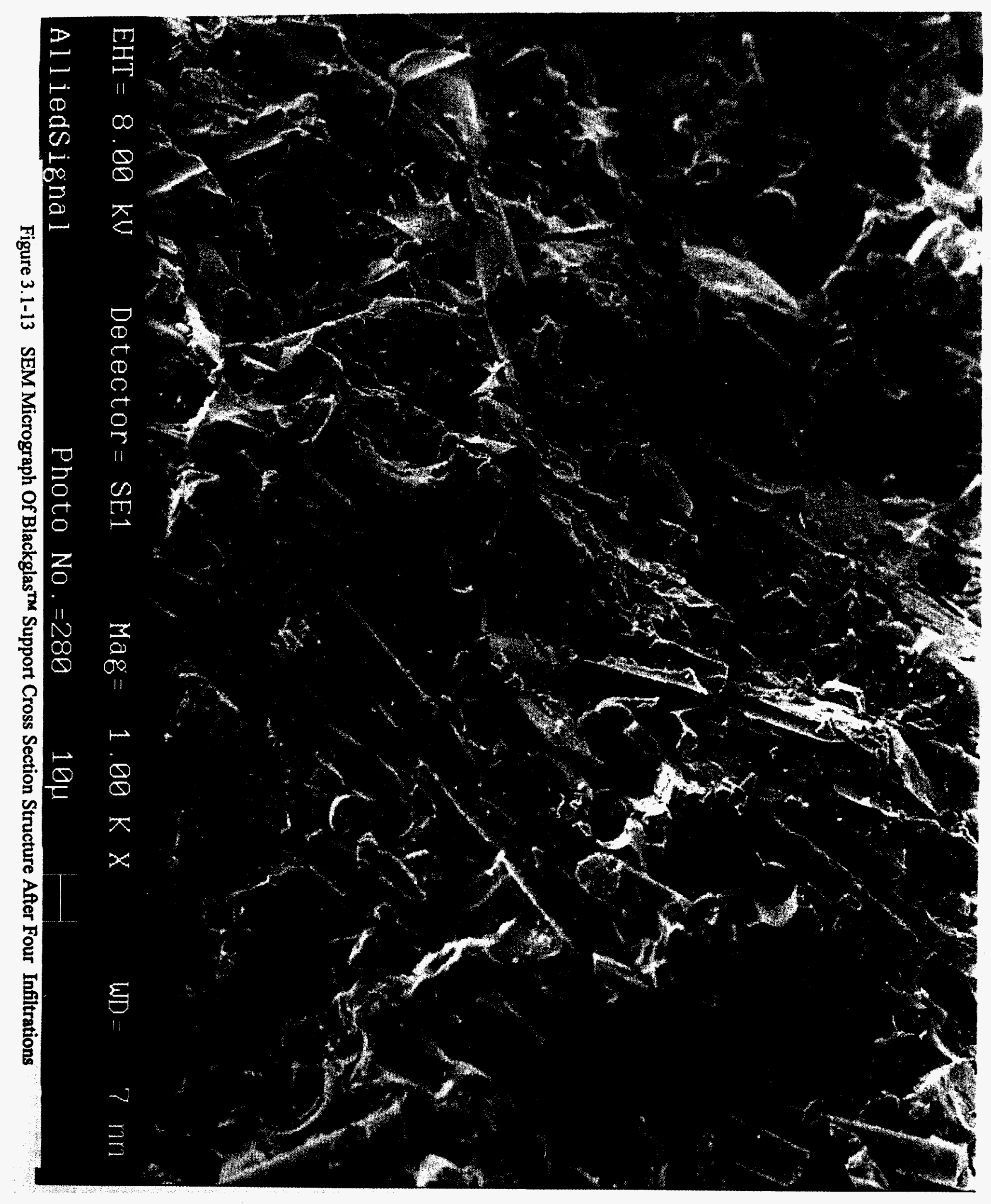




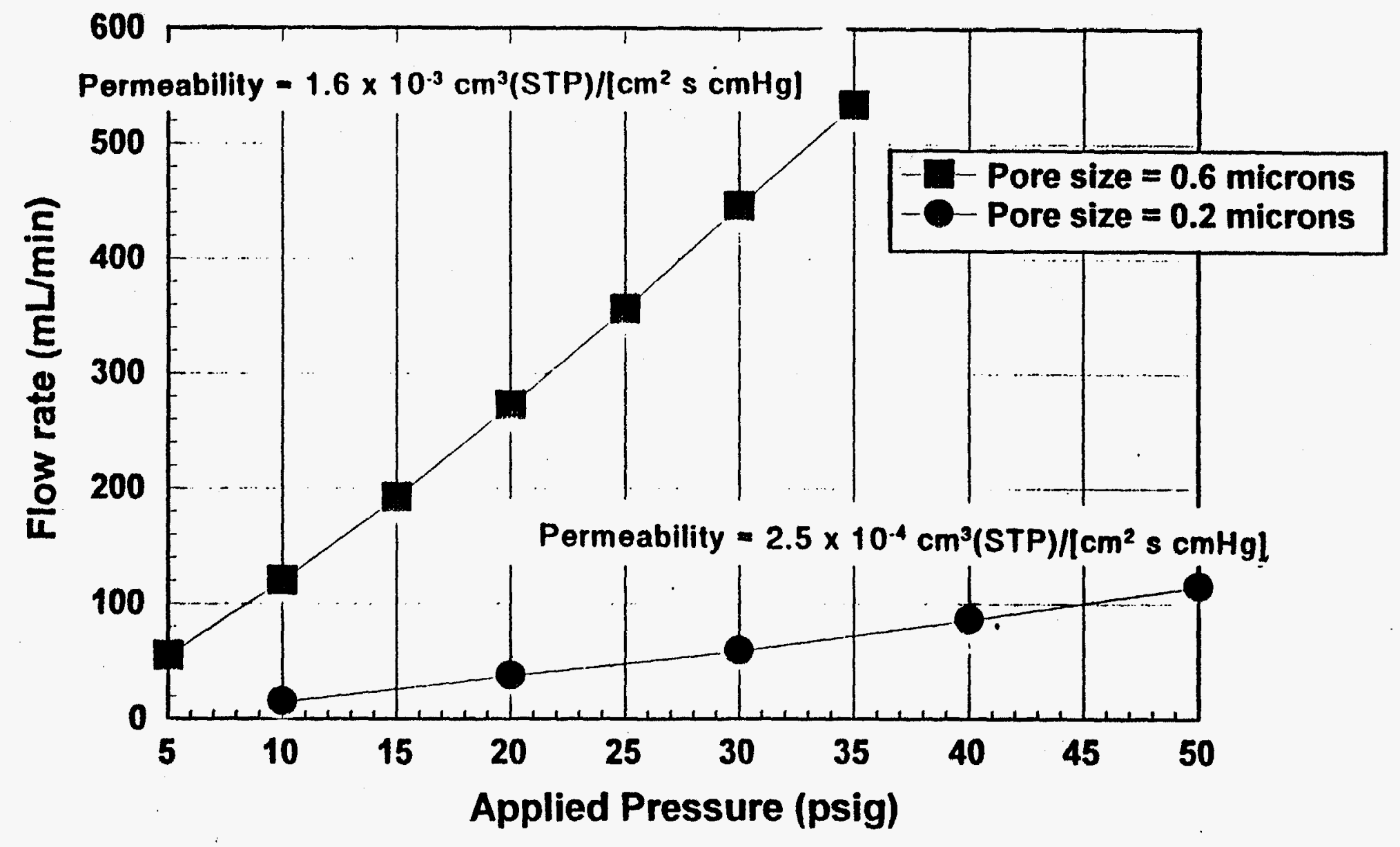

FIGURE 3.1-14 NITROGEN FLOW RATE THROUGH POROUS BLACKGLASTM SUPPORTS AT TWO DIFFERENT SUPPORT PORE SIZES 


\subsubsection{Other Blackglas ${ }^{\mathrm{TM}}$ Supports}

We have also made Blackglas ${ }^{\mathrm{TM}}$ supports using the same general procedures as described above but incorporating into the support structure either a single layer of woven carbon or Nextel 312 fabric, or seven to fourteen layers of woven carbon or Nextel 312 fabric. The general conclusions drawn from the above studies on the chopped fiber reinforced supports are found to be true for these types of supports as well. The only change occurs in the mechanical strength of the support. With even one layer of woven fabric, the support mechanical strength increases substantially. With the use of several layers of the fabric with any chopped fiber, the support becomes much stronger. However, the woven fabric reinforced support surface is not as smooth as the chopped fiber reinforced support surface. This sometimes creates a sealing problem. To circumvent this problem, the woven fabric reinforced support surfaces are sanded with fine sand paper and polished afterwards.

We have also made tubular Blackglas ${ }^{\mathrm{TM}}$ membrane supports using woven Nextel fabric by a vacuum forming method. The Blackglas ${ }^{T M}$ resin soaked fabric is tightly wound around a wood mandrel and placed inside a plastic nylon bag. The bag is sealed on all sides except the top where a vacuum is applied to collapse the bag around the tightly wound structure. The bag containing the support is placed inside an oven at 80 to $100^{\circ} \mathrm{C}$. The cured rod is pyrolyzed under the same conditions discussed above. The support thus made is reinfiltrated with Blackglas ${ }^{\mathrm{TM}}$ monomer to increase the density and mechanical strength. This kind of support can be made into membranes by the same method employed previously. Tubular membrane can be made into tube and shell type modules by means of suitable tube sheet material such as Blackglas ${ }^{\mathbf{T M}}$ and other ceramic materials. Tubular membranes should be easier to seal than its flat sheet counterpart.

\subsection{Thin Film Composite Membrane}

Thin film composite membranes are made using the Blackglas ${ }^{\mathrm{TM}}$ supports and CMS precursor polymers such as polyacrylnitrile (PAN) or polyimide. We have also tested making a $\mathrm{SiO}_{2}$ TFC membrane using a CVD method as described in section 2.2.3. This section describes in detail the results and discussions from testing these membranes. 


\subsubsection{SEM Micrographs of CMS Membrane}

CMS membranes are made by a coating method. We found that the coating layer thickness determines the carbonized CMS membrane layer structure. For example, Figures 3.2-1 and 3.2-2 are SEM micrographs of a sample top surface PAN coated Blackglas $^{\text {MM }}$. These pictures show that the coating layer after pyrolysis was broken up into pieces with large regions in between without any caating. This is most likely due to the volume change associated with pyrolysis of PAN.

The other CMS precursor used was polyimide or its precursor polyamic acid dissolved in N-methyl pyrrolidone (NMP). The surface structure of this type of coating on Blackglas $^{\text {TM }}$ support is presented in Figures 3.2-3 to 3.2-7. The first two micrographs show that top surface structure obtained when a thick (few mils before pyrolysis) coating of polyimide was carbonized to form the CMS. The surface structure is a maze of cracks much like a dried clay field in a river bed. Under higher magnification, the cracked coating layer is also seen to be lifted from the surface as seen in Figure 3.2-4. Figures 3.2-5 and 3.2-6 are the top surface and cross sectional structures of the same composite membrane. The thickness of the carbon layer is estimated to be in the range of 10 to $16 \mu \mathrm{m}$. Since the thickness of the coating layer only decreases by 5 to $10 \%$ upon carbonization as shown in Figure 3.3.2-2, the initial coating layer thickness is in the same range. The cracks on the sample are also caused by the volume change and weight change associated with pyrolysis of the polyimide. The stresses created by the volume change cannot be dissipated from the thick coating structure restricted by the porous Blackglas ${ }^{\mathrm{TM}}$ surface due to strong adhesion thus causing the crack formation. The width of the cracks ranges from 2 to $10 \mu \mathrm{m}$. Figure 3.2-7 is obtained from a slightly thinner coating. The surface is still cracked, but the cracks appear to be smaller and the plates larger.

Based on this observation, we started applying a very thin coating to the Blackglas ${ }^{\text {TM }}$ support surface each time and testing the product CMS membrane after each coating/carbonization cycle up to ten cycles. The weight changes of two samples as a function of coating/carbonization cycles are presented in Figure 3.2-8. This figure shows that the weight of the sample increases slowly with each coating/carbonization cycle. The SEM micrographs of these samples revealed that the top surface has very few cracks as shown in Figure 3.2-9. Compared with Figure 3.2-3 to 3.2-7, the new 
surface appears to be better. More interestingly, Figure 3.2-9 also showed white, random lines on the top surface, apparently formed when the cracks from a previous cycle are filled with more polyimide solution and were repaired. The repaired cracks and also cracks on the top right side shown in Figure 3.2-9 are magnified and the resulting SEM micrographs presented in Figure 3.2-10 and 3.2-11. Figure 3.2-10 shows that the crack size is now in the range of 0.5 to $4 \mu \mathrm{m}$. Figure 3.2-11 shows that the repaired cracks are filled without any gaps left. The cross sectional view (see Figure 3.2-12) of the same membrane revealed that the total thickness of the carbon layer after ten coating/carbonization cycles is only $2.5 \mu \mathrm{m}$. Previous cracked coating layer was 10 to $16 \mu \mathrm{m}$ after one coating/carbonization cycle.

\subsubsection{Gas Permeation Through the CMS Membrane}

We have measured the flow rate and selectivity of nitrogen, hydrogen, and methane through the CMS membranes at both room temperature and at elevated temperatures up to $700^{\circ} \mathrm{C}$ and at pressures up to 60 psig. The results of these measurements are summarized in Figures 3.2-13 to 3.2-16. These figures show that the flow rate through the membrane (disk shape with an effective diameter of 2.5 inches) increases with increasing temperature as expected. The ideal $\mathrm{H}_{2} / \mathrm{N}_{2}$ and $\mathrm{H}_{2} / \mathrm{CH}_{4}$ selectivities are not a strong function of temperature, and have values close to the Knudsen diffusion limit (Knudson diffusion selectivities for $\mathrm{H}_{2} / \mathrm{N}_{2}$ and $\mathrm{H}_{2} / \mathrm{CH}_{4}$ are 2.6 and 2.8 respectively). These figures also show that the fluxes of all gases are high. The ideal selectivities obtained from the present study are about 2.8 at room temperatures and 2.4 to 5.0 at elevated temperatures for $\mathrm{H}_{2} / \mathrm{N}_{2}$, and 3.6 for $\mathrm{H}_{2} / \mathrm{CH}_{4}$ at $717^{\circ} \mathrm{C}$.

The ideal selectivities obtained from the current study are comparable to those obtained by Bao and Sircar ${ }^{17}$ on poly (vinylidene chloride) coated porous graphite support, and Koresh, and Sofer ${ }^{18,}$, ${ }^{19}$ un-supported CMS membranes prepared from cellulose material. The ideal selectivities reported by Bao and Sircar for $\mathrm{H}_{2} / \mathrm{N}_{2}$ and $\mathrm{H}_{2} / \mathrm{CH}_{4}$ are 1.7 and 5.1 respectively. The ideal selectivities reported are 20 and 8 for $\mathrm{He} / \mathrm{O}_{2}$ and $\mathrm{O}_{2} / \mathrm{N}_{2}$ before heat treatment and 2.8 and 0.92 after heat treatment, respectively. Hatori et al. ${ }^{20}$ have also reported the following ideal selectivities for an unsupported carbon membrane made from Kapton polyimide: $\mathrm{He} / \mathrm{N}_{2}=19.6, \mathrm{He} / \mathrm{O}_{2}=$ 4.3, and $\mathrm{He} / \mathrm{CO}_{2}=0.4$. These selectivities show that the mechanisms for gas transport through the various carbon membranes are either Knudsen diffusion or surface diffusion. 
The permeation fluxes of the CMS membrane for nitrogen, hydrogen and methane are presented in Table 3.2-1. This table shows that the permeation flux for hydrogen ranges from $8.1 \times 10^{-5}$ to $3.0 \times 10^{-4}\left[\mathrm{~cm}^{3}(\mathrm{STP}) /\left(\mathrm{cm}^{2} . \mathrm{s.cmHg}\right)\right]$ at room temperature and at $717^{\circ} \mathrm{C}$. Nitrogen permeation flux is also a function of temperature. The permeation fluxes generally increase with increasing temperature.

Table 3.2-1 Permeation Fluxes for Nitrogen, Hydrogen, and Methane

\begin{tabular}{|c|c|c|c|c|}
\hline Gas & P Room & P $\left(520^{\circ} \mathrm{C}\right.$ & $\mathrm{P}\left(630^{\circ} \mathrm{C}\right)$ & $\mathrm{P}(7 \mathrm{7}) \mathrm{C})$ \\
\hline $\mathrm{N}_{2}$ & $3.0 \times 10^{-5}$ & $1.2 \times 10^{-3}$ & $9.1 \times 10^{-4}$ & $8.3 \times 10^{-4}$ \\
\hline $\mathrm{H}_{2}$ & $8.1 \times 10^{-5}$ & $3.1 \times 10^{-3}$ & $2.0 \times 10^{-3}$ & $3.0 \times 10^{-3}$ \\
\hline $\mathrm{CH}_{4}$ & - & - & $9.0 \times 10^{-4}$ & $1.0 \times 10^{-3}$ \\
\hline
\end{tabular}

These results may suggest that the pore size of the current CMS membrane is still too large or simply that there are still defects in the membrane. SEM has confirmed the presence of micro defects on the surface of the CMS membranes we made. Moreover, the permeabilities of our CMS membrane are about two orders magnitude higher than those reported. On the other hand, the observed selectivity of the current CMS membrane is not consistent with the SEM measured surface crack size. To have the observed selectivity, the crack size has to be much smaller than the observed 0.5 to 4 $\mu \mathrm{m}$. This suggests that the cracks are not all the way through the membrane because the membrane was made in layers. The cracks on one layer may not be connected with the ones in an adjacent layer. Furthermore, some cracks were also repaired by the subsequent coating layer.

The other interesting observation is the temperature and pressure dependence of the gas flux through the membrane. Figures 3.2-13 to 3.2-16 show that the flux is a linear function of applied pressure, which suggests that the permeation coefficient should be pressure independent. It is well known that permeability from Knudsen diffusion is independent of pressure. Therefore, this result suggests Knudsen diffusion is the dominant gas permeation mechanism. However, the temperature dependence of the permeability did not show the usual decrease with increasing temperature (Knudsen diffusion permeability is inversely proportional to the square root of temperature). We can conclude from such conflicting results that the permeation mechanism through the membrane is more complex than simple Knudsen diffusion. The other mechanisms such as surface diffusion, molecular sieving and activated diffusion, and multilayer 
diffusion may also be operative, albeit to a different extent under the high temperature conditions.

\subsection{3 $\mathrm{SiO}_{2}$ Film}

We have tried to coat the Blackglas ${ }^{\mathrm{TM}}$ support with a thin layer of $\mathrm{SiO}_{2}$ by a CVD technique using TEOS and ozone at atmosphere pressure and low temperature ${ }^{21,22,23}$. Visual observation of the coated support indicates that the coating is not uniform throughout the top surface. This is attributed to the distribution of reacting gas mixture inside the reactor. Moreover, the coating layer also appears to be porous. SEM micrographs presented in Figures 3.2-17 and 3.2-18 of the coated surface show that the coating is too thin to even bridge the slit pores on the support surface. Thus, it was not possible to test such coatings for gas permeation. 


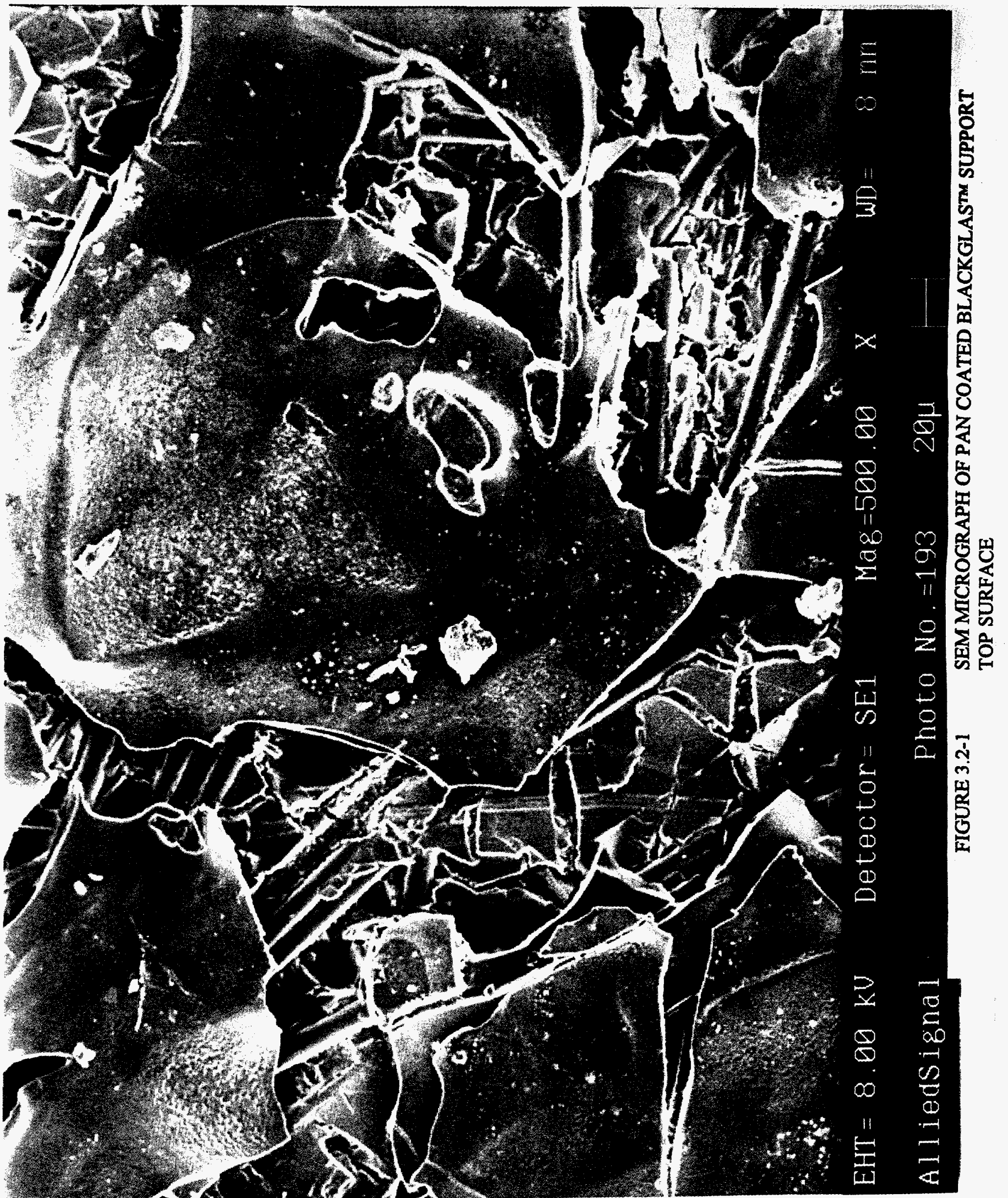




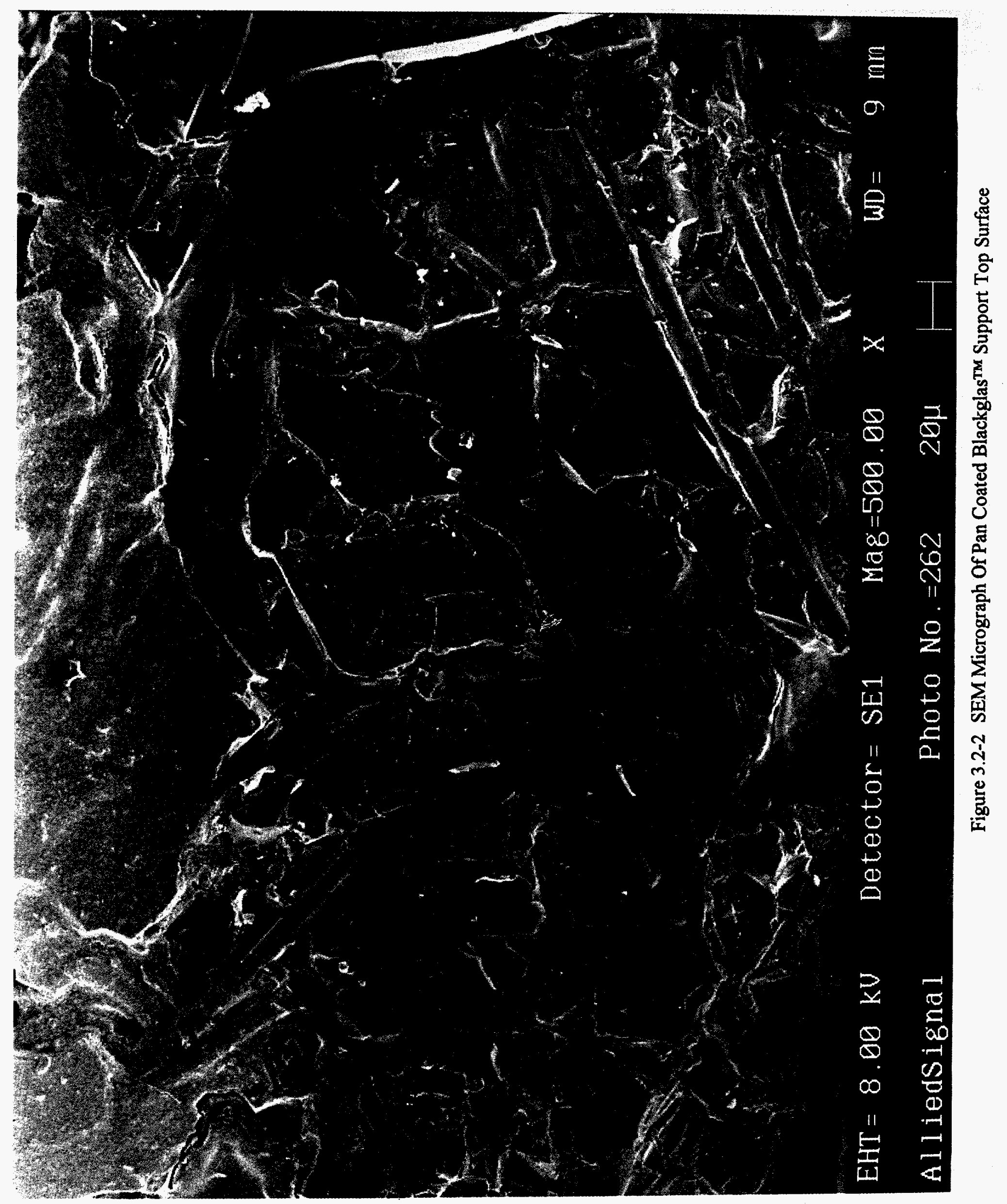




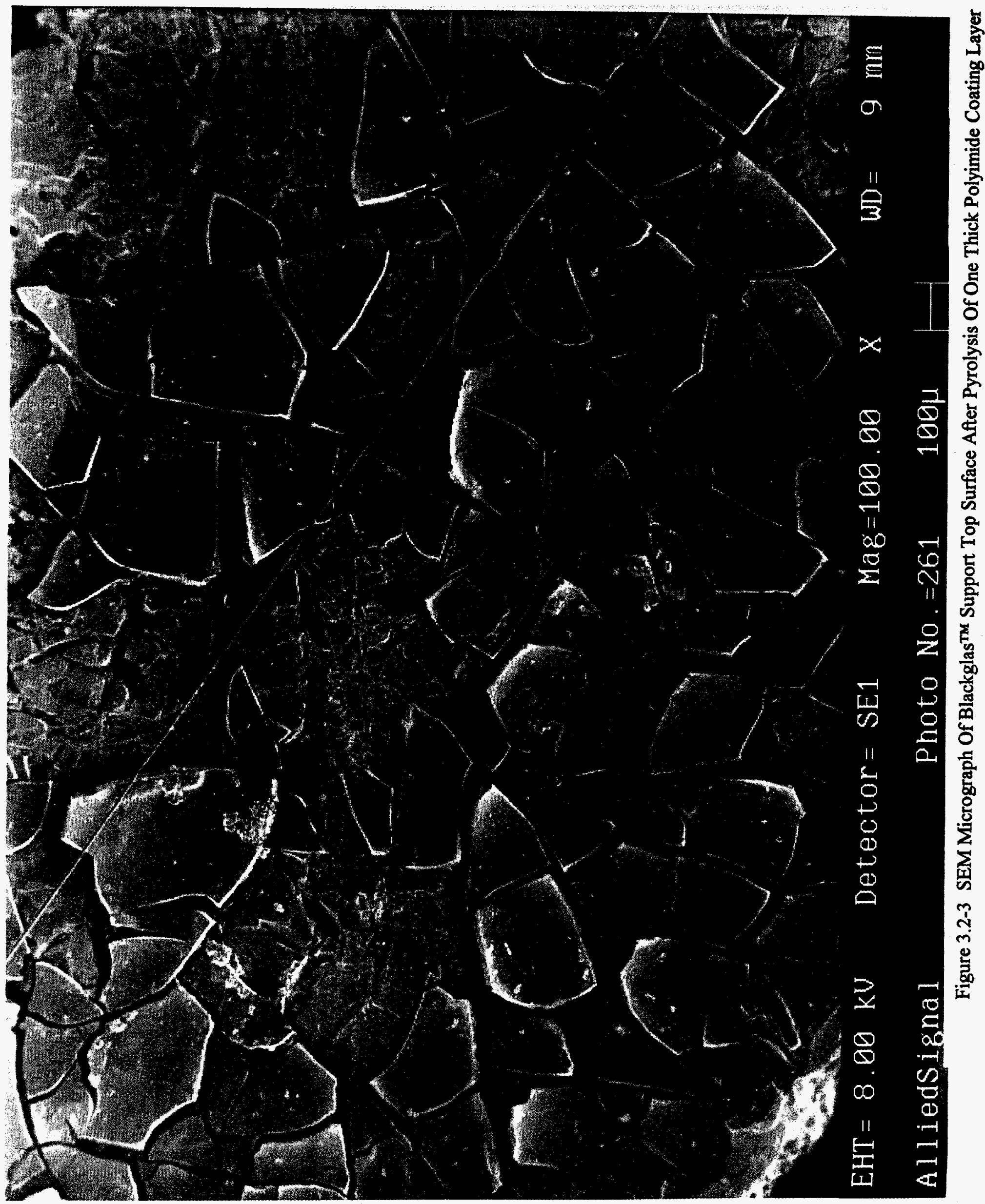




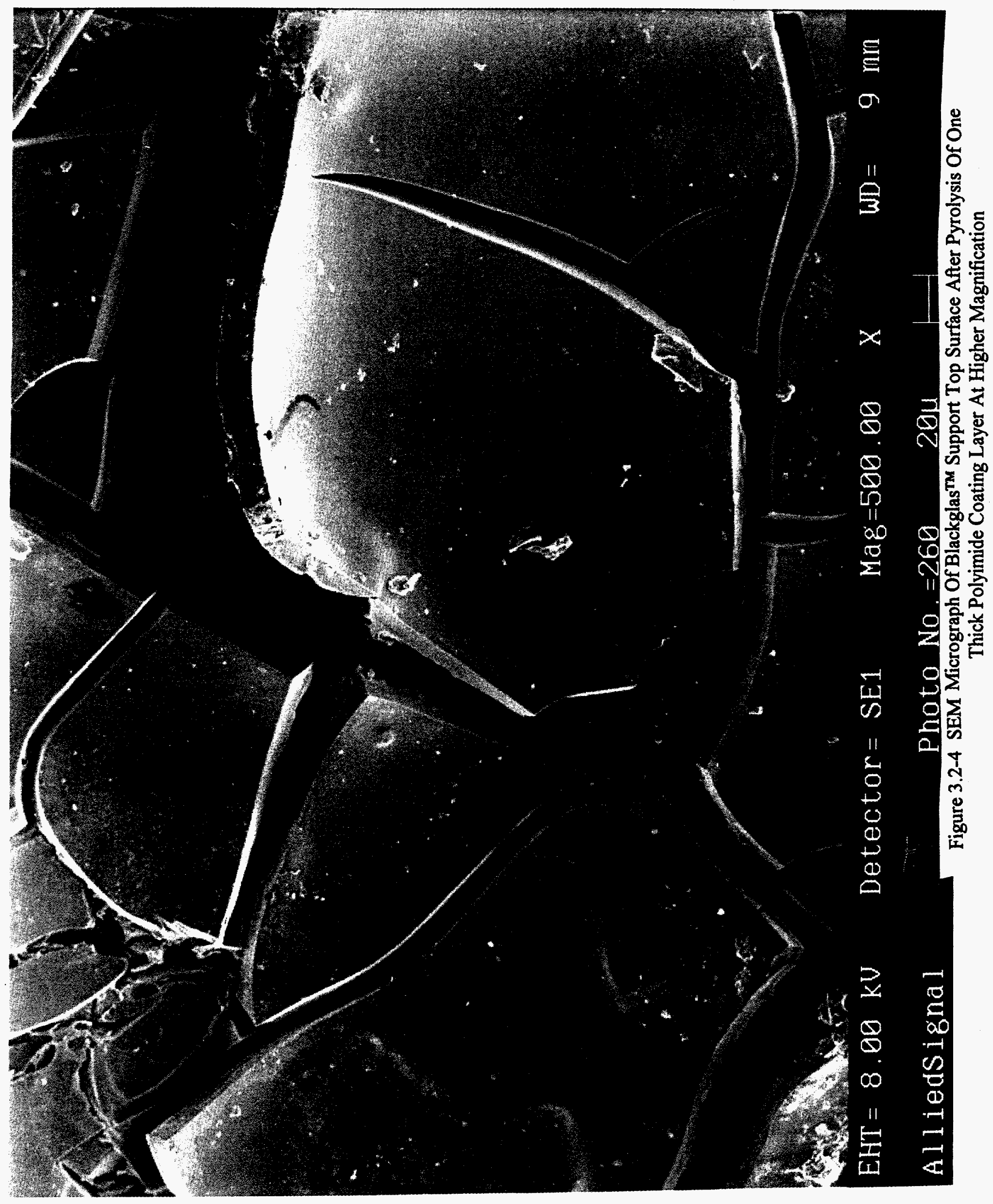




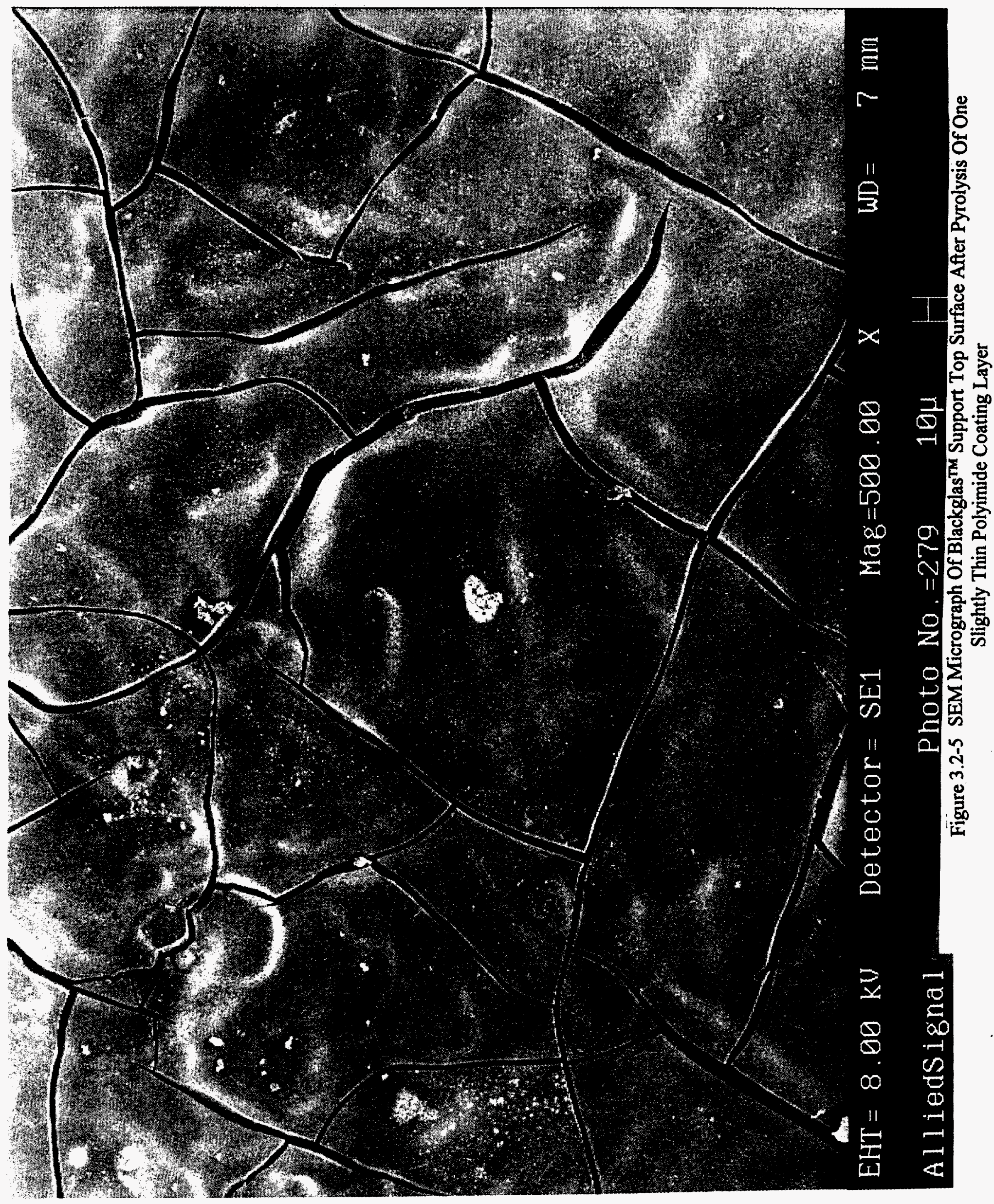




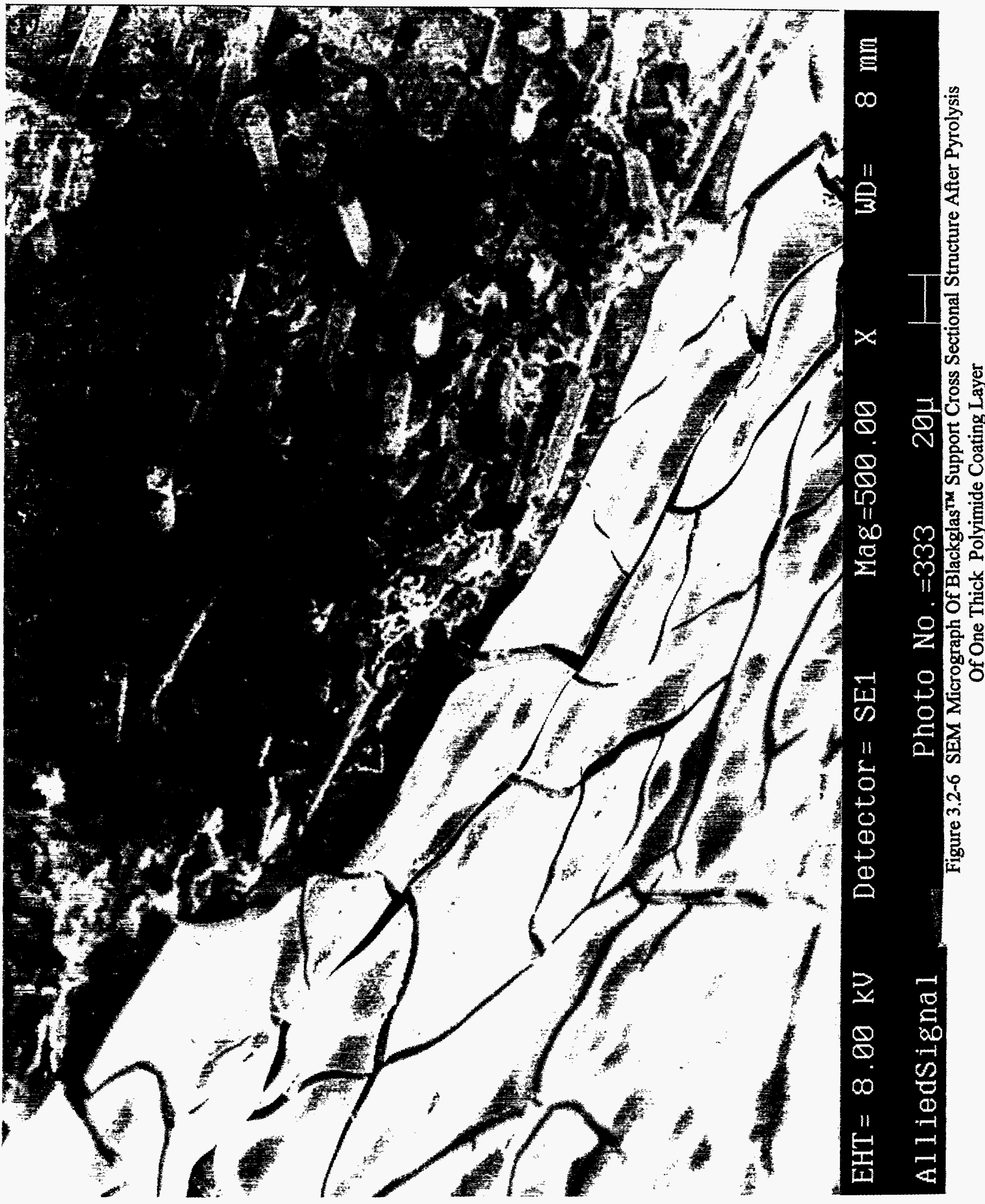




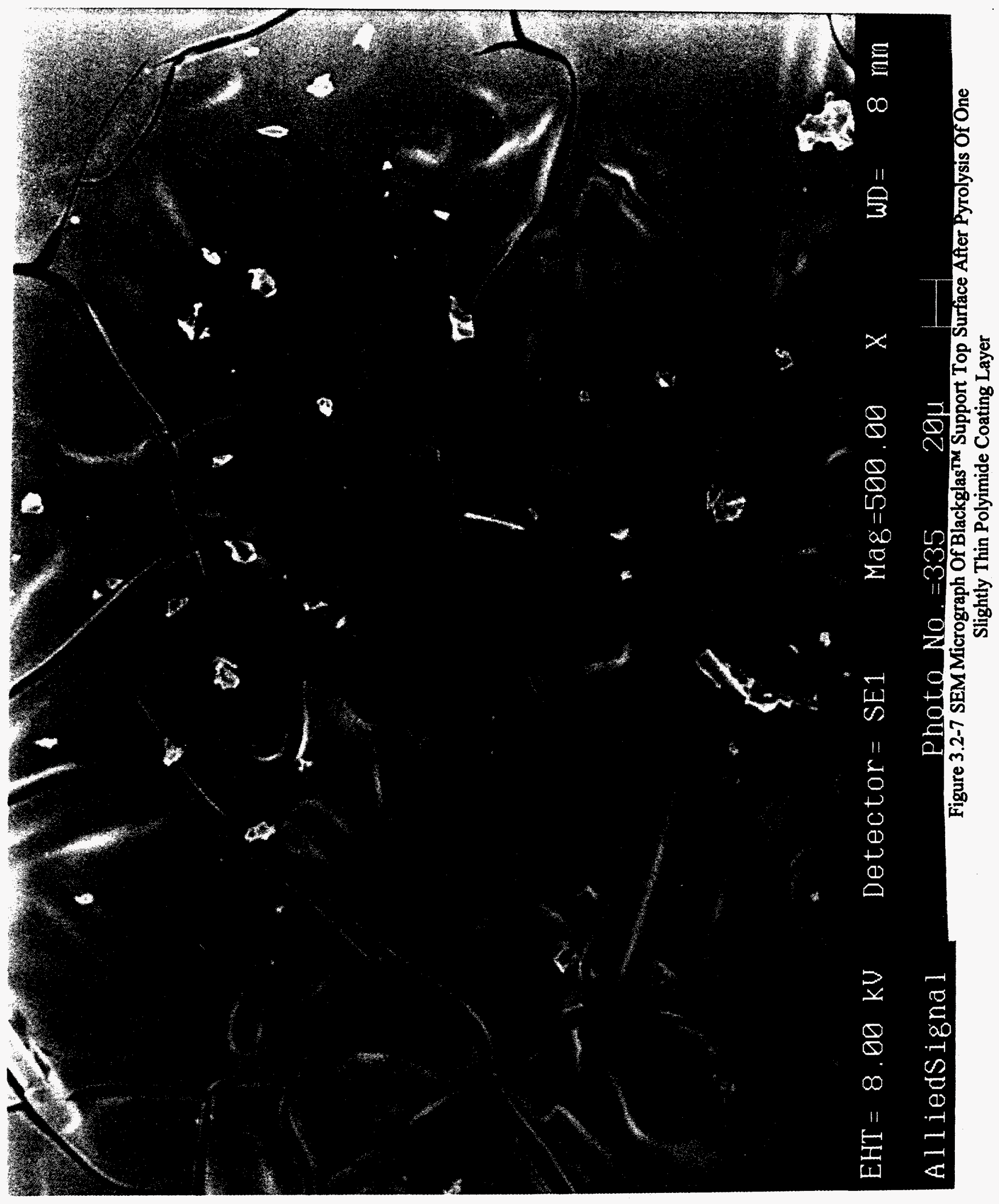




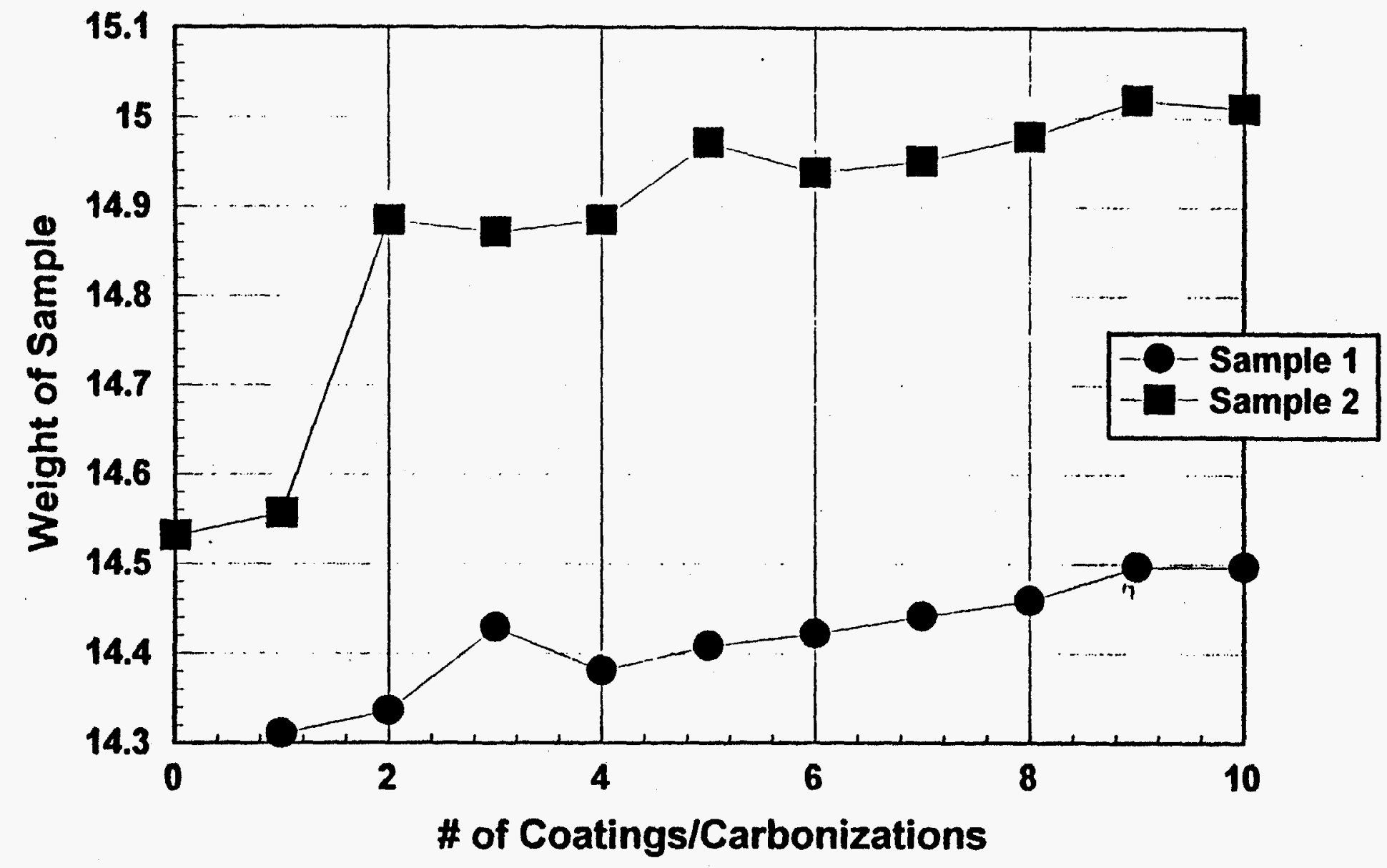

FIGURE 3.2-8 Total Weight of Two Composite BLACKGLAS ${ }^{\mathrm{TM}}$ Supported CMS Membrane as a Function of Number of Coatings/Carbonization Cycles 


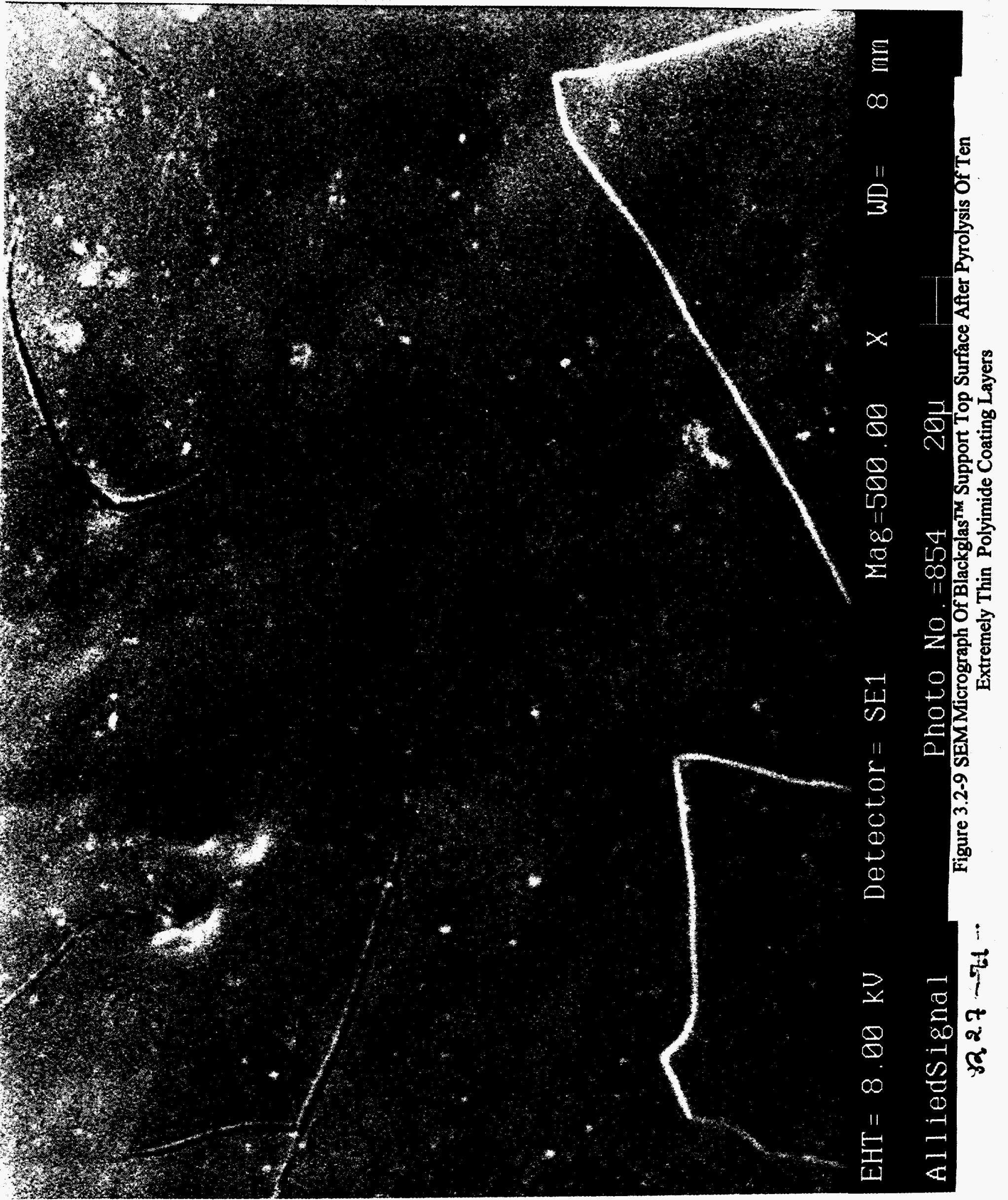




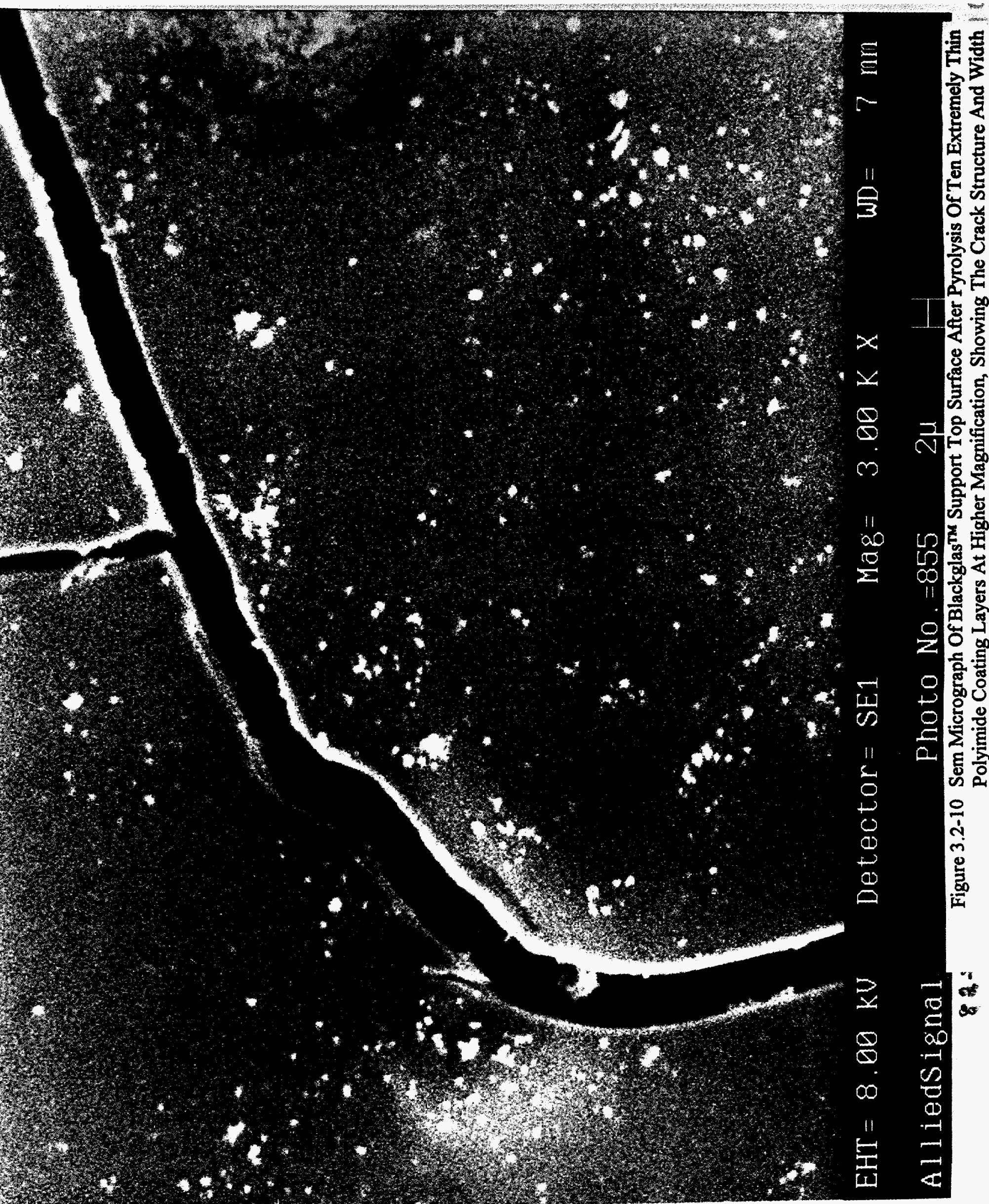




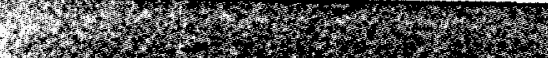

Hot

1.t.

What

4)

H,

Hing

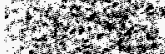

Whytw:

,

3.

6.

3ror

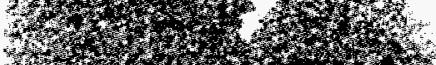

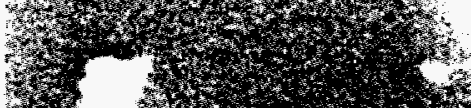

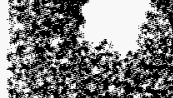

1)

䍂

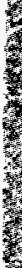

?
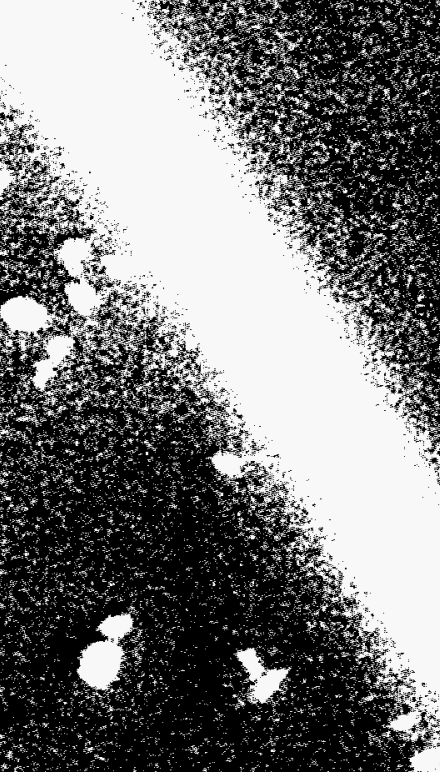

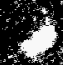

13.

3r.

X)

16.

1)

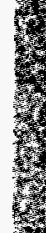

\%

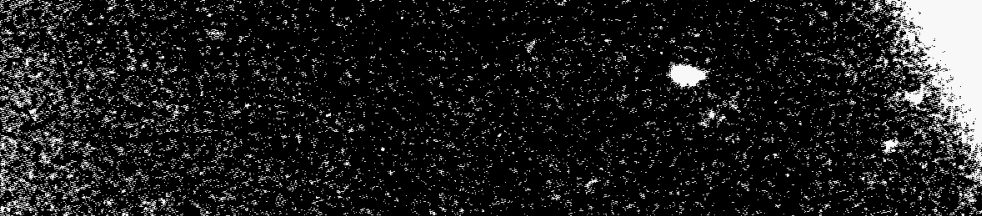

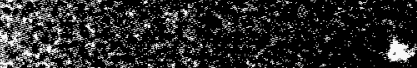

36x

35x

3.t.

3)

Norto:

13x

16x

F.7.

WX,

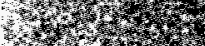

Wrotyon

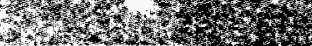

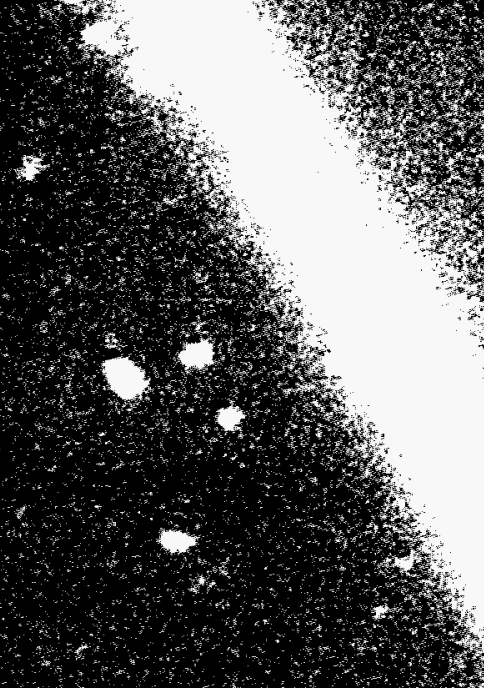

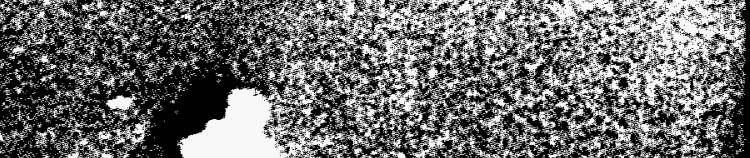

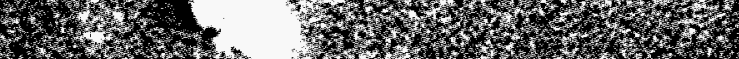

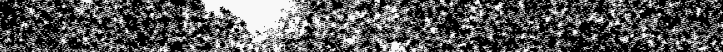

mor.

10.6.

等

$\equiv$

$\infty$

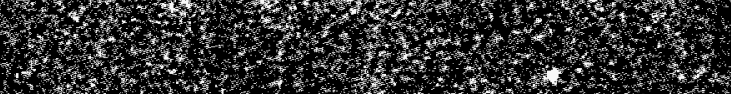




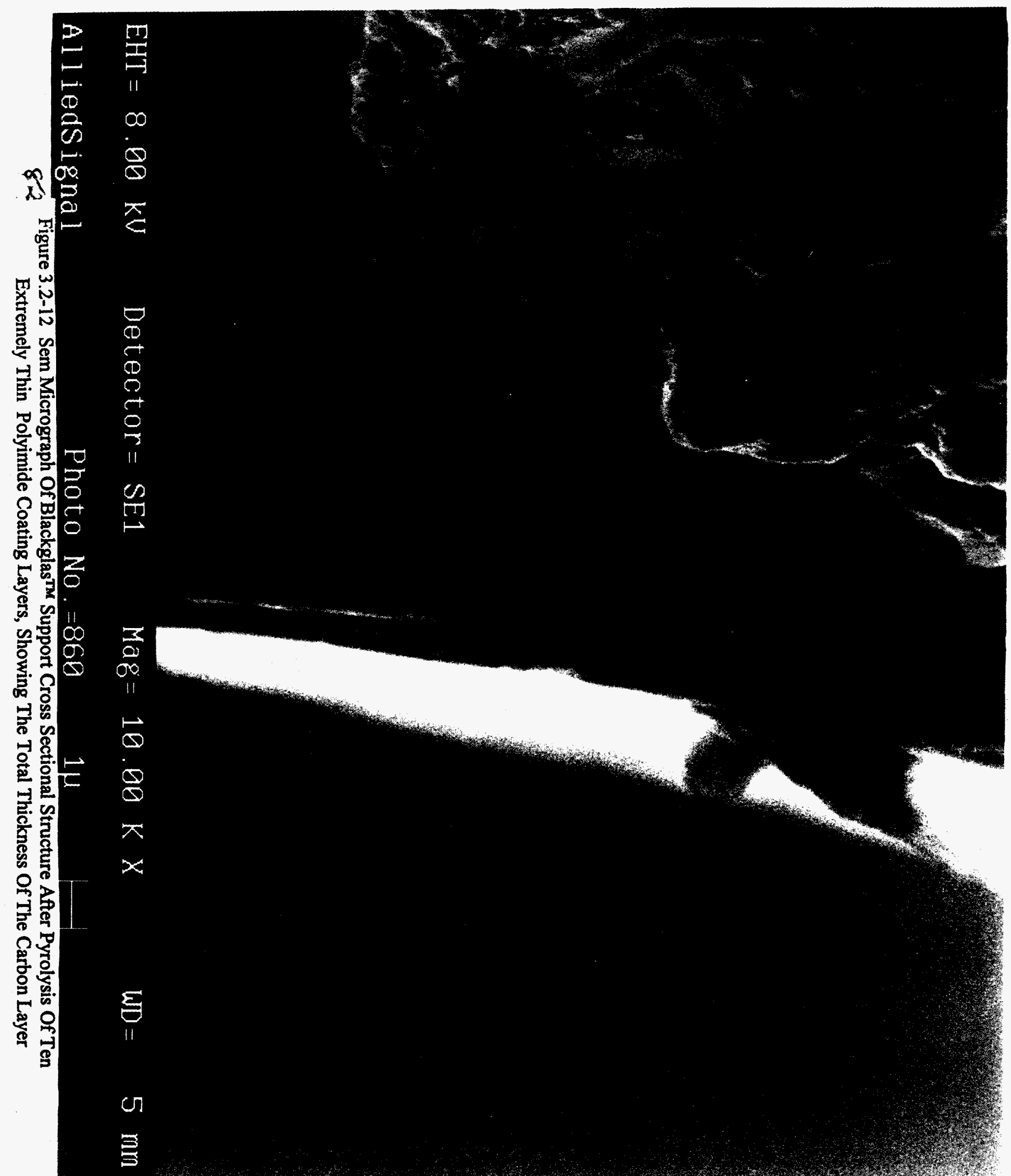




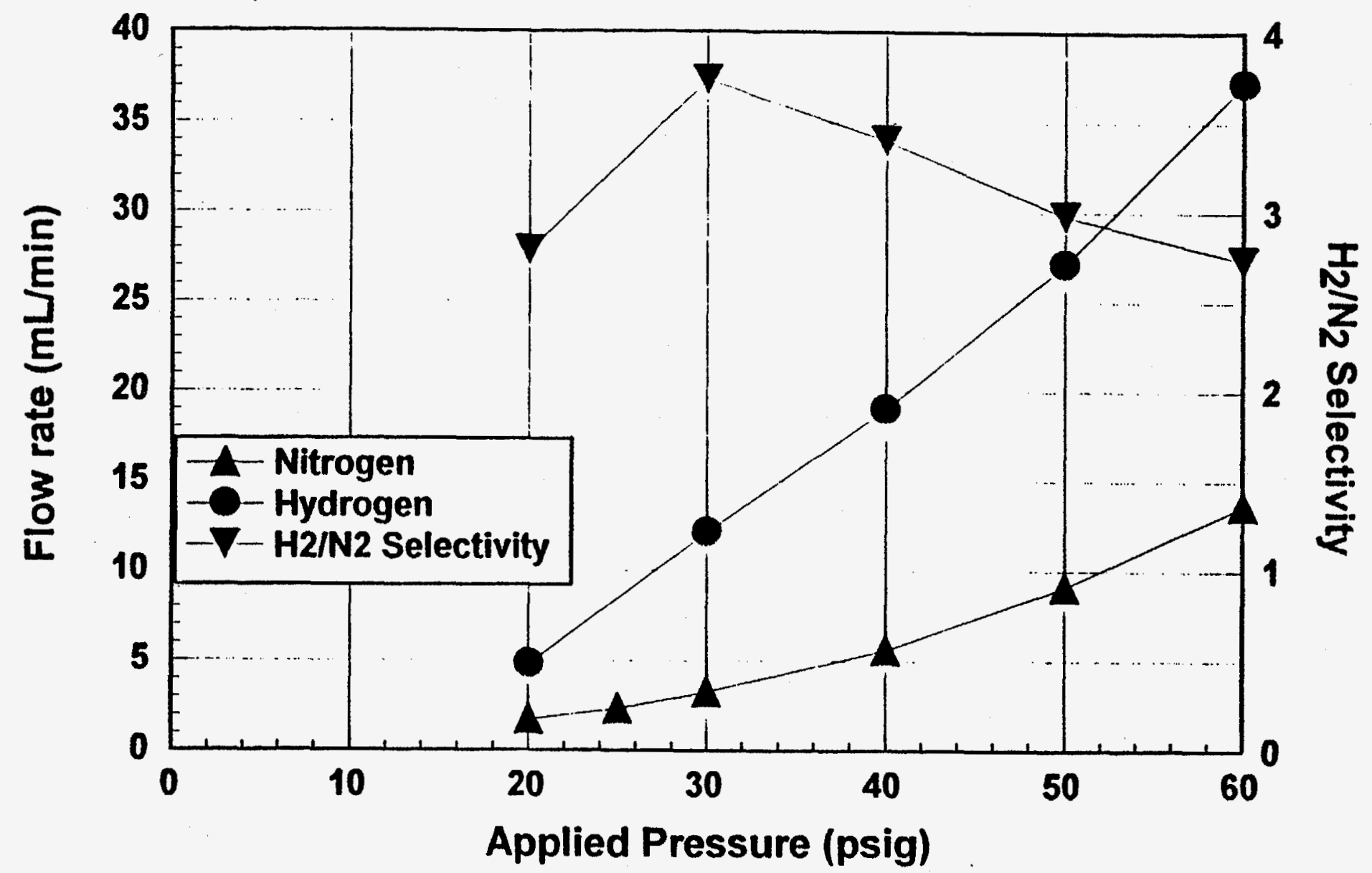

3.2-13 Hydrogen And Nitrogen Flow Rate And Selectivity Through Composite CMS Membrane As A Function Of Applied Pressure At Room Temperature 


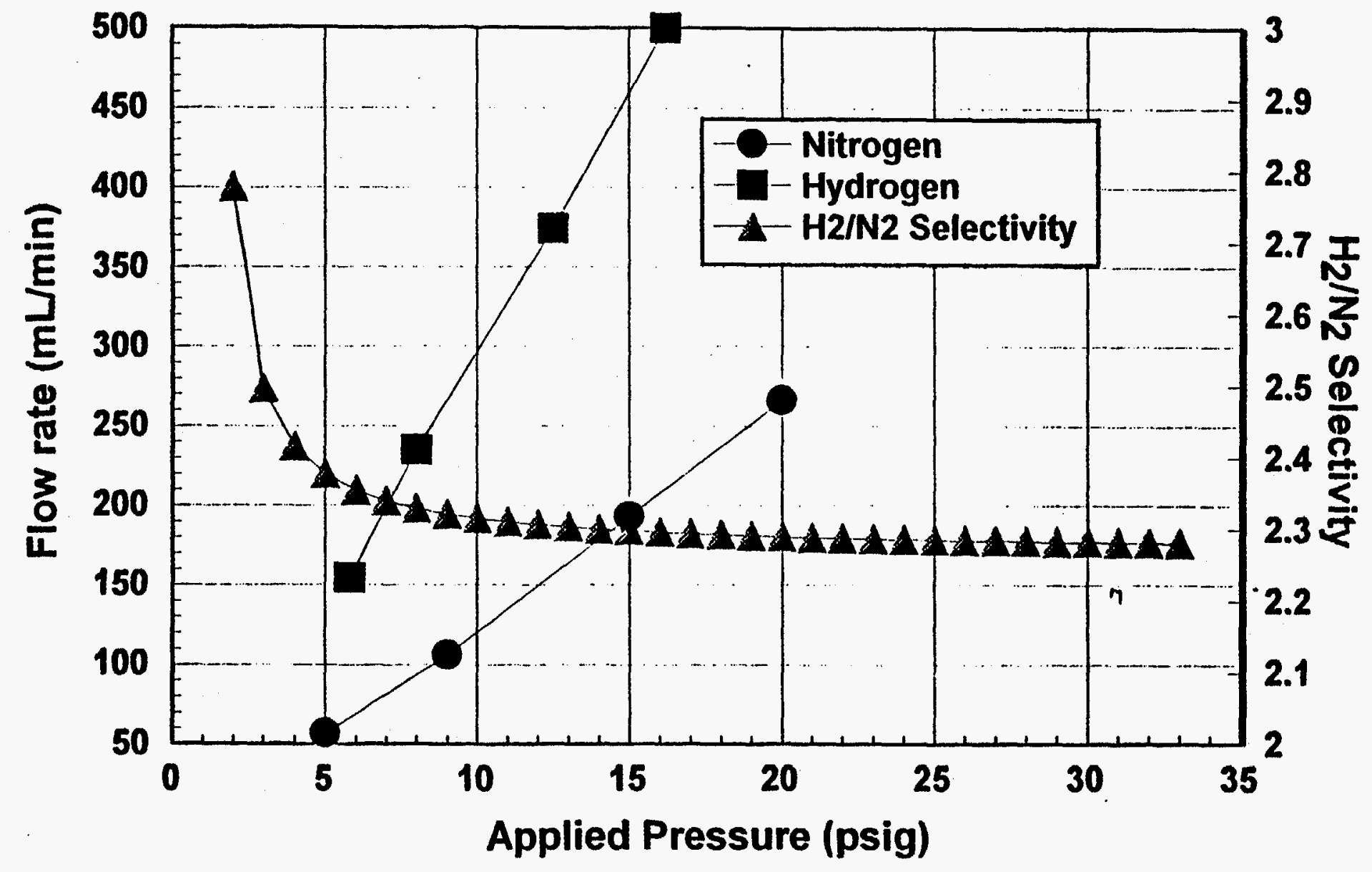

3.2-14 Hydrogen And Nitrogen Flow Rate And Selectivity Through Composite CMS Membrane As A Function Of Applied Pressure At $520^{\circ} \mathrm{C}$ 


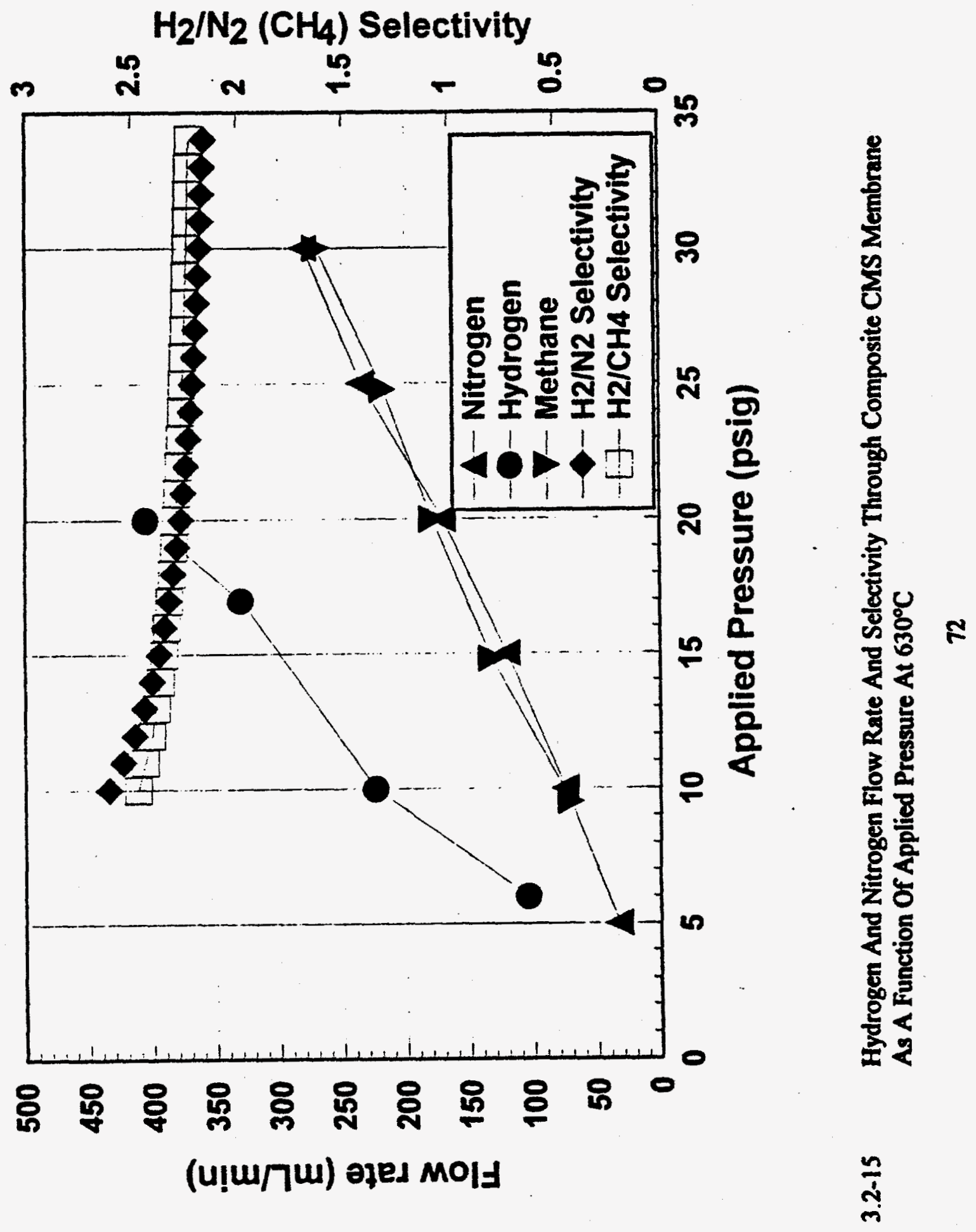




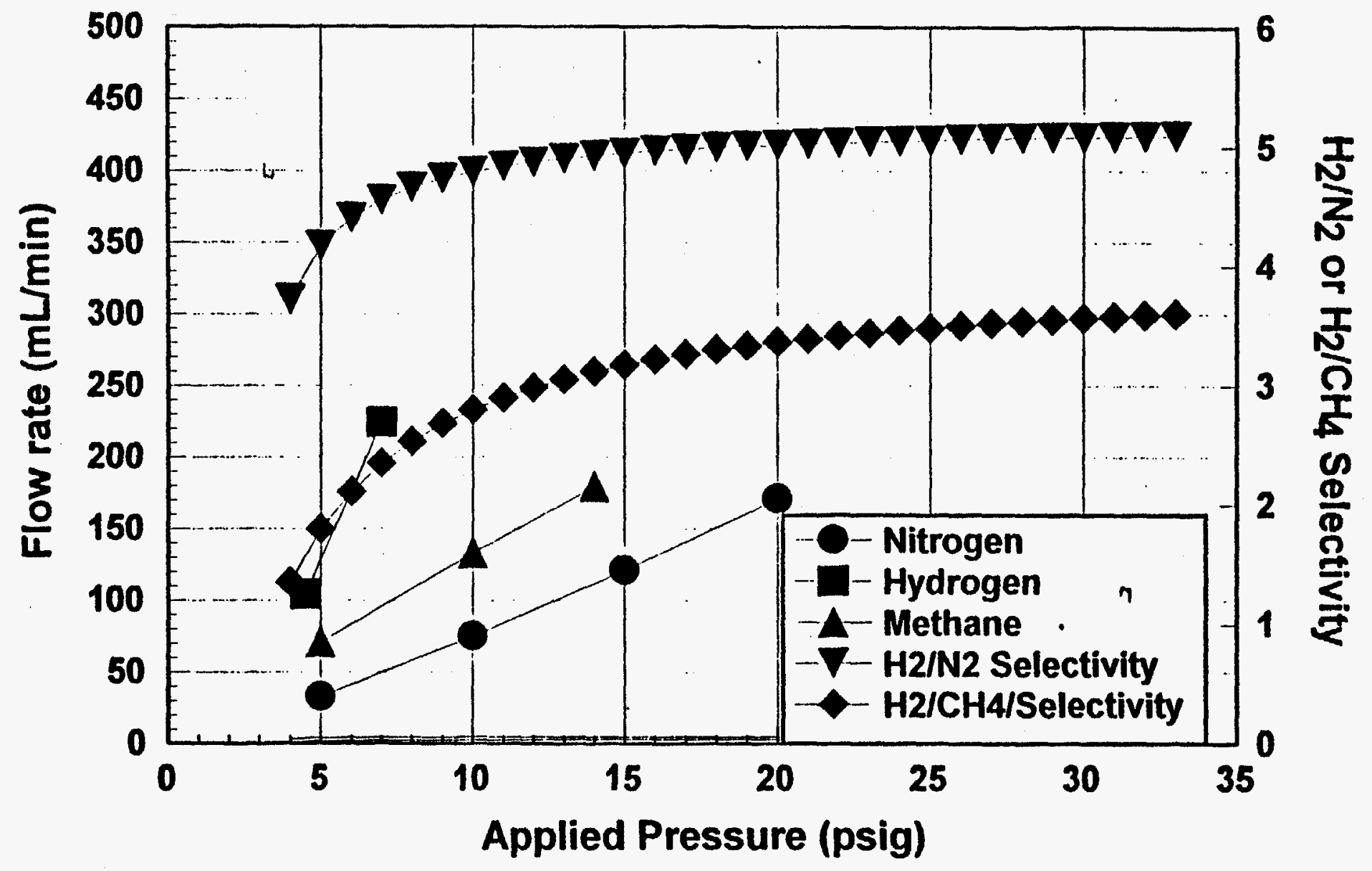

3.2-16 Hydrogen And Nitrogen Flow Rate And Selectivity Through Composite CMS Membrane As A Function Of Applied Pressure At $717^{\circ} \mathrm{C}$ 


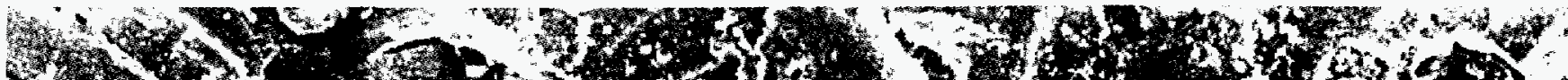

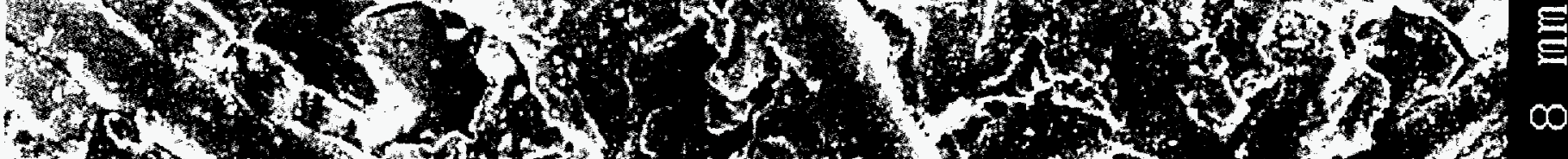

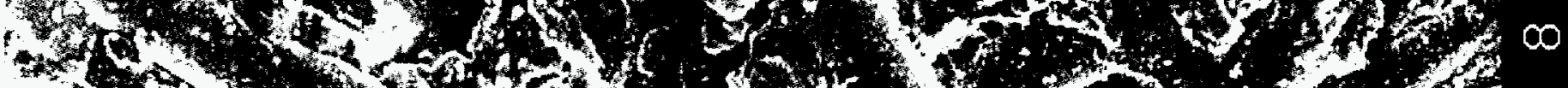

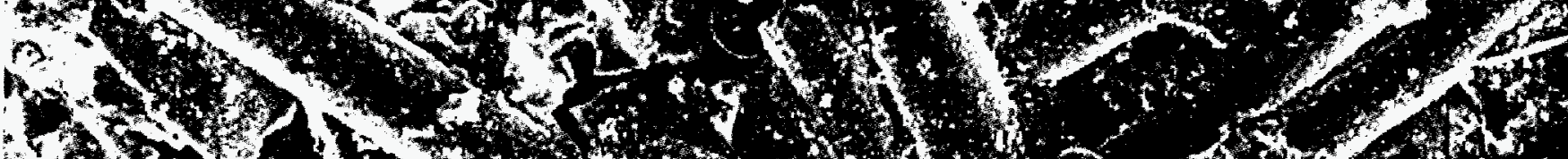

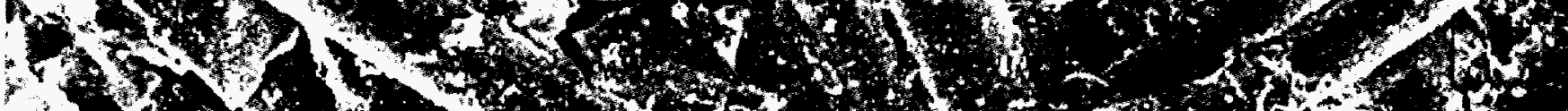
m

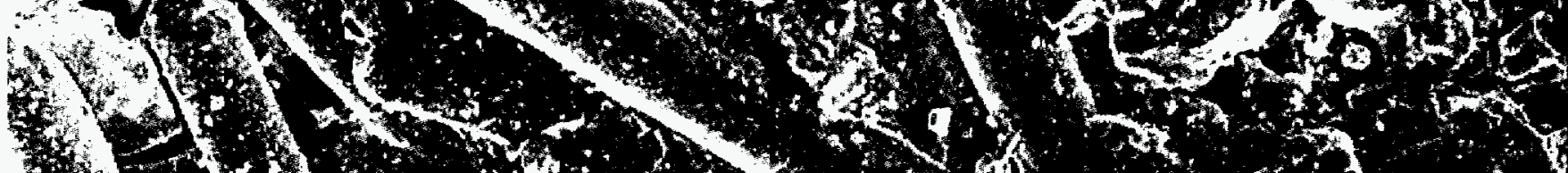

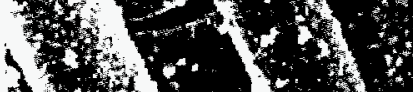

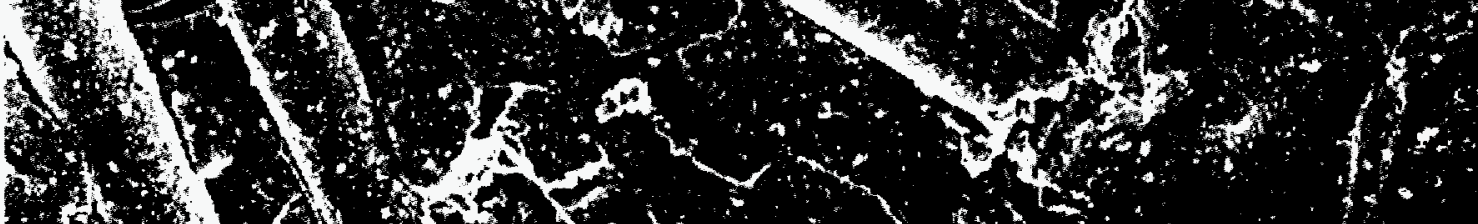

4. W X

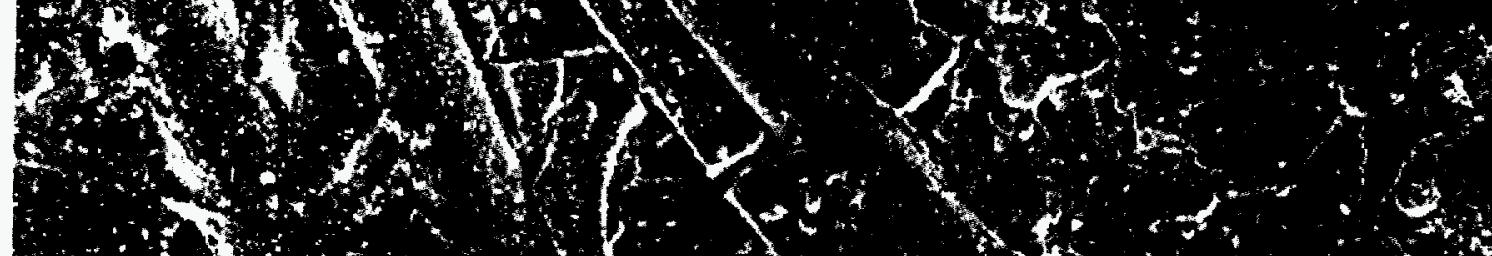

(1) क

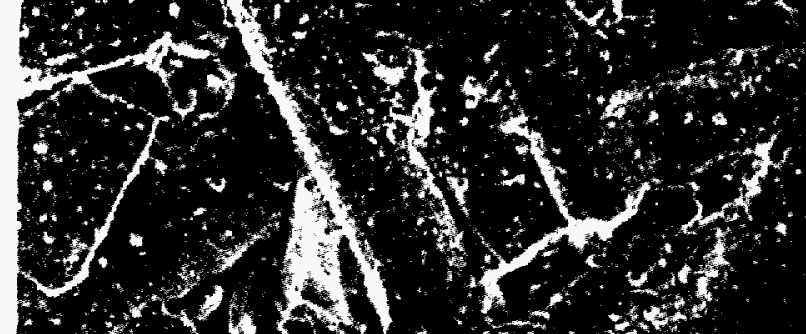

2. 1010 $5+c^{2}$

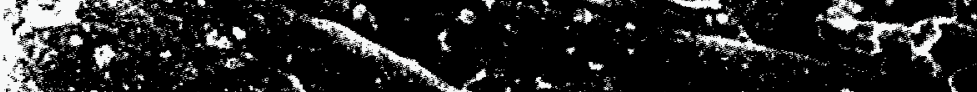

1. 140

1.21 12

W

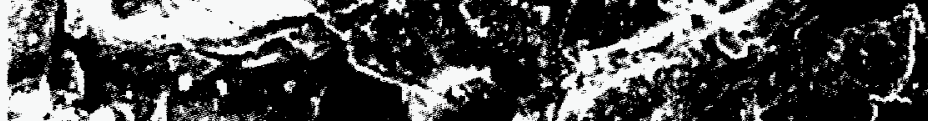
$-100$

(3)

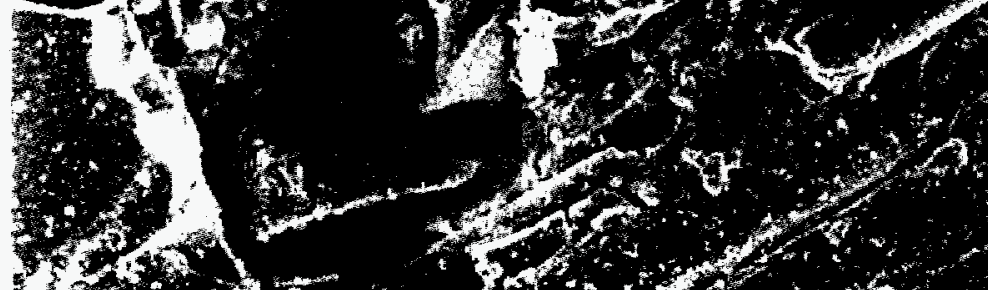

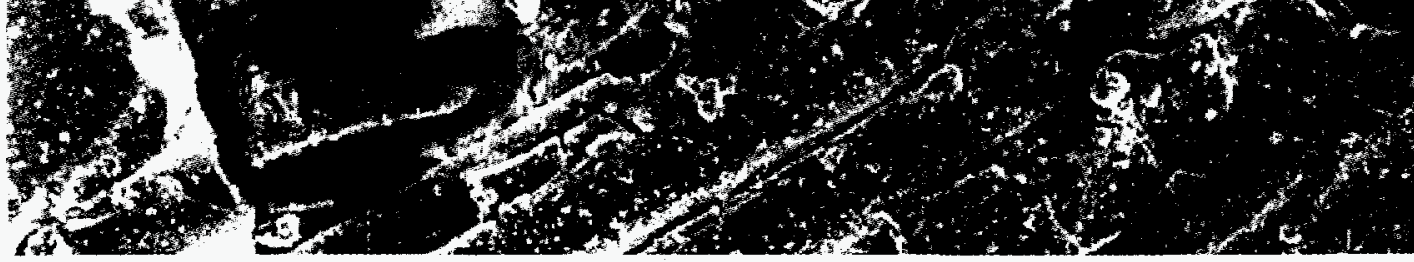




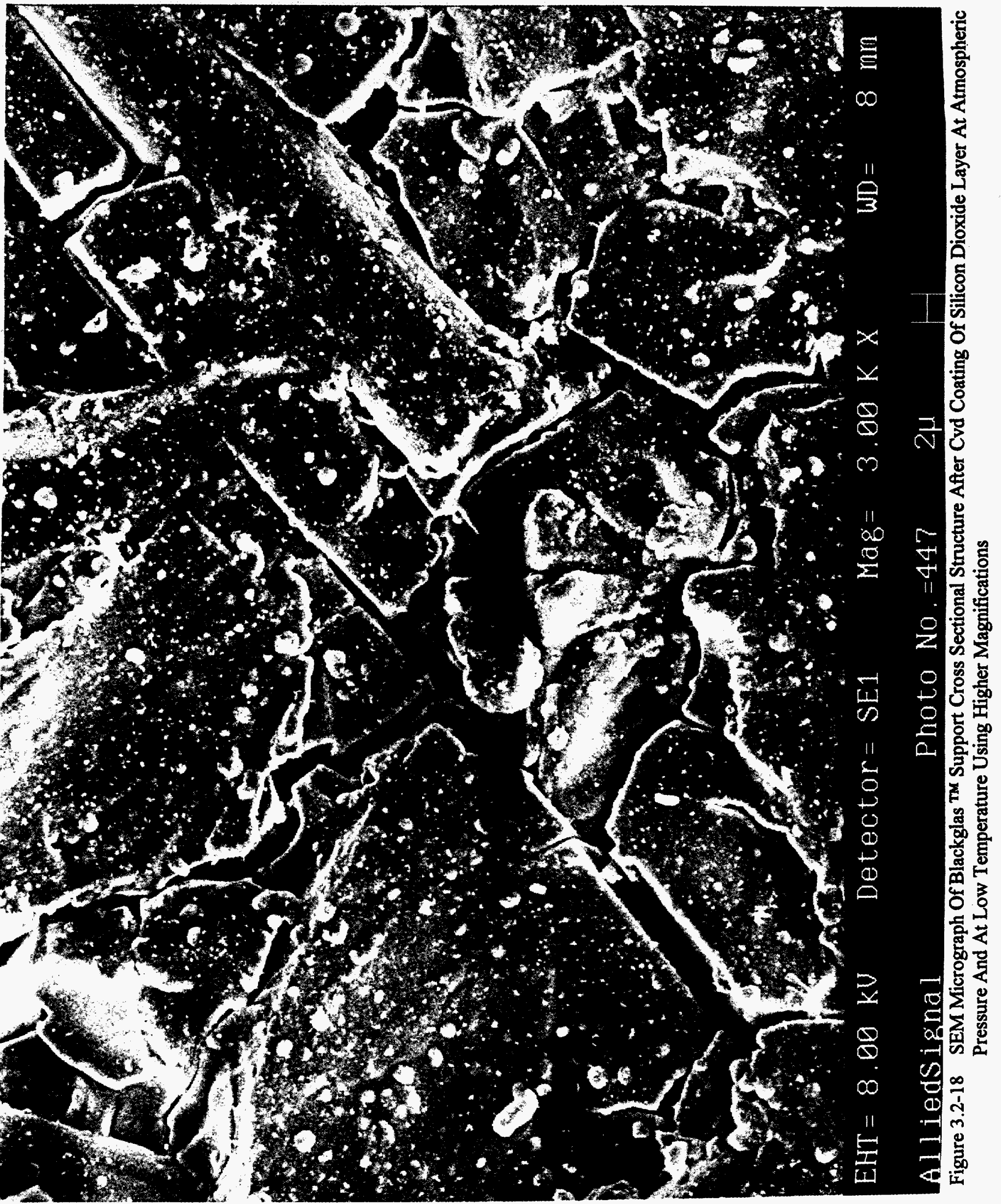




\subsection{Carbon Film Studies}

\subsubsection{Rationale}

As is apparent from our discussion of our results with carbon films, it is difficult to study the carbon membrane layer while it is in supported form. Such supported membranes are intentionally designed to be as thin as possible to maximize flux, but as a result, are a very low percentage of the total mass of the membrane composite. Since preparing a crack-free membrane for use in flux and selectivity trials was proving to be such an arduous task, we initiated a set of studies with unsupported carbon films to allow us to perfect the conditions for obtaining selectivity for hydrogen permeability without the interference of the support. The results of this effort would then be directly transferred to the supported membrane.

Our plan was as follows: First, we prepared carbon films from precursors which we felt could be cast on our supports, and used this format to perfect the carbonization conditions for the membrane. Then, we used adsorption porosimetry with various probe gases to guide us in preparing carbon films in which the pore dimensions were correct for the selective passage of hydrogen but not larger gases like nitrogen or carbon dioxide. Finally, once an optimized membrane film was available, we tried to measure fluxes for passage of gases through the films. The first two activities were successfully accomplished, but the brittle nature of the films prevented us from completing the last.

\subsubsection{Scoping Carbonization Conditions for Carbon Film Preparation}

We began our evaluation of conditions for preparing carbon films by basing conditions on our previous work in preparing carbon molecular sieve pellets for adsorption purposes. In this work, CMS materials were prepared ${ }^{24,25,26}$ from precursors such as polyvinylidene chloride and polyacrylonitrile which showed good structural strength, and had narrow pore size ranges in the desired range. Based on these studies, we chose polyacrylonitrile for our initial studies.

Polyacrylonitrile (PAN) films were prepared by casting N,N-dimethylformamide solutions of PAN $(150,000 \mathrm{MW})$ onto glass plates. After evaporation of the solvent at $100-110^{\circ} \mathrm{C}$, smooth films of PAN were obtained so long as the films were thin; 
attempts to make thicker films generated material with a rough surface. Since the smooth films appeared to be too thin to be used for carbonization, several were stacked onto each other, and hot pressed together. Pressing at 700 psig while raising the temperature from $125^{\circ} \mathrm{F}$ to $257^{\circ} \mathrm{F}$ proved to be necessary to prevent delamination. These pressed disks were then carbonized by heating in a furnace under a flow of nitrogen to $490^{\circ} \mathrm{C}$. The products of this procedure, however, proved to be extremely brittle and fragile. It proved impossible to remove the carbonized films from the furnace without shattering them.

In observing the results of this and similar experiments, it became clear that different polymer properties are required for the preparation of carbon films than for carbon adsorbents. To prepare stronger polymer films, the parent polymer must retain mechanical integrity to as high a temperature as possible, and must carbonize with retention of as much of its carbon-carbon connectivity as possible. This guided us in the direction of aromatic polymers known for high temperature performance. With this idea in mind, we became aware of reports ${ }^{27}$ in which polyimide films like the commercially available Kapton had been successfully cartonized into durable films. While the details of this procedure were not spelled out, we decided to use this as a starting point.

Kapton polyimide film has the structure shown in Figure 3.3.2-1 and is thus a fairly simple polyimide material. It has no melting point, but has a glass transition temperature between 360 and $410^{\circ} \mathrm{C}^{28}$. We found that the commercially available films, with thickness between 2 and 5 mil could be carbonized by heating the films slowly $\left(1^{\circ} \mathrm{C} / \mathrm{min}\right)$ to $850^{\circ} \mathrm{C}$ and holding the films at that temperature for 2 hours. Comparison with the results in section 3.2 will show that these conditions are not strongly dissimilar to those which also worked for polyimide films cast on supports. The resulting films appeared smooth and shiny, and could be handled carefully without breakage.

Figures 3.3.2-2 and 3.3.2-3 show SEM photos of the surface of such films at two different magnifications. Note that the surfaces appear smooth, and that the cracks characteristic of our supported films after the first coating/pyrolysis cycle are entirely absent. The only visible defects are some fine scratches. At the higher magnification, small amounts of flat plate-like material is visible adhering to the film. This may be due to layers of carbon which partially exfoliated during pyrolysis. No defects which appear to reach below the surface are visible. 
The first study which we now were able to perform was to track the dimensions and weight of the film as a function of temperature. To do this, films were heated slowly to various temperatures, then cooled, and carefully measured. The results are shown in Figure 3.3.2-4. Note that we observed that no changes occurred until the glass transition temperature was reached, and that the material then began to shrink. Shrinkage occurred equally in the length and width directions, but much less in the thickness dimension, probably due to orientation in the film. Volume, which was calculated from these dimensions, began to decline at $450^{\circ} \mathrm{C}$, decreased most rapidly over the $450-600^{\circ} \mathrm{C}$ range, and appeared to reach a new steady state near $800^{\circ} \mathrm{C}$.

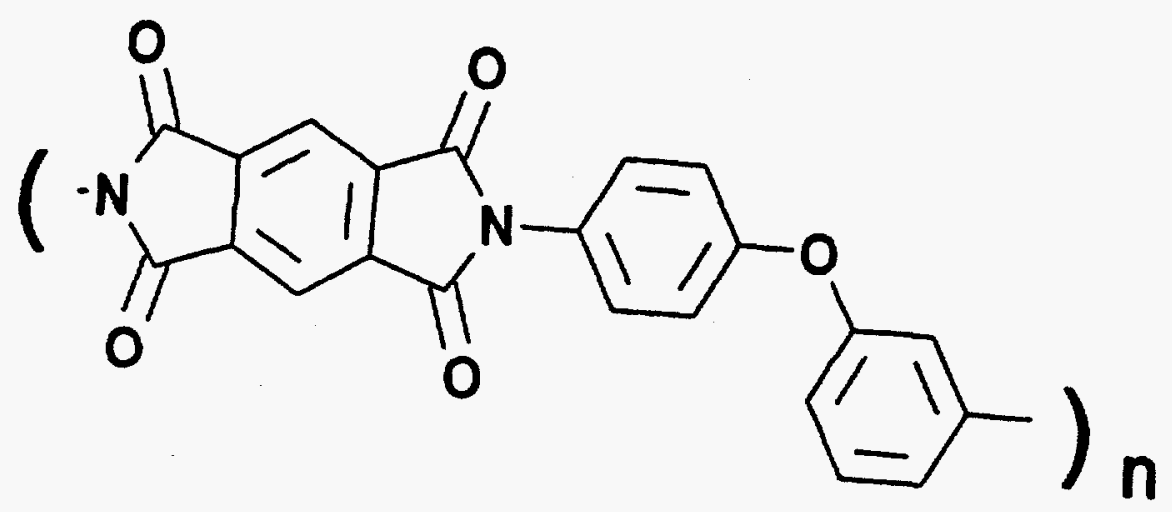

\subsection{2-1 Structure Of Polyimide Film Used In Unsupported Film Studies}

Interestingly, mass did not track directly with volume, resulting in a decline in the density of the material at intermediate temperatures. This is shown in Figure 3.3.2-5. We see that while the density at $400^{\circ} \mathrm{C}$ matched the literature density for this material, density declined to less than $1.25 \mathrm{~g} / \mathrm{mL}$ at $550^{\circ} \mathrm{C}$. It then increased to a new stable value of $1.45 \mathrm{~g} / \mathrm{mL}$. For reference, the density of graphite is $1.55 \mathrm{~g} / \mathrm{mL}$. Thus, as the polyimide film is heated past $400^{\circ} \mathrm{C}$, it first begins to lose mass as a result of pyrolytic reactions which generate volatile materials. Formation of new carbon bonds and reorganization of the bond connectivity to a more graphite-like material occurs at higher temperatures, and results in the volume reduction. Note that we can infer that 
the material is probably weakest at the temperatures at which it is least dense, and it is at these temperatures that our material will be most vulnerable to cracking.

\subsubsection{Optimizing Conditions for Preferential Adsorption of Hydrogen}

Once we had a technique for preparing CMS films which had sufficient mechanical strength to be handled, we next focused on building in a porous structure of the appropriate dimensions. As we noted in Table 1.1.3-1, hydrogen has a kinetic diameter of $2.89 \mathrm{~A}$, while the gases we wish to reject $\left(\mathrm{CO}, \mathrm{CO}_{2}, \mathrm{CH}_{4}\right)$ have kinetic diameters of 3.3-3.8 A. We therefore need to have pore dimensions intermediate between these values so that hydrogen can permeate the membrane but the larger gases cannot. Our strategy was to prepare materials and analyze them via gas adsorption porosimetry, which gives us a clear picture of the pore size distribution in the material, and then to test the best materials for flux. The benefit of this strategy is that adsorption porosimetry puts little demand on the mechanical strength of the membrane, and this strategy allowed us to focus on the pore structure of the relatively weak unsupported materials.

Gas adsorption porosimetry is a well understood, relatively standard analytical tool. Most commercial instruments are designed to use nitrogen as the probe gas, and can be adapted to run other gases. As part of a prior research program we had developed experience in using carbon dioxide as a probe gas. For the current program, however, we needed to use hydrogen as a probe gas. This has not previously been reported in the literature, and is difficult to do because of the low temperatures required. Section 2.3 describes the development of this analytical technique for use in these studies.

We established a baseline for our studies using Sample 8046-162-3, which was prepared from 5 mil Kapton film by pyrolysis between two stainless steel plates. The temperature program involved heating the film under nitrogen at $1^{\circ} \mathrm{C} / \mathrm{min}$ to $850^{\circ} \mathrm{C}$, then holding at this temperature for one hour and resulted in $41.6 \%$ weight loss (see Table 3.3.3-1).

Figures 3.3.3-1 and 3.3.3-2 show the isotherms for carbon dioxide and hydrogen for this sample. Note that the carton dioxide curve shows Type I isotherm behavior, and approaches a final value of ca. $30 \mathrm{cc} / \mathrm{g}$ STP. The corresponding curve for hydrogen is 
almost linear, and shows much less adsorption. BET surface areas for carbon dioxide, nitrogen and hydrogen were $379.15,32.19$, and $23.80 \mathrm{~m}^{2} / \mathrm{g}$ (see Table 3.3.3-2) indicating that the carbon has a much higher affinity for carbon dioxide than for the other two gases. The similarity in the surface areas for nitrogen, which has a kinetic diameter larger than carbon dioxide, and hydrogen indicates that there are very few pores in this material which only hydrogen can enter. Thus, as an adsorbent, this film sample would be selective for carbon dioxide over hydrogen due to the stronger interactions $\mathrm{CO}_{2}$ has with the surface, while as a porous barrier, no discrimination would be expected. 
W

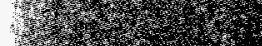

17x

慁

Q

3x

3rtrox

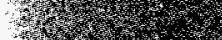

Wrox

WX

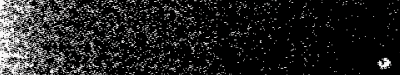

W 


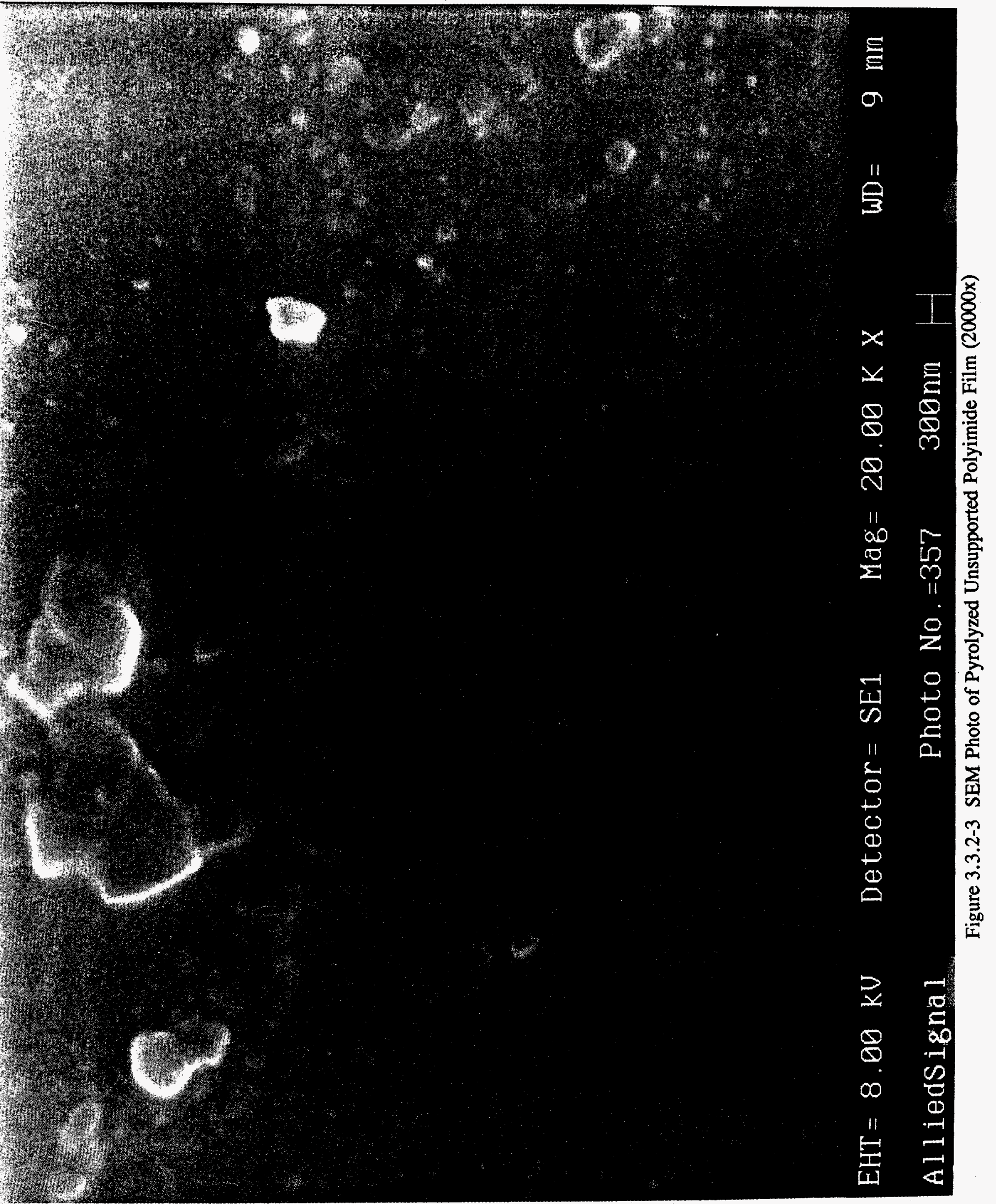




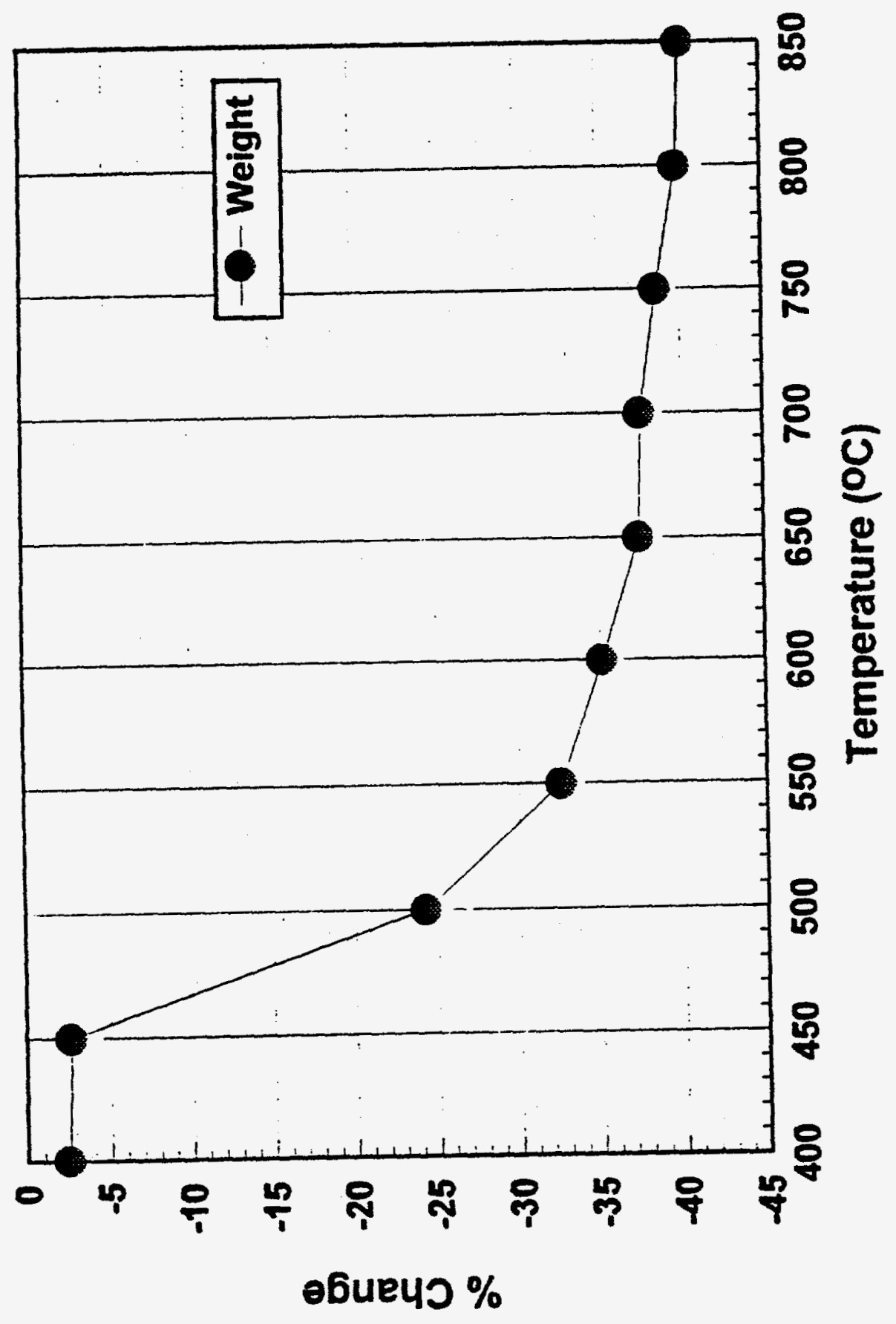

告

$\stackrel{\square}{\sim}$ 


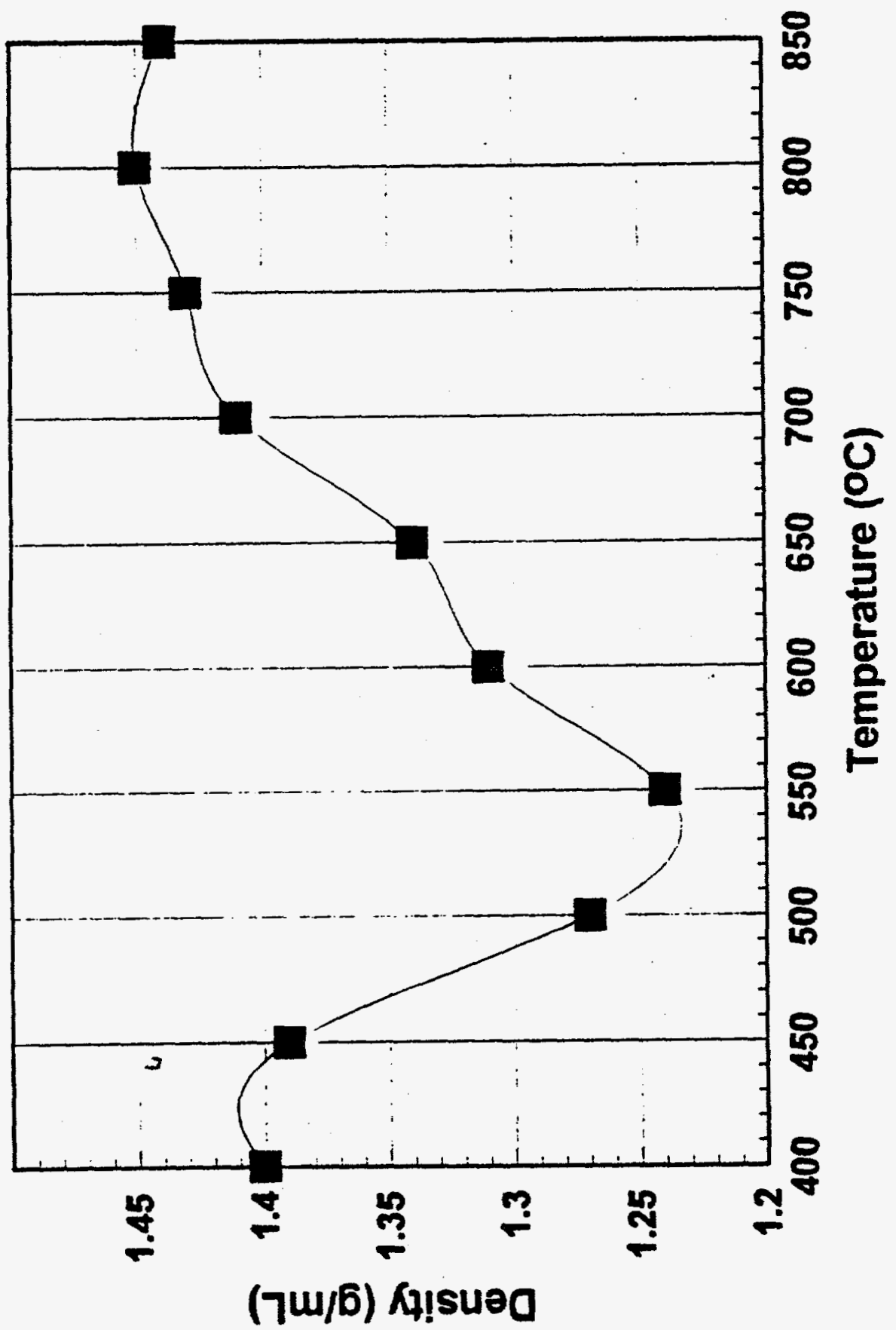

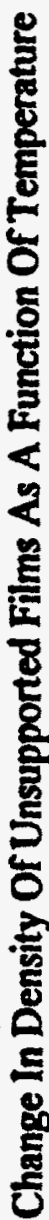

กั 


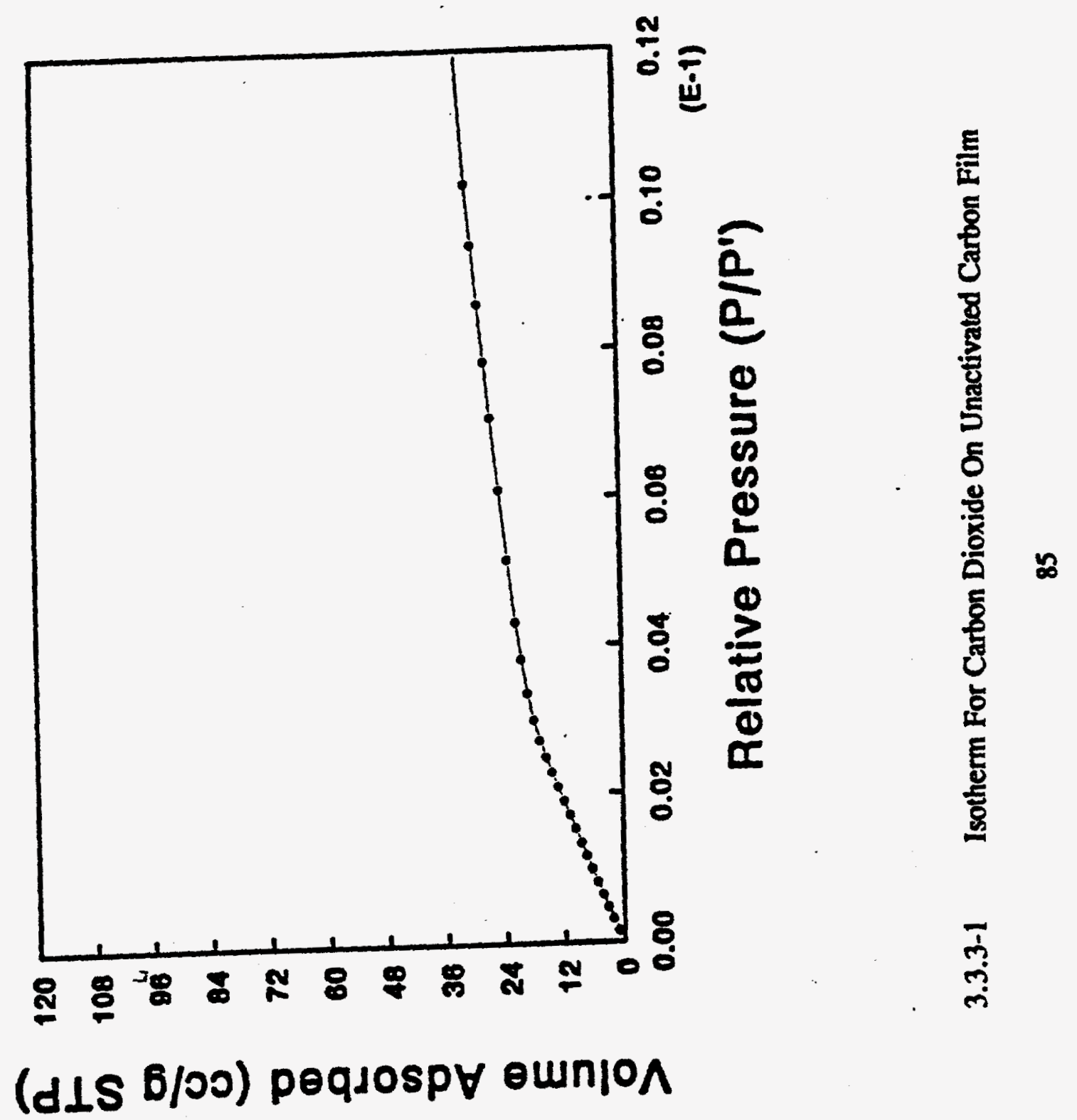




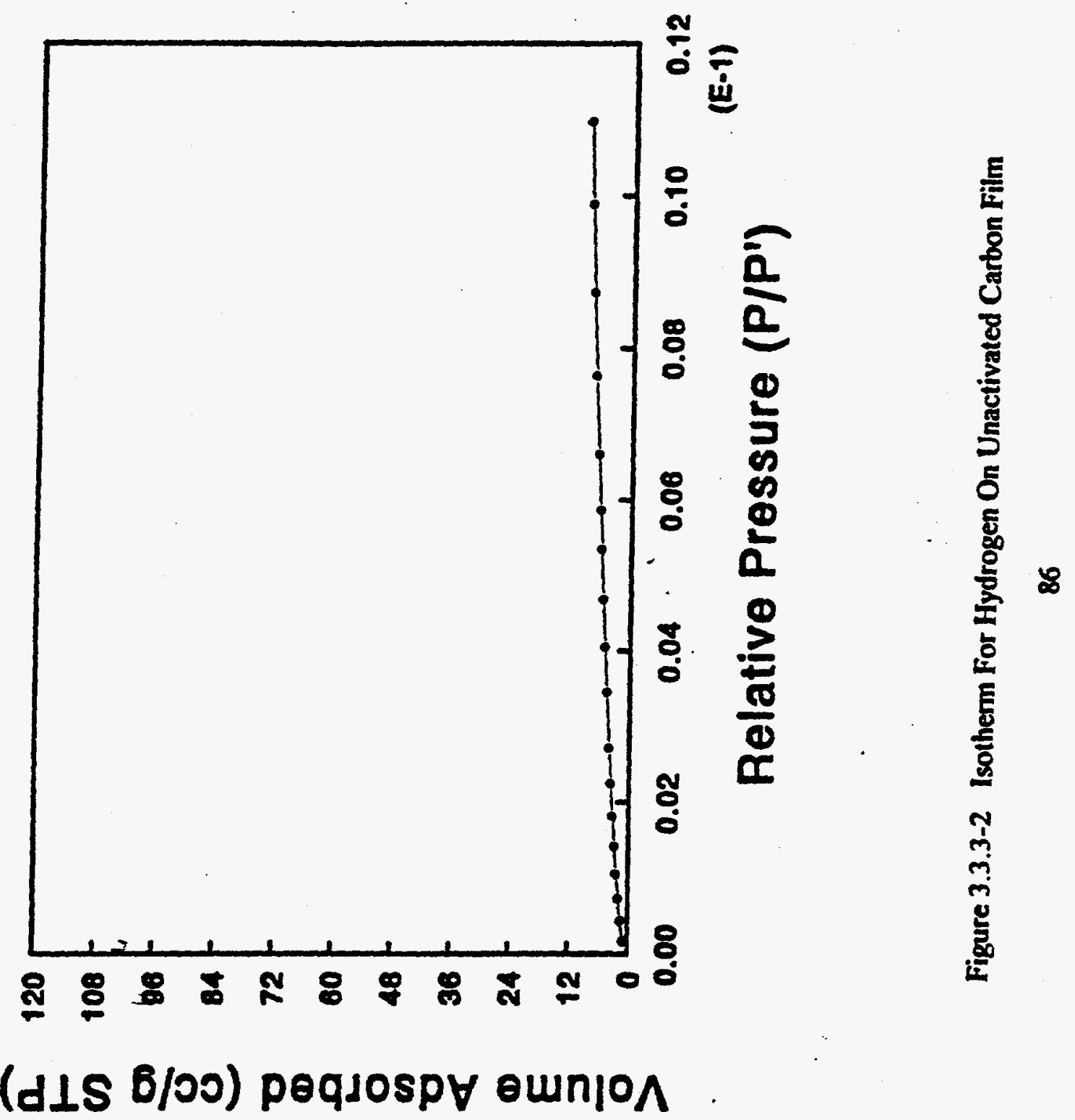




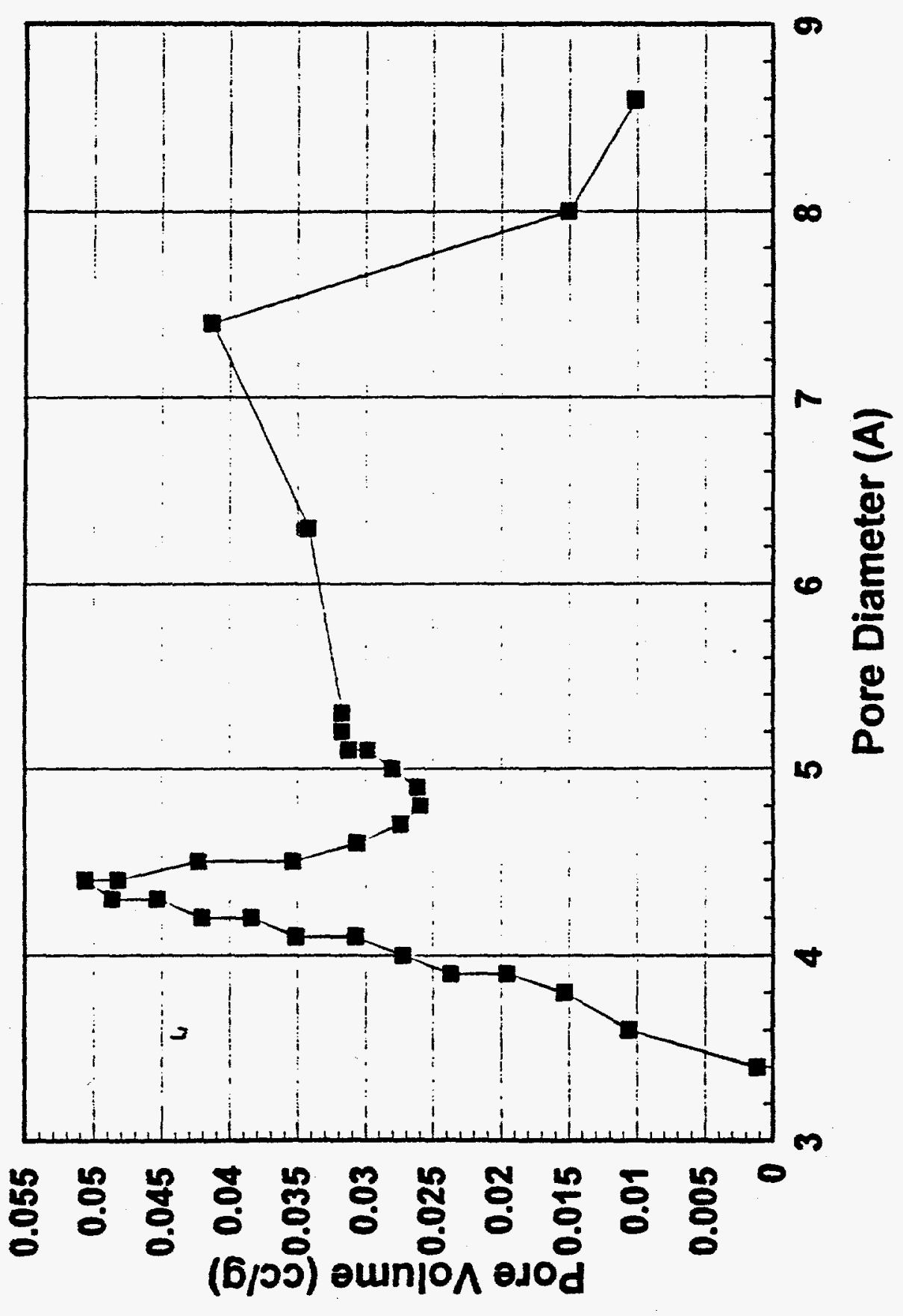

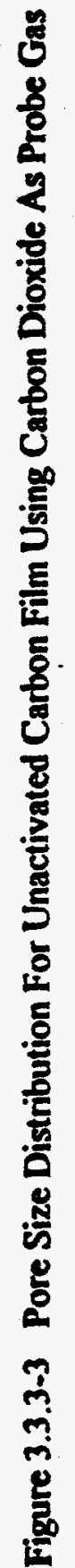




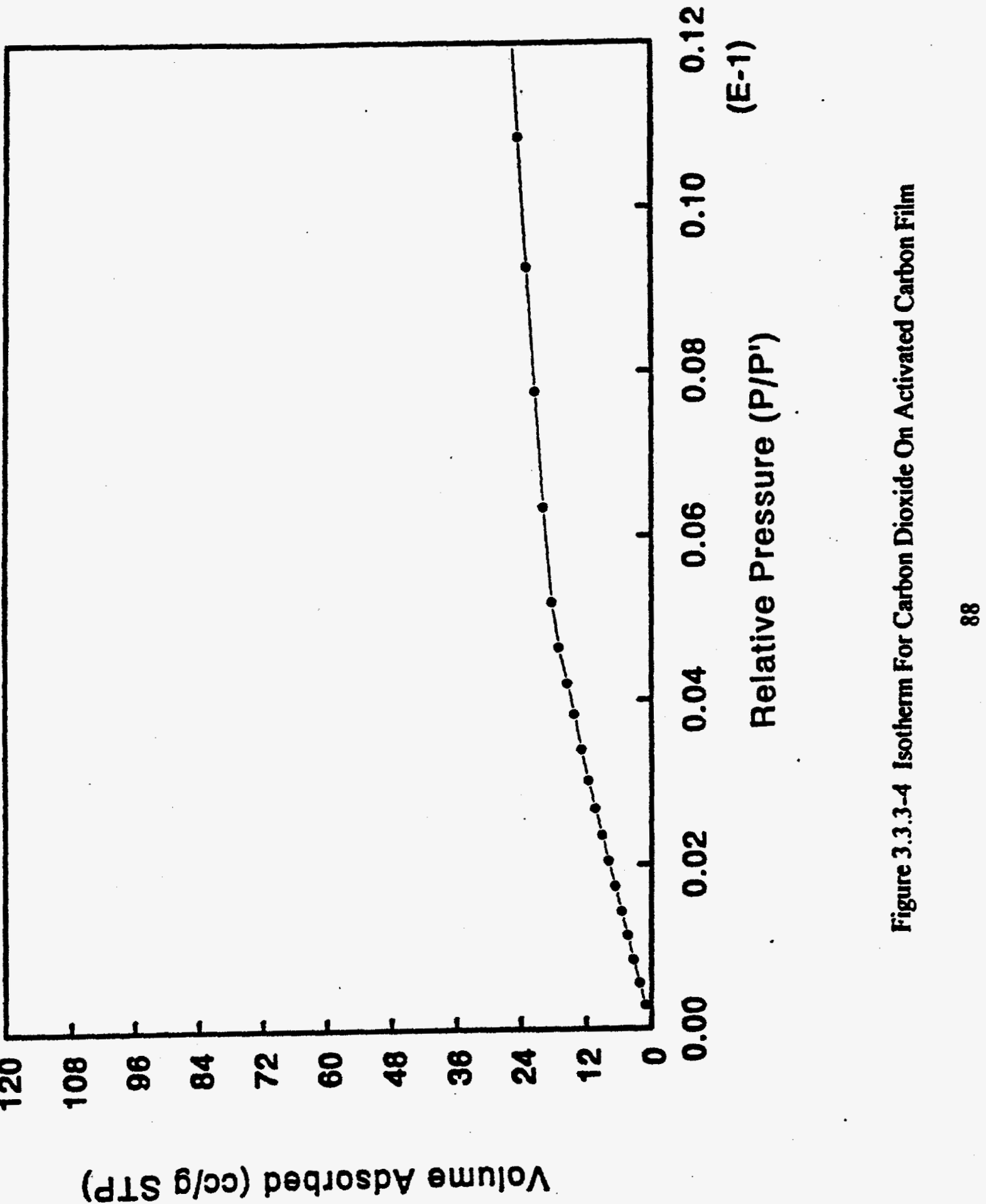




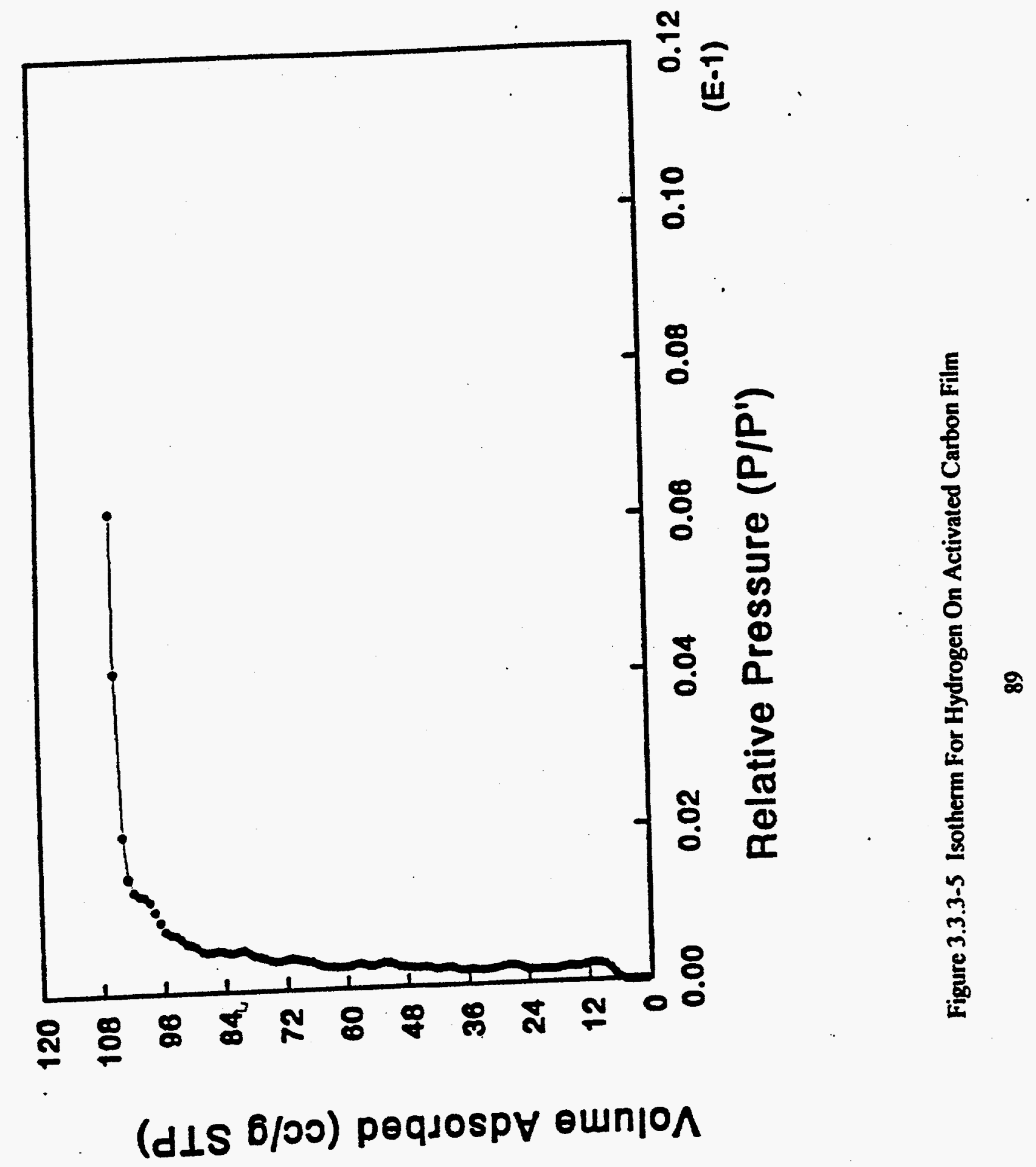




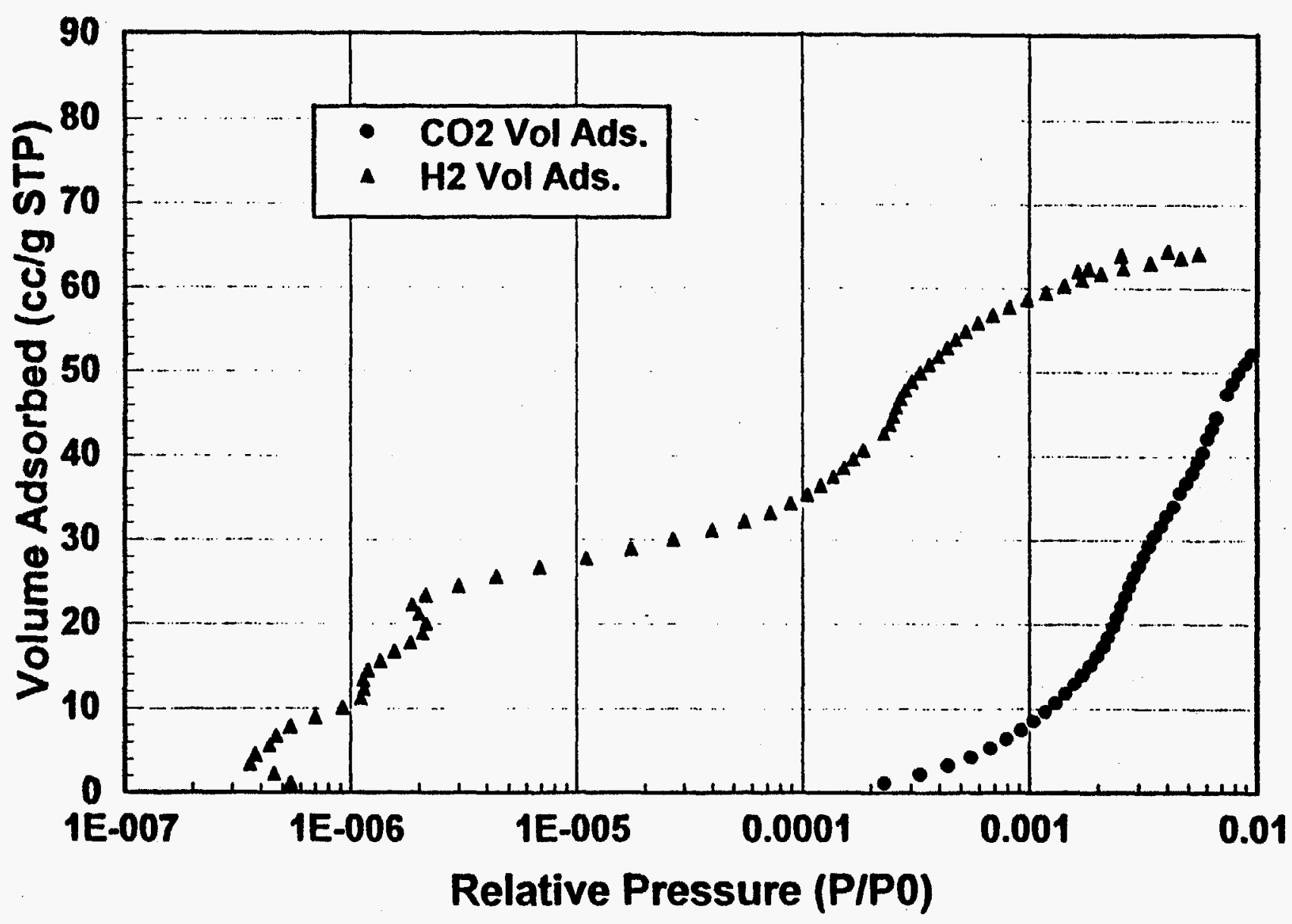

Figure 3.3.3-6 Isotherms For Hydrogen And Carbon Dioxide On Unactivated Carbon Film Produced At High Temperature Ramp Rate 


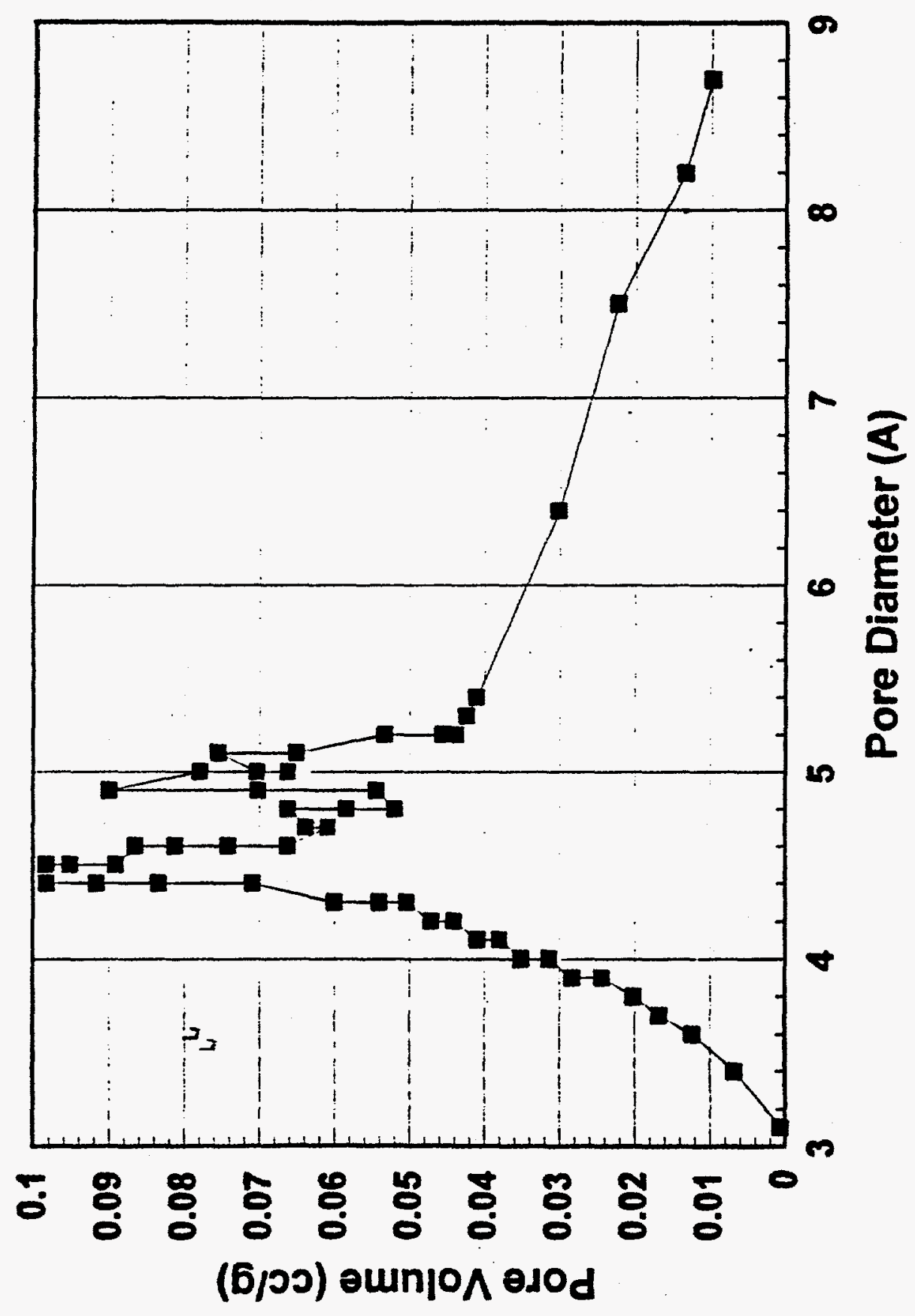

롤

욜

를

हू

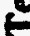

흠

$z$

$\neq \frac{8}{8}$

(1)

○

$\bar{a}$

0

8

ำ 


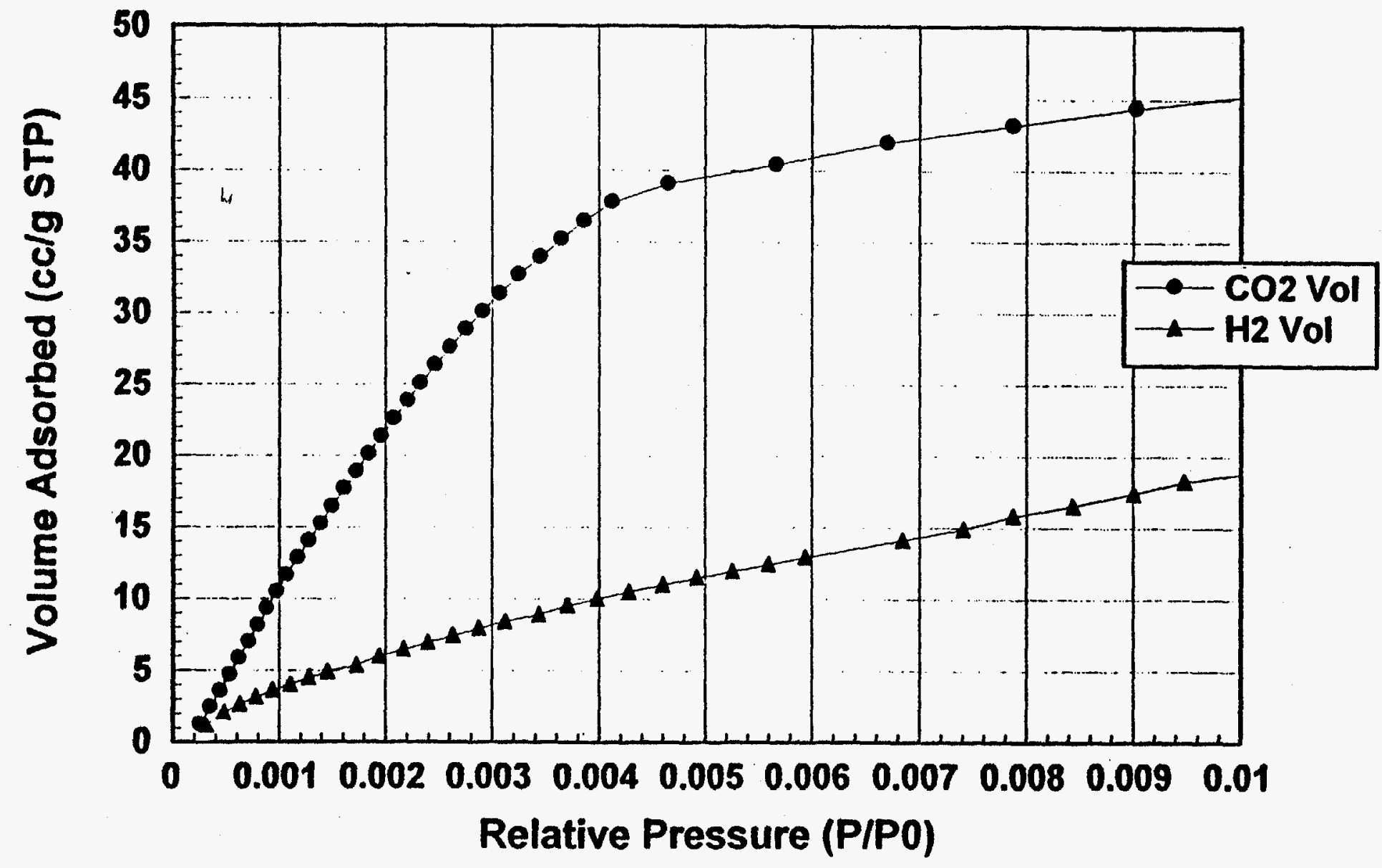

Figure 3.3.3-8 Isotherms For Hydrogen And Carbon Dioxide On Unactivated Carbon Film Produced Beneath Heavy Weight 


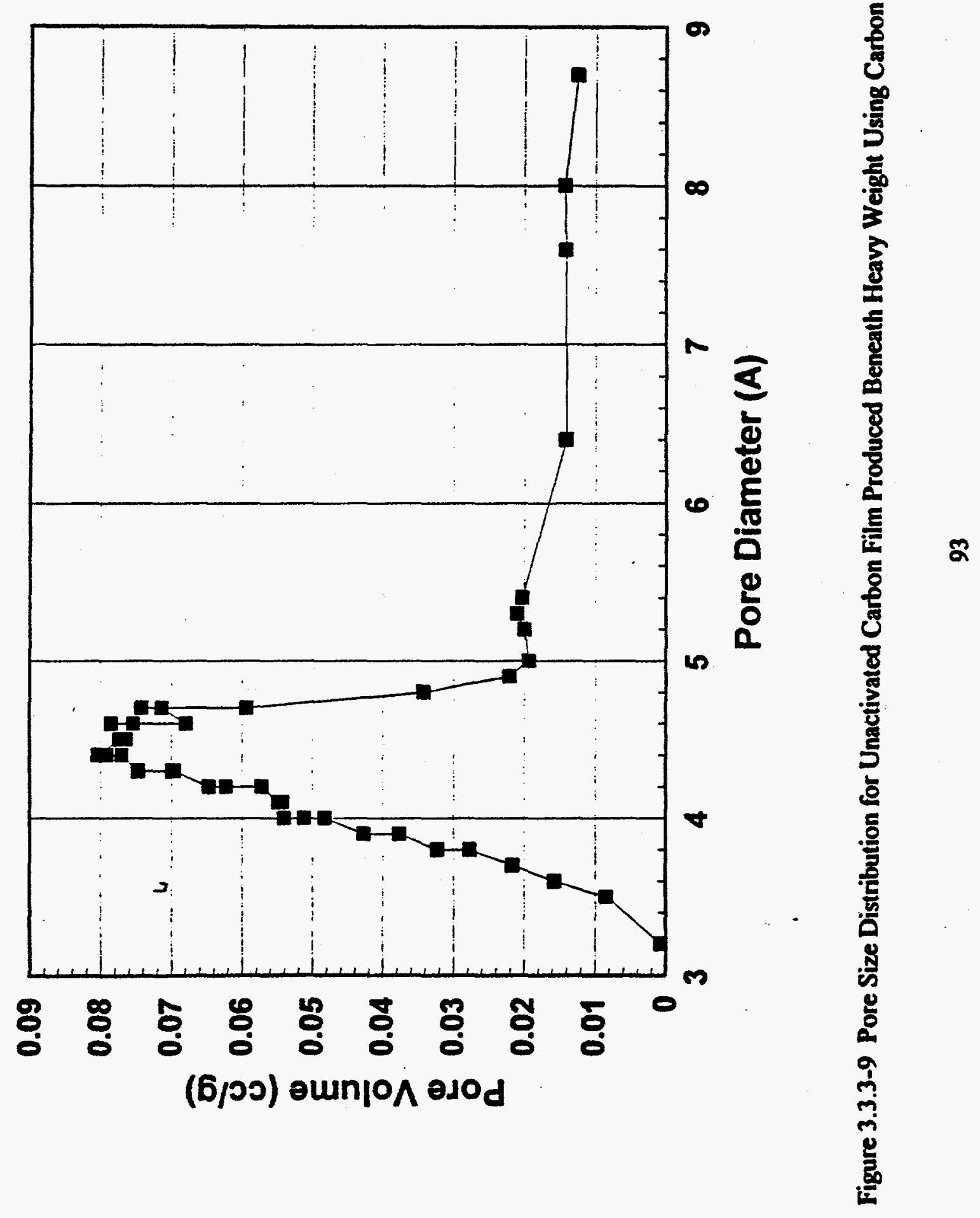


Table 3.3.3-1: Summary of Pyrolysis Conditions for Polyimide Films

\begin{tabular}{|c|c|c|c|c|c|}
\hline Sample & $\begin{array}{l}\text { Original } \\
\text { Thilin } \\
\text { Thickiess } \\
\text { (mil) }\end{array}$ & $\begin{array}{l}\text { Templature } \\
\text { Progrant }\end{array}$ & $\begin{array}{l}\text { Weight } \\
\text { = }\end{array}$ & Activation? & Weight Loss \\
\hline $8046-162-3$ & 5 & $\begin{array}{l}1^{\circ} \mathrm{C} / \mathrm{min} \text { to } \\
850^{\circ} \mathrm{C} / 1 \mathrm{hr}\end{array}$ & $0 \mathrm{~g}$ & No & 41.6 \\
\hline $8046-170-1$ & 5 & $\begin{array}{l}1^{\circ} \mathrm{C} / \mathrm{min} \text { to } \\
850^{\circ} \mathrm{C} / 1 \mathrm{hr}\end{array}$ & $0 \mathrm{~g}$ & Yes & $41.6+6.91$ \\
\hline $8227-17-1$ & 2 & $\begin{array}{l}15^{\circ} \mathrm{C} / \mathrm{min} \text { to } \\
900^{\circ} \mathrm{C} / 1 \mathrm{hr}\end{array}$ & $0 \mathrm{~g}$ & No & \\
\hline $8204-2$ & 5 & $\begin{array}{l}1^{\circ} \mathrm{C} / \mathrm{min} \text { to } \\
800^{\circ} \mathrm{C} / 1 \mathrm{hr}\end{array}$ & $301.8 \mathrm{~g}$ & No & \\
\hline $8227-87-4$ & 3 & $\begin{array}{l}15^{\circ} \mathrm{C} / \mathrm{min} \text { to } \\
850^{\circ} \mathrm{C} / 1 \mathrm{hr}\end{array}$ & $0 \mathrm{~g}$ & No & 41.8 \\
\hline $8227-91-a$ & 3 & $\begin{array}{l}1^{\circ} \mathrm{C} / \mathrm{min} \text { to } \\
850^{\circ} \mathrm{C} / 1 \mathrm{hr}\end{array}$ & $511 \mathrm{~g}$ & No & \\
\hline $8046-130$ & 5 & $\begin{array}{l}2^{\circ} \mathrm{C} / \mathrm{min} \text { to } \\
350^{\circ} \mathrm{C} / 5 \mathrm{hr} \text {, } \\
2^{\circ} \mathrm{C} / \mathrm{min} \text { to } \\
600^{\circ} \mathrm{C} / 3 \mathrm{hr} \text {, } \\
2^{\circ} \mathrm{C} / \mathrm{min} \text { to } \\
800^{\circ} \mathrm{C} / 2 \mathrm{hr}\end{array}$ & Og & No & \\
\hline
\end{tabular}


Table 3.3.3-2 Summary of Surface Area Results $\left(\mathrm{m}^{2} / \mathrm{g}\right)$ for Pyrolyzed Polyimide Films

\begin{tabular}{|c|c|c|c|c|c|c|c|}
\hline $\begin{array}{l}\text { Samplé } \\
\text { Number }\end{array}$ & $\frac{8046}{162-3}$ & $\frac{8046-}{170-1}$ & $\frac{8227}{17-1}=$ & $\frac{8204}{02}=$ & $\begin{array}{l}8227 \\
87-4\end{array}$ & $\begin{array}{l}8227 ? \\
91.2\end{array}$ & $\frac{8046^{-}}{130}=$ \\
\hline \multicolumn{8}{|c|}{ Carbon aioxide } \\
\hline Temp & $200^{\circ} \mathrm{K}$ & $195^{\circ} \mathrm{K}$ & $195^{\circ} \mathrm{K}$ & $195^{\circ} \mathrm{K}$ & $195^{\circ} \mathrm{K}$ & $195^{\circ} \mathrm{K}$ & $195^{\circ} \mathrm{K}$ \\
\hline BET & 379.15 & 222.41 & 410.12 & 301.83 & 337.32 & 461.74 & 1477.80 \\
\hline Langmuir & 427.95 & 232.21 & 457.69 & 333.24 & 347.03 & 503.10 & 1687.54 \\
\hline $\begin{array}{l}\text { Single } \\
\text { point }\end{array}$ & 344.15 & 157.57 & 381.66 & 296.69 & 321.25 & 448.60 & 1473.40 \\
\hline at $\mathrm{P} / \mathrm{PO}$ & 0.1037 & 0.0224 & 0.1023 & 0.1005 & 0.0291 & 0.1038 & 0.0959 \\
\hline \multicolumn{8}{|c|}{ Hydrogen } \\
\hline Temp & $20^{\circ} \mathrm{K}$ & $20^{\circ} \mathrm{K}$ & $19.7^{\circ} \mathrm{K}$ & $19.7^{\circ} \mathrm{K}$ & & & \\
\hline BET & 23.80 & 356.31 & 250.55 & 74.94 & & & \\
\hline Langmuir & 24.00 & 358.38 & 273.53 & 76.50 & & & \\
\hline $\begin{array}{l}\text { Single } \\
\text { point }\end{array}$ & 17.94 & 346.54 & 256.25 & 36.53 & & & \\
\hline at $\mathrm{P} / \mathrm{PO}$ & 0.0047 & 0.00062 & 0.1002 & 0.0059 & & & \\
\hline \multicolumn{8}{|c|}{ Vitrogen } \\
\hline Temp & $77^{\circ} \mathrm{K}$ & $77^{\circ} \mathrm{K}$ & & & & & $77^{\circ} \mathrm{K}$ \\
\hline BET & 32.19 & 22.87 & & & & & 72.52 \\
\hline Langmụir & 32.29 & 24.03 & & & & & 230.87 \\
\hline $\begin{array}{l}\text { Single } \\
\text { point }\end{array}$ & 30.56 & 22.83 & & & & & 4.57 \\
\hline at $\mathrm{P} / \mathrm{PO}$ & $\begin{array}{l}0.00271 \\
06\end{array}$ & $\begin{array}{l}0.01512 \\
15\end{array}$ & & & & & $\begin{array}{l}0.02203 \\
01\end{array}$ \\
\hline
\end{tabular}


Table 3.3.3-3 Summary of Monolayer Volume Results (cc/g STP) for Pyrolyzed Polyimide Films

\begin{tabular}{|c|c|c|c|c|c|c|c|}
\hline $\begin{array}{l}\text { Sample' } \\
\text { Number }\end{array}$ & $\begin{array}{l}8046 \\
162-3\end{array}$ & $\begin{array}{l}8046- \\
170-1\end{array}$ & $\frac{82227}{17-1}$ & $\begin{array}{l}8204 \\
02\end{array}$ & $\begin{array}{l}8227 \\
87-4\end{array}$ & $\begin{array}{l}8227-2 \\
91-a\end{array}$ & $8046-130$ \\
\hline \multicolumn{8}{|c|}{ Carbon dioxide } \\
\hline Temperature & $200^{\circ} \mathrm{K}$ & $195^{\circ} \mathrm{K}$ & $195^{\circ} \mathrm{K}$ & $195^{\circ} \mathrm{K}$ & $195^{\circ} \mathrm{K}$ & $195^{\circ} \mathrm{K}$ & $195^{\circ} \mathrm{K}$ \\
\hline BET & 83.00 & 48.69 & 89.78 & 66.07 & 36.63 & 101.08 & 323.50 \\
\hline Langmuir & 93.68 & 50.83 & 100.23 & 72.95 & 40.67 & 110.13 & 369.41 \\
\hline \multicolumn{8}{|c|}{ Hydrogen } \\
\hline Temperature & $20^{\circ} \mathrm{K}$ & $20^{\circ} \mathrm{K}$ & $19.7^{\circ} \mathrm{K}$ & $19.7^{\circ} \mathrm{K}$ & & & \\
\hline BET & 31.66 & 11.16 & 75.75 & 22.66 & & . & \\
\hline Langmuir & 35.42 & 11.16 & 82.72 & 23.13 & & & \\
\hline \multicolumn{8}{|c|}{ Nitrogen } \\
\hline Temperature & $77^{\circ} \mathrm{K}$ & $77^{\circ} \mathrm{K}$ & & & & & $77^{\circ} \mathrm{K}$ \\
\hline BET & 7.39 & 5.25 & & & & & 16.66 \\
\hline Langmuir & 7.42 & 5.52 & & & & & 53.03 \\
\hline
\end{tabular}


Figure 3.3.3-3 shows a Horvath-Kawazoe plot of the differential pore volume vs. pore diameter for the carbon dioxide experiment. Note that a bimodal pore distribution is revealed, with a sharp spike at $4.4 \AA$, and a broader peak at $7.4 \AA$. These peaks are larger than the pore diameters of the gases to be separated, and suggest that we should not expect discrimination between the gases based on size selectivity. Unfortunately, the analytical technique is too new for the appropriate parameters to have been developed to complete the corresponding plot for hydrogen experiments. This would extend the technique to pore sizes in the range of greatest interest.

We found that activation of the carbon film by a subsequent treatment with carbon dioxide at high temperatures resulted in a dramatic improvement in hydrogen adsorption. A film which had been prepared in a manner similar to that described above was reheated to $750^{\circ} \mathrm{C}$ at $15^{\circ} \mathrm{C} / \mathrm{min}$ under nitrogen. It was then exposed at that temperature to a stream of $4.5 \%$ carbon dioxide in nitrogen for 12 hours. The isotherms for carbon dioxide and hydrogen are shown in Figures 3.3.3-4 and 3.3.3-5. The carbon dioxide isotherm is little changed in either shape or magnitude relative to that in Figure 3.3.3-1. The hydrogen isotherm, however, shows a very steep climb at very low relative pressure values. It finally levels out to an apparent maximum near $100 \mathrm{cc} / \mathrm{g}$ STP. The BET surface area for this sample for carbon dioxide actually decreased somewhat to $222.4 \mathrm{~m}^{2} / \mathrm{g}$, while the surface area for hydrogen increased by more than a factor of 10 to $356.31 \mathrm{~m}^{2} / \mathrm{g}$. Obviously, a change occurred in the carbon film surface which increased the affinity for hydrogen while leaving the affinity for carbon dioxide unaffected.

Another way to get this large increase in hydrogen uptake proved to be a change in the temperature program. Increasing the rate of temperature increase during pyrolysis from $1^{\circ} \mathrm{C} / \mathrm{min}$ to $15^{\circ} \mathrm{C} / \mathrm{min}$ gave us samples like sample 8227-17-1. Figure 3.3.3-6 compares the isotherms for hydrogen and carbon dioxide adsorption on this sample, and shows that, once again, hydrogen was adsorbed in much higher quantity and at lower pressures than carbon dioxide. Note that the shapes of the hydrogen and carbon dioxide isotherms also resemble strongly those of the corresponding isotherms for the previous sample. The BET surface areas for carbon dioxide and hydrogen were $\mathbf{4 1 0 . 1 2}$ and $250.55 \mathrm{~m}^{2} / \mathrm{g}$. The pore size profile generated from the carbon dioxide data was again similar (Figure 3.3.3-7), with a bimodal pore distribution. Pore size statistics are shown in Table 3.3.3-4. 
Another variable of interest was the effect of applying pressure to the film during pyrolysis. For some samples, the polyimide film was pressed between two plates with a heavy weight during pyrolysis. The effect of this is shown in Figures 3.3.3-8 and 3.3.3-9. Note that this sample does not show the high hydrogen adsorption seen in the previous samples, as expected from the temperature program used. It does, however, show a significantly sharper profile in the pore size distribution. 
Table 3.3.3-4: Summary of Horvath-Kowazoe Pore Size Statistics

\begin{tabular}{|c|c|c|c|c|c|}
\hline \multirow{2}{*}{$\begin{array}{l}\text { Sample } \\
\text { Number. }\end{array}$} & \multirow[t]{2}{*}{ Gas: } & \multirow{2}{*}{ Tenp } & \multicolumn{3}{|c|}{ Horvath-Kowpzos data } \\
\hline & & & $\begin{array}{c}\text { Max. } \\
\text { Pore } \\
\text { vol cc/g }\end{array}$ & $\begin{array}{c}\text { Median } \\
\text { Pore } \\
\text { diameter } \AA\end{array}$ & $\begin{array}{l}\text { at relative } \\
\text { Pressure }\end{array}$ \\
\hline $8046-162-3$ & $\mathrm{CO2}$ & 200 & 0.152633 & 5.9 & 0.0062045 \\
\hline $8046-162-3$ & $\mathbf{N} 2$ & 77 & 0.11119 & 6.5 & 0.014414 \\
\hline $8046-170-1$ & $\mathrm{CO2}$ & 195 & 0.184175 & 7.1 & 0.4380038 \\
\hline $8046-170-1$ & $\mathrm{~N} 2$ & 77 & 0.008547 & 6.5 & 0.0512153 \\
\hline $8227-17-1$ & $\mathrm{CO} 2$ & 195 & 0.169001 & 5.1 & 0.1022836 \\
\hline 8204-02 & $\mathrm{CO2}$ & 195 & 0.131112 & 4.7 & 0.1004862 \\
\hline $8227-87-4$ & $\mathrm{CO2}$ & 195 & 0.131845 & 4.2 & 0.024417 \\
\hline $8227-91-a$ & $\mathrm{CO} 2$ & 195 & 0.203378 & 4.4 & 0.2504304 \\
\hline $8046-130$ & $\mathrm{CO} 2$ & 195 & 0.122465 & 4.5 & 0.0095438 \\
\hline $8046-130$ & $\mathbf{N} 2$ & 77 & 0.005667 & 13.6 & 0.078554 \\
\hline
\end{tabular}




\subsubsection{Flux Measurements with Unsupported Carbon Films}

It proved to be very difficult to measure fluxes with the unsupported carton films we prepared. Since the films were unsupported, their mechanical strength was low. They therefore needed to be very carefully padded and mounted or they would shatter as the membrane test cell was tightened. Then, trans-membrane pressure differentials could not exceed ca. 60 psi without damage to the membranes. It is well known that membrane fluxes decrease sharply as the membrane thickness increases. Because the membranes were unsupported, they could not be made too thin without becoming too fragile to handle. Our membranes were normally discs $\mathbf{c a} .3$ inches in diameter. After subtracting surface area for attachment of the edges, and frequently supporting attachments across the center, the surface area of membrane available for permeation was low. This meant that the expected fluxes, even for high performing membranes corresponded to very low volumetric flow rates.

In most cases, membrane fluxes were measured in a very simple apparatus. Membranes were sandwiched between two rubber pads perforated with holes, and clamped into a circular membrane test cell. Hydrogen was then used to pressurize the inlet side of the test cell to $30-60$ psig. The outlet side was attached to a length of capillary tubing partially filled with water. The flux was measured by tracking the height of this water slug as a function of time. For a membrane tested at 30 psig pressure differential, this unit would allow us to see a flux of $1.2 \times 10^{-11} \mathrm{~cm}^{3} \mathrm{~cm} \mathrm{~cm}^{-2}$ $\sec ^{-1}$ torr $^{-1}$. In fact, no carbon film was tested which showed any detectable flux.

The fact that carbon films which reproducibly had high surface areas and could take up significant volumes of carbon dioxide or hydrogen still proved impermeable reveals a great deal about how the pyrolysis and activation occur. We believe that as pyrolysis occurs, weight loss begins at the surfaces and works in from the surface. Film contraction also occurs, as noted in section 3.3.2, and may tend to densify the centers of the discs (Figure 3.3.4-1). The net result is that, even for the thinnest disks tried (2 mil), the films were unable to provide continuous pathways for diffusion from one side of the film to the other. The logical next step, using thinner films, was barred to us for unsupported films by the difficulties in preventing these films from breaking. Films thin enough to permeate hydrogen can probably only be formed in a supported form. 
While the above hypothesis explains the results we have obtained, we noticed that there was one difference in treatment between the samples used for porosimetry and the samples used for flux measurements. Samples used for porosimetry were routinely degassed at high vacuum for a period of time before measurements were begun. On the chance that this degassing changed the performance of the films, we degassed a series of films at room temperature and $<1 \mathrm{~m}$ torr pressure. The results, as shown in Table 3.3.4-1, were the opposite of what we had expected. Degassing the samples increased the weight of the samples. One reasonable hypothesis is that this degassing removes debris which blocked some pores in the structure. Once these pores were open, they adsorbed components from the air, resulting in a net increase in weight.

In one final attempt to measure a flux through a carbon film sample, we prepared a device in which a carbon film sample separated two chambers, one pressurized with hydrogen to $318 \mathrm{psig}$, and the second pressurized with argon to 290 psig. After two hours, the argon was sampled and analyzed for hydrogen. Less than 0.1 mass $\%$ was observed. This corresponds to a permeability of less than $5.4 \times 10^{-11} \mathrm{~cm}^{3} \mathrm{~cm} \mathrm{~cm}^{-2} \mathrm{sec}^{-1}$ torr ${ }^{-1}$.

Table 3.3.4-1: Effect on Carbon Film Weight of Degassing at $<1$ mtorr

\begin{tabular}{|l|l|l|l|}
\hline | Sample & Initial Weight $(\mathrm{g})$ & Final Weight $(\mathrm{g})$ & \\
\hline $8222-18-13$ & 0.08628 & 0.09200 & +6.63 \\
\hline $8227-18-8$ & 0.03063 & 0.03320 & +8.59 \\
\hline $8222-20-\mathrm{C}$ & 0.13100 & 0.13918 & +6.24 \\
\hline $8222-22-15$ & 0.12475 & 0.13335 & +6.89 \\
\hline $8222-22-6$ & 0.04535 & 0.04802 & +5.88 \\
\hline
\end{tabular}



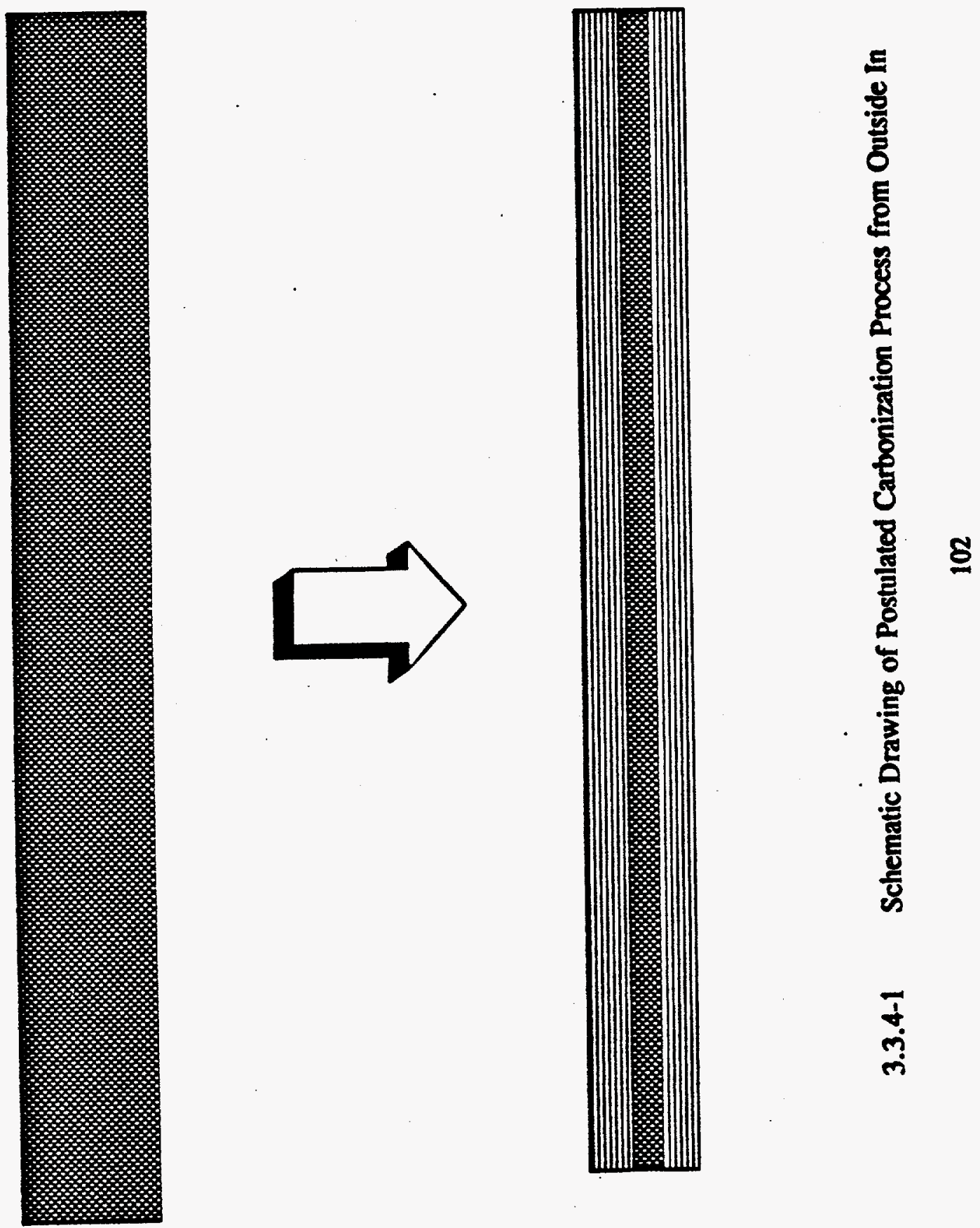

i⿱ 


\subsection{CONCLUSIONS}

This research program has had several technical successes which together pave the way to the first durable high temperature membrane. A durable high temperature support has been developed which has the strength and porosity needed for this role. The support is made of Blackglas'm, and techniques were developed to adjust the porosity of this support along with the density of the support. This support has the smooth surface needed for membrane preparation, has a high transmembrane flux and has a coefficient of thermal expansion close to that of the CMS membrane. The support can be prepared either as flat sheets or as \& tube.

A technique was developed to prepare a thin continuous CMS membrane on this support which is also non-brittle, and crack-free. This support is made by a technique involving repetitive casting of a polyimide film on the support, then pyrolyzing it. The process has the advantage that any cracks which are formed in the first casting are sealed in later castings to generate a smooth, defect-free layer. This layer was shown to have a selectivity for hydrogen over nitrogen of 2.8 3.8 and a selectivity for hydrogen over carbon dioxide of 2.4. This selectivity is close to the Knudsen limit.

Using unsupported films as model substrates, a method was developed for preparing a CMS structure which has the pore structure necessary to achieve a true size-selective separation of hydrogen from larger gases. Pore sizes were characterized by hydrogen adsorption porosimetry, a new technique specifically designed for this application. Using this technique, we were able to observe that, by adjusting the pyrolysis conditions used to prepare the CMS film, we could introduce pores which admit hydrogen, but exclude carbon dioxide. In the best case, the ratio of BET surface areas for hydrogen over carbon dioxide was $222.4 / 356.1$.

The preparation of a complete hydrogen-selective high temperature membrane was not completed in this program. What remains incomplete is the unification of all of these pieces to make a finished membrane. Thus, while we have merged the technology needed to make the support, with the technology needed to cast a continuous CMS film on it, we have not transferred the technique developed with un-supported films of increasing the hydrogen porosity. In fact, since those studies were completed with thick unsupported films, we do not yet know whether it is possible to introduce trans-membrane pores by this technique.

We do not see any large technical barriers to the completion of this program. The two technologies must be merged, and the resulting membrane optimized for its intended purpose. 
Since the unsupported membranes were prepared in a single pyrolysis, while the supported membranes require many, adjusting the pyrolysis conditions to tailor the pore size might require significant effort. Once such a membrane could be prepared, one would need to (1) prepare it in a tubular format, and (2) learn how to manifold several tubes into a unit of useful size. Here the concept of using non-porous Blackglas as the principal structural material would have the natural advantage of having a unit with a single coefficient of thermal expansion for the overall product, minimizing the potential for stresses and leaks in the unit at high temperature. 


\subsection{ACKNOWLEDGEMENTS}

The authors wish to thank Damyanti Patel for her efforts in performing the work discussed in this paper. The authors also wish to thank Hayuta Zafrir and Edwin Figueroa for their help in preparing porous supports and carbon films. Dr. Robert Sedath oversaw the NEPA qualification, and contributed to our initial test plan. Dr Xavier Pillai prepared the first test apparatus and did the initial work on CMS supported films, and Dr. David Anderson supervised some of the unsupported film studies. Dr. Alan van Til devised and built the apparatus for hydrogen adsorption porosimetry, and performed all of these experiments. Without his attention to detail, this entire area of our work would remain a wishful dream.

We wish to thank Dr. Venkat Venkateraman of METC for his continuing interest and encouragement of our work. Dr. Venkateraman helped to guide us in tailoring our work to DOE's needs, and was a valuable advisor and encouraging voice throughout our work. It was a pleasure to work with him.

Our work would not have been completed without the technical advice of many. Drs. Steven Gonczy, Roger Leung and Jack Sikonia were generous with advice and help in preparing Blackglas materials, and Drs. Brian Bedwell, Li Wang, Craig Chang and Norman Li gave valuable technical advice. Peggy Vesely and Larry Kravitz smoothed the way through the process of proposal writing and contract monitoring with their usual panache, and Mary Martin typed this report. 


\subsection{REFERENCES}

1 D.C. Cicero, L.A. Jarr Separation Sci. Tech., 25, 1455 (1990).

2 R.W. Baker, "Membrane and Module Preparation", p.1-1, vol 2 in Membrane Separations Systems: A Research Needs Assessment Final Report, April 1990, U.S. Department of Energy, Office of Energy Research, Washington, D.C.

3 S. Ilias, R. Govind, Symposium Series, AIChE 85, 18, (1989)

4 A.F.M. Leenaars, K. Keizer, A.J. Burggraaf, Chemtech, 560, September 1986.

5 A.J. Burggraaf, K. Keizer, B.A. Van Hassel, Solid State Ionics, 32/33, 771, (1989).

6 M. Tsapatsis, S. Kim, S.W. Nam, G.Gavalas Ind. Eng. Chem. Res., 30, 2152 (1991).

7 A.J. Bird, D.L. Trimm, Carbon, 21, 177 (1983).

8 J.E. Koresh, A. Foffer, Separations Sci. Tech., 22, 973 (1987).

9 D.E. Fain, G.E. Roettger Proc. 4th Annu. Conf. Fossil Energy Mater., pp.183-194, E91,001158, (1990).

10 L. Kniel, O. Winter, C.H. Tsai Kirk-Othmer Encyclopedia of Chemical Technology, 3rd ed. vol. 9, p. 393, Wiley-Interscience, N.Y. (1980)

11 Test D1434 in Annual Book of ASTM Standards, vol 15.09, 1993.

12 A.L. MoClellan, H.F. Harnsberger J. Colloid Interfac. Sci., 23, 577-509 (1967).

13 G. Horvath, K. Kawazoe J. Chem. Eng. Japan, 16(0), 470 (1983).

14 Roger Y. Leung, Stephem T. Gonczy, and Ming S. Shum "Carbon-Containing Black Glass Monoliths" U.S. Patent 5.242.866, Sept. 7, 1993.

15 Roger Y. Leung, Gerald T. Stranford, and Stephen T. Gonczy "High Flexural Strength Ceramic Fiber Reinforced Silicon Carboxide Composite" US Patent 5.258.084, Nov. 2, 1993. 
16 Roger Y. Leung and Bryan A. Weyneth "Coating for Protecting a Carbon-Carbon Composite from Oxidation Degradation" US Patent 5.225.283, July 6, 1993.

17 M. B. Bao and S. Sircar, "Nanoporous Carbon Membranes for Separation of Gas Mixtures by Selective Surface Flow," J. Membrane Sci., 85, 253-264 (1993).

18 J. E. Koresh and A. Sofer, Molecular Sieve Carbon Permselective Membrane. Part I. Presentation of a New Device for Gas Mixture Separation." Sep. Sci. Technol., 18, 723734 (1983).

19 J. E. Koresh and A. Sofer, "Mechanism of Permeation through Molecular-Sieve Carbon Membrane," J. Chem. Soc., Faraday Trans. 1, 82, 2057-2063 (1986).

20 H. Hatori et al., "Carbon Molecular Sieve Film from Polyimide," Carbon, 30 , 719-720 (1992).

21 K. Murase, N. Yabymoto, and Y. Komine, "Thermal Desorption Studies of Silicon dioxide Deposited by Atmospheric-Pressure Chemical Vapor Deposition Using Tetraethylorthosilicate and Ozone," J. Electrochem. Soc., 140, 1722-1727 (1993).

22 K. Fujino, Y. Nishimoto, N. Tokumasu, and K. Maeda, "Silicon Dioxide Deposition by Atmospheric Pressure and Low-Temperature CVD Using TEOS and Ozone," J. Electrochem. Soc., 137, 2883-2887 (1990).

23 K. Fujino, Y. Nishimoto, N. Tokumasu, and K. Maeda, "Doped Silicon Dioxide Deposition by Atmospheric Pressure and Low Temperature Chemical Vapor Deposition Using Tetraethoxysilane and Ozone," J. Electrochem. Soc., 138, 3019-3024 (1990).

24 C.H. Chang "Preparation and Use of Carbon Molecular Sieves in Purification of Chlorofluorocarbons" U.S. Patent 4,903.312 Assigned to AlliedSignal, Inc. (1990).

25 C.H. Chang, G.J. Seminara "Shaped Hydrophobic Carbon Molecular Sieve Products" U.S. Patent 4.820.681 Assigned to AlliedSignal Inc., (1989).

26 H.A. Zinnen, A.R. Oroskar, C.H. Chang "Carbon Dioxide Removal Using Aminated Carbon Molecular Sieves" U.S. Patent 4,810.266 Assigned to AlliedSignal, Inc. (1989).

27 M. Inagaki, S. Harada, T. Sato, T. Nakjima, Y. Horino, K. Morita Carbon, 27, 253-257 (1989); Y. Hishiyama, U. Kaburagi, A. Yoshida, M. Inagaki Carbon 31, $773-776$ (1993).

28 Kapton polyimide film - Summary of Properties, Brochure from Dupont High Performance Films 231302A (8/93). 